\title{
EVALUATION OF PREVENTATIVE SOLUTIONS FOR FRETTING FATIGUE DAMAGE OF Ti-6242 IN AIRCRAFT ENGINES
}

\author{
by \\ Jason Paul Dyer \\ B.Eng., Aerospace, Carleton, 1995 \\ A thesis submitted to the Faculty of Graduate Studies and Research \\ in partial fulfilment of the requirements for the degree of
}

\section{Master of Applied Science}

Ottawa-Carleton Institute for Mechanical and Aerospace Engineering

Department of Mechanical and Aerospace Engineering

$$
\begin{gathered}
\text { Carleton University } \\
\text { Ottawa, Ontario } \\
\text { Canada } \\
\text { January } 2003 \\
\text { C copyright } \\
\text { 2003, Jason P. Dyer }
\end{gathered}
$$


National Library

of Canada

Acquisitions and

Bibliographic Services

395 Wellington Street

Ottawa ON K1A ON4

Canada
Bibliothèque nationale

du Canada

Acquisitions et services bibliographiques

395, rue Wellington

Ottawa ON K1A ON4

Canada
The author has granted a nonexclusive licence allowing the National Library of Canada to reproduce, loan, distribute or sell copies of this thesis in microform, paper or electronic formats.

The author retains ownership of the copyright in this thesis. Neither the thesis nor substantial extracts from it may be printed or otherwise reproduced without the author's permission.
L'auteur a accordé une licence non exclusive permettant à la Bibliothèque nationale du Canada de reproduire, prêter, distribuer ou vendre des copies de cette thèse sous la forme de microfiche/film, de reproduction sur papier ou sur format électronique.

L'auteur conserve la propriété du droit d'auteur qui protège cette thèse. $\mathrm{Ni}$ la thèse ni des extraits substantiels de celle-ci ne doivent être imprimés ou autrement reproduits sans son autorisation.

\section{Canadä}


The undersigned recommend to the Faculty of Graduate Studies and Research acceptance of the thesis

EVALUATION OF PREVENTATIVE SOLUTIONS FOR FRETTING FATIGUE DAMAGE OF Ti-6242 IN AIRCRAFT ENGINES

\author{
submitted by \\ Jason Paul Dyer, \\ B.Eng., Aerospace, Carleton, 1995 \\ in partial fulfilment of the requirements for \\ the degree of Master of Applied Science \\ J. Beser \\ Thesis Supervisor \\ J. Red \\ Chair, Dept. of Mechanical and Aerospace Engineering \\ Carleton University \\ January 2003
}




\begin{abstract}
Fretting is a wear phenomenon that occurs between two contacted surfaces having oscillatory relative motion of small amplitude. Although the actual fretting wear damage can be slight when combined with cyclic fatigue, it can cause a considerable reduction of fatigue life. This reduction is particularly problematic in the dovetail region of blade and disc combinations within an aircraft engine.
\end{abstract}

The objective of this thesis is to design a fretting fatigue test rig and associated test specification to aid in the evaluation of potential processes used to increase Titanium 6242 resistance to fretting fatigue. These processes include coatings, anodizing and mechanical hardening techniques. In addition to the fretting fatigue tests, low cycle fatigue and notch sensitivity tests will also be conducted to evaluate the processes effect on other material characteristics.

After testing, it is found that a combination of both shot peening and anodizing provides an improvement of 1.9 times over the current OEM solution of CuNiIn and molybdenumdisulphide without detrimentally altering any other material characteristic. 


\section{ACKNOWLEDGEMENTS}

This thesis has been a long and drawn out process, which has shortened my life by several years. However, it has been both enlightening and educational, and could not have been completed without the help of several key people and the support of my family and friends.

I would first like to thank my Thesis Supervisor, Dr. Jonathan Beddoes, for his seemingly infinite patience. My appreciation also goes to the Orenda Aerospace Corporation and the National Research Council for providing the opportunity and equipment to conduct this work. I would also like to thank Dr. Ashok Koul for his technical knowledge and supervision.

The support of my family and friends has been endless. Their innate ability to know when to push me to get things done and when to leave me alone has led to many of my successes. Special thanks must be extended to: Thomas and Lynn Dyer, Adrian Dyer, Paul Malcomson, Chuck Hartsell, Quynton Robertson, Steve Quast, Rick Kearsey, Erin Felice, Stephanie Steele and my adorable godson Evan Malcomson. Also, I am sorry that I couldn't get this thesis done in time for you to see me graduate, but thank you too Nana.

Finally I would like to thank Laura Lucier for her superior editorial abilities. Without her patience, support and talent this document would have never have been published. 


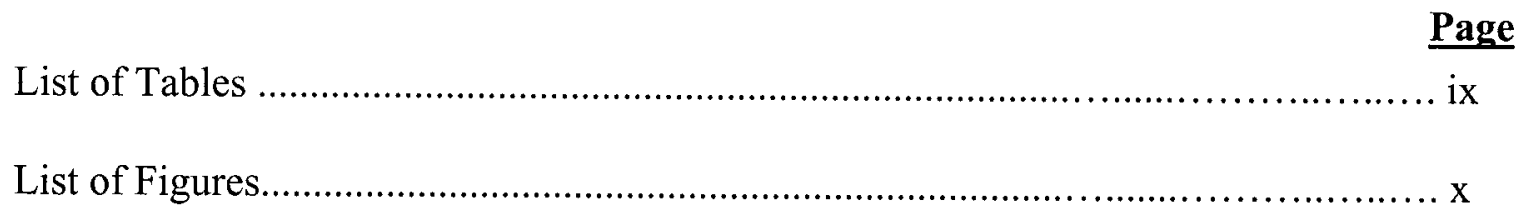

Nomenclature .................................................................. xii

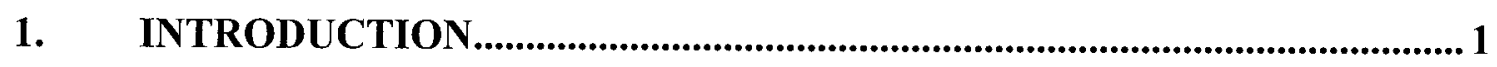

2. LITERATURE REVIEW .........................................................................

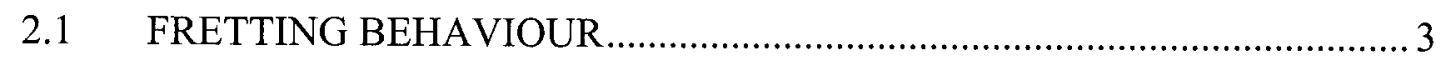

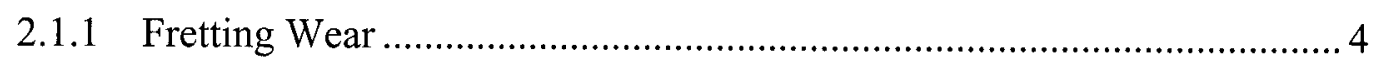

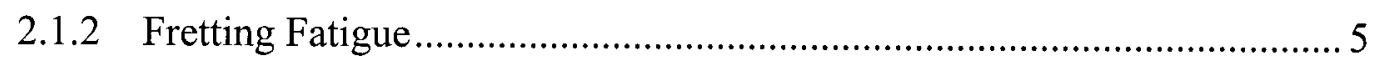

2.1.3 Fretting Fatigue Theories.......................................................................

2.1.4 Promotion of Crack Initiation and Crack Growth due to Fretting Fatigue8

2.2 FACTORS INFLUENCING FRETTING FATIGUE .................................. 10

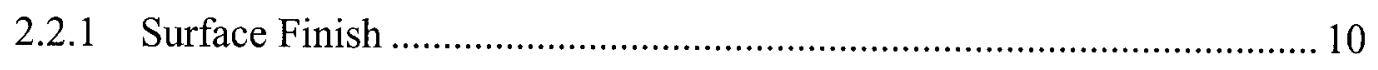

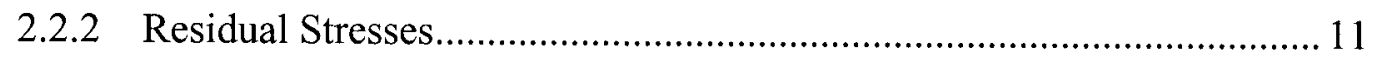

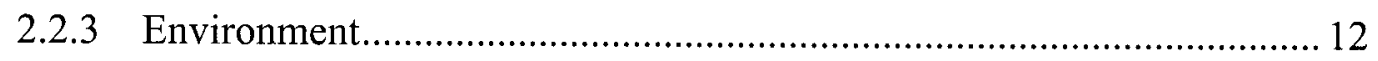

2.2.4 Coefficient of Friction ...................................................................... 13

2.2.5 Normal Load ...................................................................................... 14

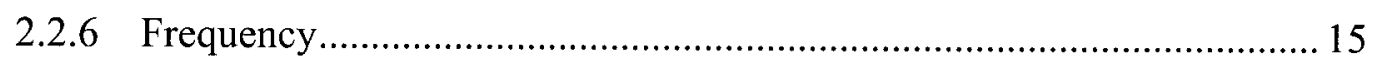

2.2.7 Amplitude of Slip......................................................................... 15

2.3 METHODS OF RESISTING FRETTING FATIGUE ………….................. 16

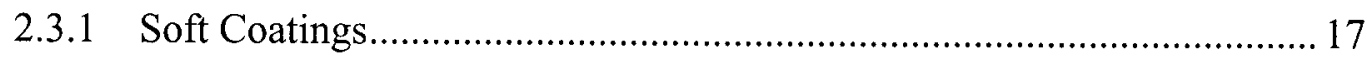

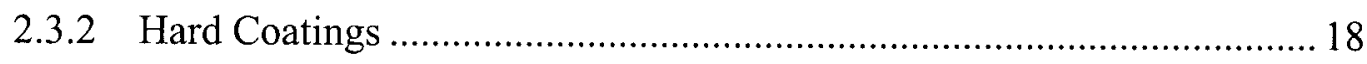




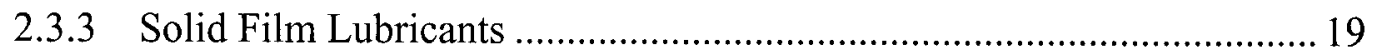

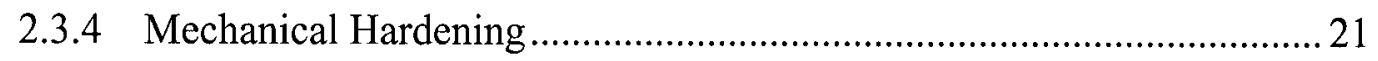

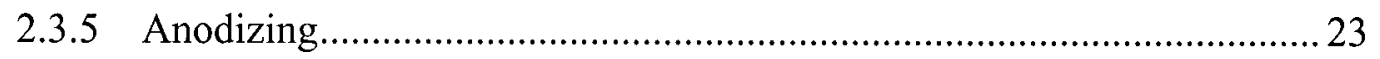

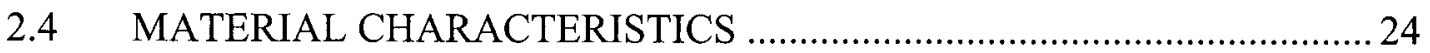

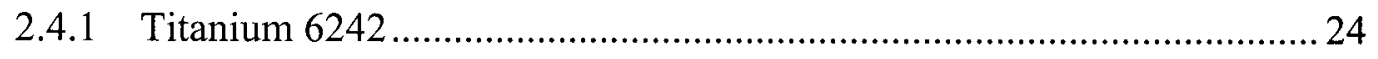

2.4.2 Titanium's Susceptibility to Fretting Fatigue ……………………….... 27

3. THESIS OBJECTIVES AND SCOPE ....................................................28

4. DEVELOPMENT OF THE TEST PROGRAM............................................. 29

4.1 DESIGNING THE FRETTING FATIGUE TEST RIG ..............................29

4.2 DESIGNING THE SCREENING PROCESS AND TEST MATRIX .......... 34

4.2.1 Design of the Orenda Chemical Treatment and Solid Film Lubricant ... 38

4.2.2 Geometric Impact Analysis.............................................................. 40

5. TESTING AND ANALYSIS PROCEDURES ................................................43

$5.1 \quad$ FRETTING FATIGUE TESTING AND ANALYSIS …............................... 43

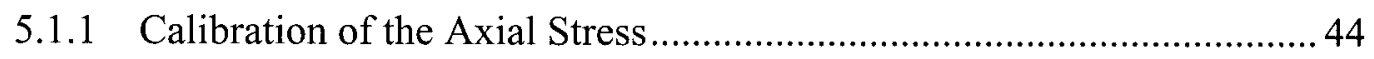

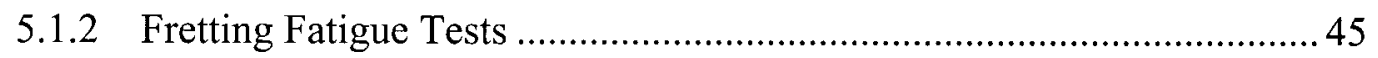

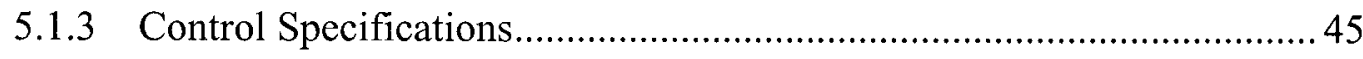

5.1.4 Normal or Contact Load Application .................................................... 45

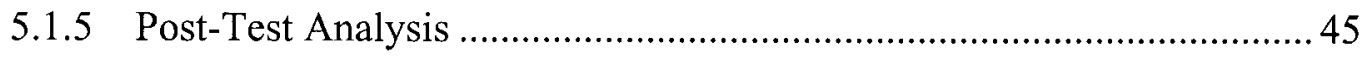

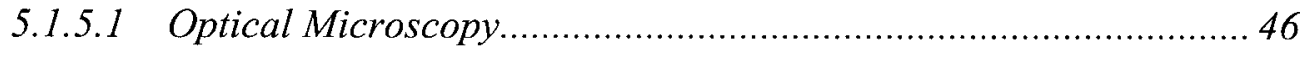

5.1.5.2 SEM (Scanning Electron Microscope) Analysis............................ 46

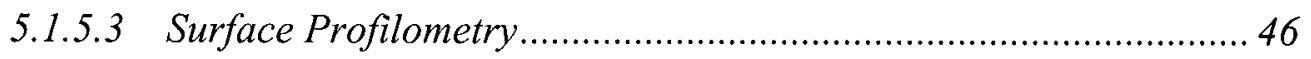

5.2 LOW CYCLE FATIGUE TESTING AND ANALYSIS ...............................46 


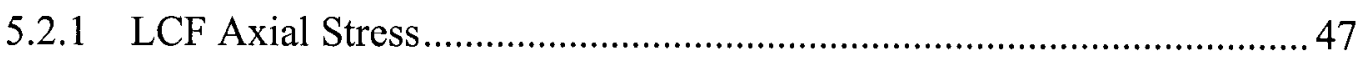

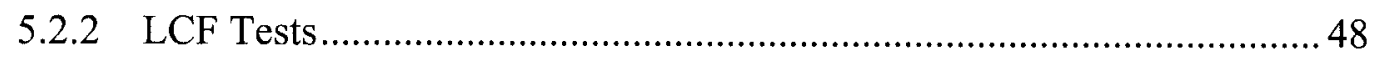

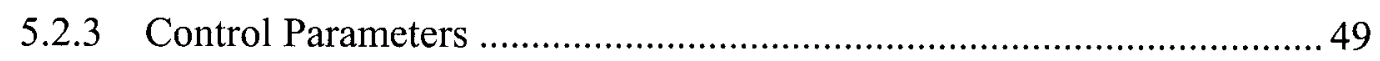

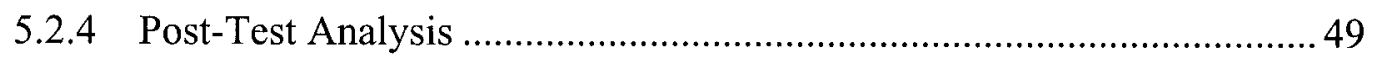

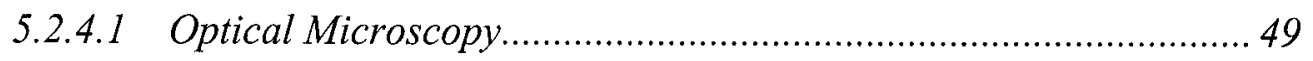

5.2.4.2 SEM (Scanning Electron Microscope) Analysis ............................ 49

5.3 NOTCH SENSITIVITY TESTING AND ANALYSIS …………………....50

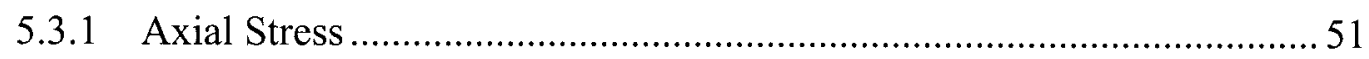

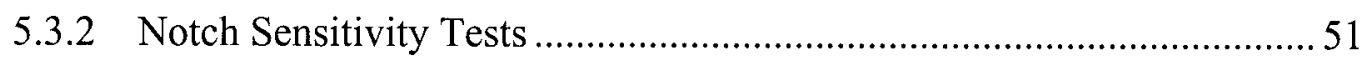

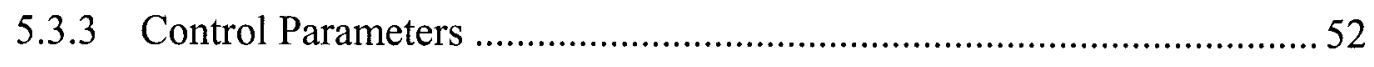

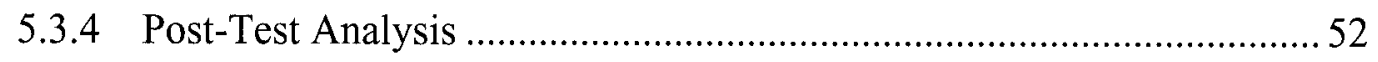

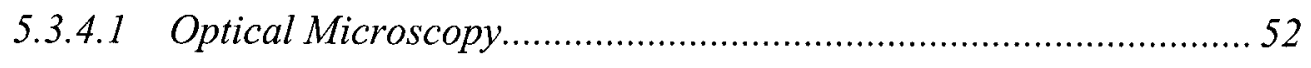

5.3.4.2 SEM (Scanning Electron Microscope) Analysis ............................ 52

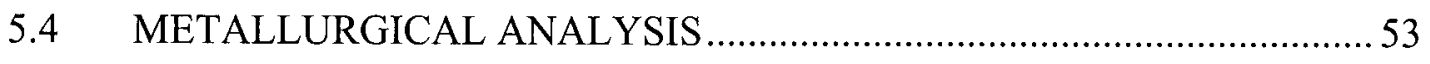

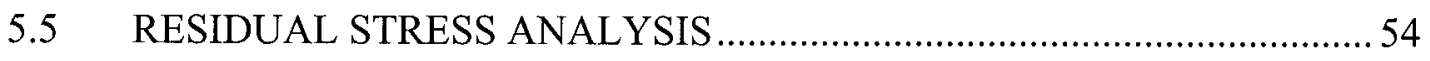

6. RESULTS AND DISCUSSION .............................................................5

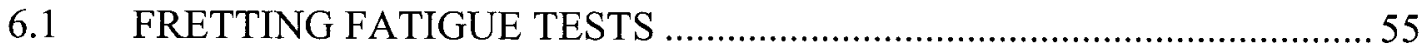

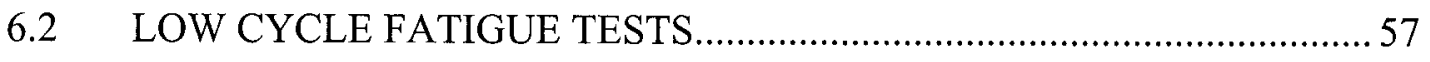

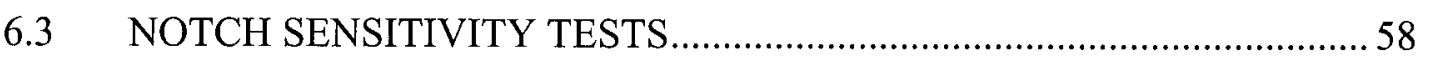

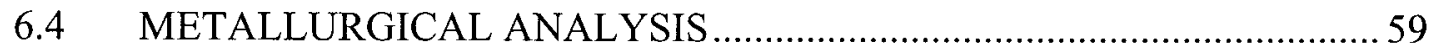

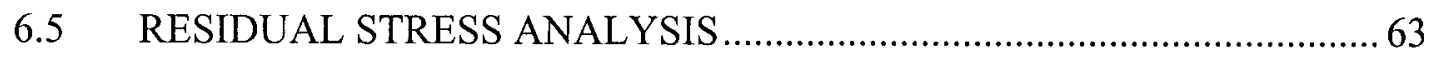

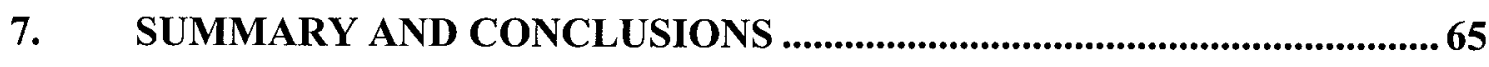

8. RECOMMENDATIONS AND FUTURE WORK............................................67 


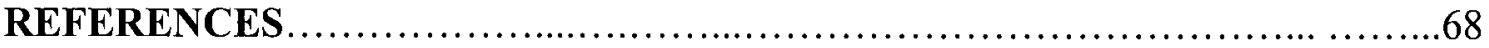

\section{TABLES}

FIGURES 


\section{LIST OF TABLES}

\section{SECTION 2}

Table 2.1 Advantages and Disadvantages of Select Solid Film Lubricant Base Materials [55]

\section{SECTION 6}

Table 6.1 HPC Disc/Blade Coupon Fretting Fatigue Test Summary

Table 6.2 Ti-6242 Individual LCF Test Results

Table 6.3 Individual Ti-6242, $\mathrm{K}_{\mathrm{t}}=1.52$ Notch Sensitivity Results

Table 6.4 Individual Ti-6242, $\mathrm{K}_{\mathrm{t}}=2.6$ Notch Sensitivity Results

Table 6.5 Residual Stress Measurements of Failed Fretting Coupons

Table 6.6 Improvement Factor for HPC Fretting Results 


\section{LIST OF FIGURES}

\section{SECTION 1}

Figure 1.1 Blade-Disc Dovetail Orientation [10]

\section{SECTION 2}

Figure 2.1 Distribution of Stresses in Dovetail Joint (Blade/Disc) and Ruiz Criterion [2,5]

Figure 2.2 Three Regions of a Crack Growth Rate Curve [26]

Figure 2.3 Constant Amplitude Crack Growth Data [26]

Figure 2.4 Stage I and Stage II Development of a Propagating Fatigue Crack [25]

Figure 2.5 SEM Micrographs of Fretting Surfaces Illustrating Galling [56]

Figure 2.6 Fracture Surface Photos Showing Presence of Material Smearing [57]

Figure 2.7 Fretting Scar Photos of a Titanium Alloy Showing Smearing and

Delamination [6]

Figure 2.8 Mindlin Diagram Showing Central Locked Region Surrounded by Annulus of Slip for Sphere in Contact with Plane [5, 32]

Figure 2.9 Dual Peening Rene 95 Specimens [38]

Figure 2.10 Dual Peening Ti-6Al-4V Blades [38]

Figure 2.11 Isothermal Time-Temperature-Transformation (TTT) Diagram for Ti-6Al$2 \mathrm{Sn}-4 \mathrm{Zr}-2 \mathrm{Mo}[45]$

Figure 2.12 Effect of Stress Relief Time and Temperature on Relaxation of Restrained Bend Specimens of Triplex Annealed Sheet [45]

\section{SECTION 4}


Figure 4.1 Original Bridge Design of the Fretting Fatigue Test Rig [53]

Figure 4.2 Original Specimen Design of the Fretting Fatigue Test Rig [53]

Figure 4.3 New Bridge Design of the Fretting Fatigue Test Rig

Figure 4.4 New Specimen Design of the Fretting Fatigue Test Rig

Figure 4.5 Fretting Fatigue Test Rig

Figure 4.6 Completed Test Bridge with Strain Gauges

Figure 4.7 Fretting Fatigue Test Facility

\section{SECTION 5}

Figure 5.1 Low Cycle Fatigue (LCF) Test Specimen

\section{SECTION 6}

Figure 6.1 HPC Disc/Blade Coupon Fretting Fatigue Test Results

Figure 6.2 LCF Test Results

Figure 6.3 Notch Sensitivity Test Results

Figure 6.4 Residual Stress Results of Failed HPC Fretting Fatigue Test Coupons

Figure 6.5 Multiple Crack Initiation Sites for Ti-6242 CuNiIn +DAG LCF Specimen

Figure 6.6 CuNiIn+DAG Coating Breakdown on Ti-6242 LCF Specimen

Figure 6.7 Delamination of CuNiIn+DAG on Ti-6242 LCF Specimen

Figure 6.8 Failed LCF Specimen with CuNiIn+DAG Coating Showing Multiple Initiation Sites

Figure 6.9 Failed LCF Specimen with OCT+OCC1 treatment

Figure 6.10 Fretting Specimen Surface Scar SP+OCT+OCC1, Spec. 2 
Figure 6.11 Fracture surface, Ti-6242 Substrate Spec. 5, 1 div. $=1 / 2 \mathrm{~mm}$

Figure 6.12 Fracture Surface, Ti-6242 Substrate, Spec 6, Secondary Crack Growth Region

Figure 6.13 Fretted Surface Showing Galled Areas Leading to Surface Cracking, Ti-6242

Substrate, Spec. 6

Figure 6.14 Shot Peened Specimen 3, Surface Smearing and Cracking

Figure 6.15 Shot Peened Specimen 5, Gouging and Surface Cracks

Figure 6.16 SP+OCT+OCC1 Specimen 4, Fretting Ridges, Material Transfer and Cracking

Figure 6.17 Baseline, Ti-6242 Parent Material Specimen 4, Fatigue Striations on Crack Growth Surface

Figure 6.18 Bridge Surface Profile Results

Figure 6.19 Specimen Surface Profile Results 


\begin{tabular}{|c|c|}
\hline 0 & degree (angular) \\
\hline${ }^{\circ} \mathrm{C}$ & degrees Celsius \\
\hline${ }^{\circ} \mathrm{F}$ & degrees Fahrenheit \\
\hline$\delta$ & slip amplitude \\
\hline$\Delta \mathrm{K}$ & change in stress intensity factor \\
\hline$\Delta \mathrm{l}$ & change in length \\
\hline$\Delta \sigma$ & change in stress \\
\hline$\mu_{\mathrm{f}}, \mu$ & coefficient of friction \\
\hline$\mu \mathrm{m}$ & micrometer $\left(10^{-6}\right.$ meters $)$ \\
\hline$\nu$ & Poisson's ratio \\
\hline$\sigma$ & tensile stress \\
\hline$\sigma_{\max }$ & maximum tensile stress \\
\hline$\sigma_{\mathrm{ys}}$ & yield stress \\
\hline$\tau$ & shear stress \\
\hline a & crack length \\
\hline AGARD & Advisory Group for Aerospace Research and Development \\
\hline AMS & Aerospace Materials Specifications \\
\hline ASTM & American Society for Testing and Materials \\
\hline BARE & as received Titanium 6242 \\
\hline bcc & body-center cubic \\
\hline $\mathrm{BL}$ & baseline \\
\hline
\end{tabular}




\begin{tabular}{|c|c|}
\hline $\mathrm{C}$ & material constant \\
\hline $\cos$ & cosine \\
\hline CuNiln- & copper-nickel-indium coating \\
\hline $\mathrm{da} / \mathrm{dN}$ & crack growth rate \\
\hline $\mathrm{DAG}$ & molybdenum disulphide $\left(\mathrm{MoS}_{2}\right)$ solid film lubricant \\
\hline $\operatorname{div}$ & division \\
\hline DSP & dual shot peened \\
\hline $\mathrm{E}$ & Youngs modulus of elasticity \\
\hline $\mathrm{F}$ & applied force required for movement \\
\hline$f(g)$ & correction factor \\
\hline Hast B & Hastelloy B coating \\
\hline $\mathrm{HCF}$ & high cycle fatigue \\
\hline hep & hexagonal close-packed \\
\hline $\mathrm{HPC}$ & high pressure compressor \\
\hline HVOF & high velocity oxy-fuel \\
\hline $\mathrm{Hz}$ & Hertz \\
\hline IAR & Institute for Aerospace Research \\
\hline in & inches \\
\hline $\mathrm{K}_{\mathrm{c}}$ & fracture toughness \\
\hline $\mathrm{K}_{\max }$ & maximum stress intensity factor \\
\hline $\mathrm{K}_{\min }$ & minimum stress intensity factor \\
\hline $\mathrm{kN}$ & kilo Newton (1000 x Newton) \\
\hline ksi & $1000 \times$ pounds per square inch \\
\hline
\end{tabular}




\begin{tabular}{ll}
$\mathrm{K}_{\mathrm{t}}$ & stress concentration factor \\
$\mathrm{K}_{\mathrm{th}}$ & stress intensity factor threshold \\
$\mathrm{kV}$ & kilo Volt \\
1 & length \\
$\mathrm{LCF}$ & low cycle fatigue \\
LOB & LOB 1800G solid film lubricant \\
LSP & laser shock peened \\
$\mathrm{m}$ & material constant \\
$\mathrm{mA}$ & milli Amperes \\
$\mathrm{Mb}$ & megabytes (computer memory) \\
$\mathrm{Met} 33$ & Metcolly 33 coating \\
$\mathrm{MIL}$ & military specification \\
$\mathrm{N}$ & normal force \\
$\mathrm{N}$ & number of cycles, cycles to failure \\
MPa & mega Pascal (1x10 ${ }^{6}$ Pascal) \\
$\mathrm{NRC}$ & National Research Council \\
$\mathrm{MTS}$ & Material Testing System \\
O.C.1 & Orenda coating \\
O.C.C. & Orenda chemical coating (lubricant) \\
O.C.C1 & modified Orenda chemical coating \\
O.C.T. & Orenda chemical treatment \\
OCTA & Orenda chemical treatment + modified lubricant \\
OEM & original engine manufacture \\
\hline
\end{tabular}




\begin{tabular}{|c|c|}
\hline O.I.T. & Orenda ion plating treatment \\
\hline OP\# & operation number \\
\hline $\mathrm{P}$ & normal load \\
\hline $\mathrm{Pa}$ & Pascal \\
\hline $\mathrm{p}_{\max }$ & maximum pressure \\
\hline psi & pounds per square inch \\
\hline PVD & physical vapour deposition \\
\hline$q$ & shear stress \\
\hline RA & reduction in cross-sectional area \\
\hline RAM & Random Access Memory \\
\hline RJ 143 & RJ 143 solid film lubricant \\
\hline SEM & scanning electron microscope \\
\hline $\sin$ & sine \\
\hline SP & shot peened \\
\hline SPCD & shot peened + copper-nickel-indium + molybdenum disulphide \\
\hline Spec. & specimen \\
\hline SRF & strength reduction factor \\
\hline $\mathrm{t}$ & thickness \\
\hline UTS & ultimate tensile strength \\
\hline $\mathrm{w}$ & width \\
\hline
\end{tabular}




\section{EVALUATION OF PREVENTATIVE SOLUTIONS FOR FRETTING FATIGUE DAMAGE OF TI-6242 IN AIRCRAFT ENGINES}

\section{INTRODUCTION}

The fretting phenomenon can be defined as a type of sliding wear occurring between two surfaces having oscillatory relative motion of small amplitude (approximately 3-75 $\mu \mathrm{m}$ (0.0001-0.003 inches) $[1,2,3,4])$. Fretting can be found in many different loading situations and applications including mechanical joints of vibrating structures, wire ropes, orthopedic implants and in aircraft engines.

Fretting fatigue is the combination of the fretting wear phenomenon and cyclic fatigue. The predominant effect that fretting has on cyclic fatigue is an increase in the rate of crack initiation. This effect can reduce the fatigue life of some components by up to $90 \%$, and has its greatest impact on components designed for high cycle fatigue life $[2,5$, $6,7,8]$.

The dovetail region of an engine blade and disc combination is susceptible to fretting fatigue because of the tight tolerances between the blade and disc and the high cyclic rotational speeds of the engine. Loading between the two surfaces can come from two different sources. First, the engine transitional speeds experienced during power up and power down situations cause significant changes in the rotational speed of the disc [9]. The centrifugal forces exerted on the blade result in a small relative motion between the 
blade and disc combination, as shown in Figure 1.1 [10], which may lead to fretting fatigue $[5,9,11]$. The second source of loading is the vibrational loading caused by aerodynamic flutter on the blade [9]. This causes a high frequency, high cyclic loading on the dovetail. Although these parts are designed for a high cycle fatigue life, many engine blades and discs are being retired prematurely as a result of fretting fatigue. As these components are expensive to repair or replace, it is important to understand and find ways to reduce the impact of fretting fatigue.

Titanium alloys are commonly used in rotating gas turbine engine compressor components due to their high specific strength and excellent corrosion resistance $[10,12$, 13]. Unfortunately, titanium and its alloys have been found to be particularly susceptible to wear and fretting damage $[6,11,14]$. Recent developments however, have shown that with protective coatings and surface modifications, the reduction of fatigue life in titanium and other materials caused by fretting can be mitigated $[1,6,7,11,15]$.

This thesis addresses the fretting fatigue problem of the blade disk combination in the compressor section of a gas turbine engine. As suggested by the original engine manufacturer (OEM), the titanium alloy Ti-6242 will represent the compressor blade and disc material in question. Fretting resistant processes will be tested and evaluated under several conditions against the current OEM fretting solution to try and improve the life of these components. 


\section{LITERATURE REVIEW}

The following section introduces some of the more important topics related to fretting fatigue based on a literature review.

\subsection{FRETTING BEHAVIOUR}

The fretting phenomenon can be defined as a type of sliding wear occurring between two surfaces having oscillatory relative motion of small amplitude (approximately 3-75 $\mu \mathrm{m}$ (0.0001-0.003 inches) $[1,2,3,4])$. This process ultimately creates a situation where the generated wear debris becomes trapped between the contacting surfaces accelerating the damage caused $[16,17]$

Fretting can be broken into 3 categories based on the predominant mechanism that ultimately causes failure $[18,19]$. Fretting wear is a mechanism that results in surface damage and is caused by the cyclic nature of fretting (discussed further in section 2.1.1.) Fretting fatigue can be defined as the reduction in fatigue life of a component due to fretting [14], and is discussed further in section 2.1.2. Fretting corrosion deals with the chemical reactions, such as oxidation, that can lead to accelerated damage caused by both fretting fatigue and fretting wear. Although fretting corrosion is addressed separately in some cases, it will be included in both discussions since it cannot occur independently of fretting wear or fretting fatigue. 


\subsubsection{Fretting Wear}

Eden et al. first reported fretting wear in 1911. They found that brown oxide debris was forming in the steel grips of their fatigue machine when in contact with a steel specimen [20]. Later, in 1927, Tomlinson designed a facility to study fretting, which he described as "fretting corrosion" since the chemical reaction of iron and air was causing the brown iron oxide formation [21]. Since wear and corrosion were fairly well understood at the time, much of the early fretting research concentrated on the production of wear debris and oxidation (i.e. fretting wear and fretting corrosion).

Fretting wear in contrast to fretting fatigue, typically occurs at larger relative displacements, in the range of 20-75 $\mu \mathrm{m}(0.0008-0.003$ inches) [19]. The larger amount of slip, which is usually caused by a lower normal load, tends to create more surface damage than fretting fatigue. During the initial stages of fretting wear, debris is formed at the contacting surfaces. This debris can then oxidize, introducing oxide particles, which can be harder than the original surface. These oxide particles accelerate the damage leading to scarring and pitting [22]. In later stages, galling, seizing, delamination or material transfer can occur. Additionally, this surface damage may lead to the initiation of microcracks. However, due to the lower surface stress associated with fretting wear, these microcracks will not necessarily become cracks that result in component failure [21]. 


\subsubsection{Fretting Fatigue}

The effects fretting has on fatigue properties were not investigated until 1941, when Warlow and Davies found that fretting, through pitting of the surface, could cause a reduction in fatigue strength of approximately $13-17 \%[20,23]$. Later investigations by McDowell showed that the joint action of fretting and fatigue could produce strength reduction factors (SRF) of 2-5 [20]. The SRF can be defined as the fatigue strength without fretting divided by the fatigue strength with fretting applied. It should be noted that fatigue strength is usually calculated after $10^{7}$ cycles of load application [5].

In 1958, Fenner and Field showed that fretting fatigue greatly accelerates the crack initiation process. Normally, the time to crack initiation can account for as much as $90 \%$ of the fatigue life however, time to crack initiation influenced by fretting fatigue may only take $5 \%$ of the fatigue life [8]. This would indicate that fretting fatigue predominately affects those components that are designed to resist high cycle fatigue such as gas turbine engine blades or discs $[2,5,6,7,8]$.

Fretting fatigue tends to occur at smaller relative displacement ranges than those of fretting wear. These are typically less than $20 \mu \mathrm{m}$ (0.0008 inches) of displacement [19]. Although the type of surface damage tends to be similar, it is usually less severe $[11,19]$.

\subsubsection{Fretting Fatigue Theories}

Theories have been developed to try and explain the unique wearing effect of fretting and its detrimental impact on fatigue life. Unfortunately, the effects of fretting damage are 
quite varied. At one extreme, it is possible to have fretting fatigue causing significant surface wear damage that does not result in cracks causing notable fatigue life debits. In contrast, fretting fatigue that causes little surface wear damage but creates numerous cracks, contributing to a large fatigue life debit, is also possible. As a result, theories describing fretting fatigue must be flexible enough to account for both extremes as well as those cases that fall between.

One fretting fatigue theory, gaining general acceptance is the micro welding of small asperities [9]. It suggests that most surfaces can be represented by irregular surface profiles or asperities even at the micro level. The poorer the surface finish or surface polish, the higher the number of asperities and/or their depth. These surfaces, when placed together, will mesh; and opposing asperities will come into contact, similar to irregular gear teeth. Once cyclic motion is added, loading on the individual asperity will occur. The fretting fatigue process causes repetitive stripping of the contact surface, exposing virgin material. The virgin material will then oxidize, and the process will repeat. This process is sometimes referred to as fretting oxidation [5]. While the virgin material is exposed, the increased direct metal-to-metal contact and the increased temperature due to friction can cause the adjoining asperities to weld together.

Eventually the stress of motion and/or welding will cause plastic deformation and eventual separation of the asperities from their respective surfaces [5]. If the asperities have welded, material transfer between the two surfaces may occur. Since displacement is small, these asperity particles will remain at the fracture site, adding to the stress of 
neighbouring asperities [3]. Over a period of time these broken asperities may oxidize producing a by-product harder than its parent material. This leads to an increase in pitting and gouging in the local area and eventual crack formation.

Although there are theories that explain fretting fatigue there are currently no governing equations that accurately predict the detrimental effect fretting fatigue has on fatigue life. This is primarily due to the large number of variables affecting fretting fatigue and the fact that many are independent $[1,11]$. Several such as, normal load, surface finish and environment are discussed in detail in section 2.2.

The independent nature of the many variables influencing fretting fatigue means that most preventative work conducted to date is based on empirical methods for a given material, environment or loading condition. Work conducted by Ruiz and Chen has led to the development of an empirical criterion for predicting the location and the likelihood of a fretting fatigue crack in a blade and disc combination $[2,5]$. By considering the energy available for causing fretting as the product of the shear stress, $\tau$, at a given point with the slip amplitude, $\delta$, at the same given point and relating this with the maximum tensile stress, $\sigma$, in the same given area, the final criterion $\sigma \cdot \tau \cdot \delta$ is developed. As shown in Figure 2.1, when $\sigma \cdot \tau \cdot \delta$ is plotted along the contact surface, the peak value indicates the target location for crack initiation. However, until that peak reaches a certain value the crack will not initiate $[2,24]$. Waterhouse applied this criterion to a steel ball and plate and found that $\sigma \cdot \tau \cdot \delta$ accurately predicted the crack location [5]. 


\subsubsection{Promotion of Crack Initiation and Crack Growth due to Fretting Fatigue}

Fatigue crack growth can be represented in three stages as shown in Figure 2.2. Recent work has shown that fretting predominantly affects the initiation of cracks and their propagation rate through Stage I $[5,25]$. For this reason, only short descriptions on Stage II and Stage III fatigue crack growth are given in this thesis. The reader may investigate further in References 26 and 27.

Figure 2.3 illustrates the usual relationship between fatigue crack length, a, and the number of cycles, $\mathrm{N}_{\mathrm{f}}$, under constant amplitude loading. As Figure 2.3 shows, during most of the life of the specimen or component, short crack lengths are experienced, and an increase in stress range, $\Delta \sigma$, increases the rate of growth [26]. Typically, the logarithmic rate of crack growth, da/dN, is plotted against the logarithmic rate of the stress intensity factor, $\Delta \mathrm{K}$ (Figure 2.2 ), where $\Delta \mathrm{K}$ is defined as [26]:

$$
\Delta K=K_{\max }-K_{\min }=f(g) \Delta \sigma \sqrt{\pi a}
$$

Where: $\mathrm{K}_{\max }$ and $\mathrm{K}_{\min }$ are the $\max$ and min stress intensity factors respectively $\mathrm{f}(\mathrm{g})$ is a correction factor based on crack length and geometry $\Delta \sigma$ is the stress range between $\sigma_{\max }$ and $\sigma_{\min }$ $a$ is crack length

It should also be noted that Figure 2.2 refers to $\Delta \mathrm{K}_{\mathrm{th}}$, which is the stress intensity threshold below which crack growth will not occur, and $K_{c}$, which is the fracture toughness of the material. 
Stage II crack growth is considered to occur in a predominantly linear fashion when the $\log (\mathrm{da} / \mathrm{dN})$ is plotted against the $\log (\Delta \mathrm{K})$. Many equations have been suggested to model this growth including that by Paris, which is given as [26]:

$$
\mathrm{da} / \mathrm{dN}=\mathrm{C}(\Delta \mathrm{K})^{\mathrm{m}}
$$

Where: $\mathrm{C}$ and $\mathrm{m}$ are material constants

other symbols are as previously defined

Dominated by the applied tensile stress intensity at the crack tip, the Stage II crack growth generally propagates perpendicular to the applied load as shown in Figure 2.4 $[25]$.

Stage III crack growth is rapid and unstable. Since it accounts for such a small amount of the total life of the component, it is usually ignored in predictions of number of cycles to failure, $\mathrm{N}_{\mathrm{f}}[26,27]$.

As stated in section 2.1.4, fretting predominantly affects the time to crack initiation and the Stage I crack growth. Accelerated crack initiation is triggered by surface damage caused by fretting. Pitting and gouging, resulting from the debris generated in the early stages of fretting, can lead to surface stress raisers [9]. The energy available to initiate a crack is effectively increased by the local shear stress regions induced by fretting $[5,25]$. A typical Stage I initiated fatigue crack will tend to grow at approximately $45^{\circ}$ to the 
surface due to the maximum shear stress being orientated in that direction [25] as shown schematically in Figure 2.4. Fretting does not seem to affect this, as a crack initiated by fretting is usually inclined at an angle of $35-50^{\circ}$ to the normal surface during Stage I development. However, the lengths of fretting fatigue initiated Stage I cracks are typically longer than those of standard, unfretted fatigue cracks [5]. Once slip completely occurs between the two surfaces, the local coefficient of friction becomes constant, and fretting wear becomes the predominant failure characteristic. This will lead to galling (Figure 2.5), smearing (Figure 2.6) and surface delamination (Figure 2.7) [5].

\subsection{FACTORS INFLUENCING FRETTING FATIGUE}

The surface damage caused by fretting fatigue is a function of the contact conditions such as normal load, amplitude of slip and frequency [5]. The following sections describe some of the major factors that are known to directly affect fretting fatigue.

\subsubsection{Surface Finish}

An improved surface finish (less rough) typically reduces the number of surface stress concentrations, which is known to improve the fatigue life of a component or coupon [5, 26]. However, in fretting fatigue, it has been shown that a rougher surface tends to resist fretting better than a smooth one [5]. This may be due to the distribution of the load over a greater number of asperities. This distribution is associated with the $\delta$ variable of the Ruiz criterion outlined in section 2.1.3. However, there is a limit to the positive increase in surface roughness before the induced stress concentrations outweigh the increase in 
asperity count. Further work is being conducted to verify this difference between cyclic fatigue and fretting fatigue and the tolerances each have towards surface roughness.

\subsubsection{Residual Stresses}

Compressive residual stresses have been used for years to extend the cyclic fatigue life of metallic components. Typically, cracks can only progress in tension. By forcing the surface into a compressive stress state, the tensile stresses required to propagate a crack must first overcome these induced compressive states. Permanent compressive states can be induced by several methods including shot peening, cold working and laser shock peening, all of which are described in section 2.3.4.

The improvement of fretting fatigue resistance in components due to surface compressive residual stress has been well documented $[1,5,28]$. Tests have been conducted to verify that compressive residual stresses are effective in both steels and titanium alloys [5].

It should be noted that the environment to which the component is exposed limits the benefit it may derive from compressive residual stresses. Depending on the material and the duration of exposure, compressive stresses will relieve themselves at elevated temperatures. This stress relief typically occurs at temperatures above $350{ }^{\circ} \mathrm{C}\left(662{ }^{\circ} \mathrm{F}\right)$ for high strength steels and titanium alloys [5]. 


\subsubsection{Environment}

As suggested in section 2.2.2, the service environment must be taken into consideration when selecting a surface modification for protection against fretting fatigue. It can play either a positive or a negative role in the fretting fatigue life of components [10]. Certain environments, such as oxygen rich or salt water, can cause corrosion of the surface, which can lead to crack initiation and fretting fatigue failure. These environments can also break down protective coatings used to reduce the effects of fretting wear or fretting fatigue.

There are however, several materials that exhibit improved fretting fatigue resistance in oxygen rich environments. Alloyed systems, typically steels and those that are nickel based, which include iron, nickel and chromium in their alloying elements, tend to form a stable oxide, which greatly reduces the coefficient of friction and therefore reduces the wear rate $[6,10]$. The secondary benefit of this oxide is its ability to naturally repair itself. Due to its morphology, virgin surfaces created by fretting will reoxidize and restore the protective oxide layer even after the initial layer has been stripped. This oxide is shown to have an increased growth rate as temperature increases $[3,29]$, reducing the amount of metal-to-metal contact and the coefficient of friction [3].

Although both titanium and aluminum alloys produce a stable oxidation layer that aids in their ability to perform in certain environments, this layer does not have the same morphology as the oxide mentioned above, and is typically composed of $\mathrm{TiO}_{2}$ for titanium alloys $[3,10,29]$. This layer does provide protection against corrosion and does 
reduce the coefficient of friction, but frequently contains surface cracks and has a tendency to spall. The formation of this titanium or aluminum oxide layer is also temperature dependant. Aluminum alloys tend to produce a thin oxide layer at room temperature, which rapidly increases with temperature. However, titanium alloys typically do not produce a sufficiently thick coating to provide protection until a temperature of approximately $500{ }^{\circ} \mathrm{C}\left(932{ }^{\circ} \mathrm{F}\right)$ is reached, when tests show a significant drop in the coefficient of friction $[3,5,6]$.

\subsubsection{Coefficient of Friction}

The coefficient of friction, $\mu_{\mathrm{f}}$, is related to the amount of force required to generate motion between two surfaces. It can be defined as the ratio between the normal force, $\mathrm{N}$, between the two surfaces and the force, F, required for relative motion [30].

$$
\mu_{\mathrm{f}}=\mathrm{F} / \mathrm{N} \text { or } \mathrm{F}=\mu_{\mathrm{f}} \cdot \mathrm{N}
$$

The value of the coefficient of friction lies between 0 (no friction) and infinity. This equation pertains to both static and kinetic coefficients of friction. The static value is calculated when the bodies are at rest and the kinetic value is calculated when the bodies are in relative motion. In the case of measuring the effectiveness of a coating or surface modification, the coefficient of kinetic friction is used.

Generally, the coefficient of friction is related to the amount of wear experienced during a given period of time. For this reason, many fretting fatigue resistant processes aim 
solely at reducing the coefficient of friction between the two contacting surfaces. Harder coatings tend to produce lower coefficients of friction compared to softer coatings. However, the application of many hard coatings can cause detrimental effects to the fatigue life of the component, several of which will be discussed in section 2.3.2.

Although reducing the coefficient of friction aids in wear reduction, it does not always guarantee a reduction in fretting wear and certainly not in fretting fatigue since, as mentioned in section 2.2.1, a certain amount of surface roughness or higher coefficient of friction, when in contact with another surface, can be beneficial in certain cases of fretting fatigue $[11,31]$.

\subsubsection{Normal Load}

Studies have been conducted to determine the effect that the variance of applied normal load has on fretting fatigue [5]. Typically, a minimum normal load is required before fretting fatigue can occur [5]. At lower normal loads (contact stresses), fretting wear is dominant, causing significant surface damage but not drastically affecting the high cycle fatigue life of the component. However, as the normal load is increased, the severity of fretting wear is decreased and fretting fatigue becomes the dominant influence reducing the overall fatigue life of the component [23]. There is also a maximum point beyond which additional loading will not cause further reduction in fatigue life [10]. It is generally accepted that surface damage occurs as a result of plastic deformation of the asperities [5]. The Ruiz criterion, $\sigma \cdot \tau \cdot \delta$, shows that the normal load, proportional to the coefficient of friction between the two surfaces, affects $\tau$ with respect to the number of 
asperities in contact and their respective plastic deformation [5]. The normal load also influences the amount of slip occurring between the two surfaces, which greatly affects the amount of fretting damage that occurs [2]. This is discussed further in section 2.2.7.

\subsubsection{Frequency}

Frequency is known to affect the fatigue life of components and/or test specimens [5]. Even if a fixed stress amplitude is maintained, variation in cycle frequency causes changes in number of cycles to failure by orders of magnitude. For example, at lower frequencies, especially when loading is applied in a corrosive environment, the open crack is exposed to the environment for longer periods of time, increasing corrosive activity and therefore reducing the time to failure [26].

Increased frequencies can also cause dramatic heating effects depending on the substrate materials' ability to dissipate heat. This potentially leads to non-representative failures in protective coatings. Further explanation of frequency effects on the fretting fatigue life of materials can be found in References 26 and 27.

\subsubsection{Amplitude of Slip}

As stated in section 2.2.5, the normal load magnitude affects the amplitude of slip. Slip in turn, greatly affects the type and amount of fretting damage [2, 23]. Generally, there are two types of slip: partial and total. Mindlin's analysis, shown in Figure 2.8, illustrates the difference between the two [5, 32]. Mindlin uses a sphere loaded against a flat plate with an applied normal load, P. The pressure distribution in the circular contact 
region is represented by a hemisphere with a maximum value of $\mathrm{p}_{\max }$ at the center and zero at the circumference. A shear stress, $q$, is also represented. If the coefficient of friction is not zero, then $\mathrm{q}$ is maximized at the edge and minimized in the center. The coefficient of friction, $\mu$, is assumed to be constant but less than 1 . When a force, $\mathrm{F}$, tangential to the normal load is applied, motion is resisted by frictional force, $\mu \mathrm{p}$. In the regions where the frictional force is less than the applied force slip will occur. However, towards the center, where the frictional force exceeds the applied force, slip will not occur. This slip amplitude is the variable $\delta$ referred to in the Ruiz criterion described in section 2.1.3. As F increases, the no-slip amplitude decreases until total slip occurs [5, 32]. The boundary between the slip and no-slip amplitude is the most common region for crack initiation [3]. However, as the fretting fatigue damage progresses, the position of this boundary moves because of changes in the coefficient of friction. This change is caused by the formation of debris and surface stress relief due to crack formation [5].

\subsection{METHODS OF RESISTING FRETTING FATIGUE}

Several processes are available to minimize the effects of wear and/or increase fatigue life. Some of these are used to mitigate the effects of fretting fatigue since both mechanisms are known to affect the fretting phenomenon, and typically improve surface finish and increase surface hardness. Processes that are applied to protect against fretting fatigue tend not to have severe application methods that induce high processing temperatures. These high temperatures can cause a reduction in the compressive residual stress or induce tensile stresses, therefore reducing the fatigue life of the component [1]. 
Since each process has its own distinct advantages, in most cases they are used in combination to maximize their effect. Special consideration must be taken in selecting the combination of coatings and treatments to be used as certain processes may reduce wear or increase fatigue life individually, but may react differently in conjunction with another process and ultimately cause detrimental effects.

Understanding the service environment and the potential failure mechanism of the component is paramount in selecting the correct surface modification solution [1]. It is noted that a solution that may reduce fretting fatigue or fretting wear under one set of service conditions may not have the same effect under another.

\subsubsection{Soft Coatings}

Soft coatings, which include copper-nickel-indium (CuNiIn), aluminum-bronze (Al$\mathrm{CuZn})$ and pure copper $(\mathrm{Cu})$, tend to be among the most widely used coatings for fretting fatigue prevention. Plasma-sprayed $\mathrm{Cu}$ coatings of a thickness greater than $15 \mu \mathrm{m}$ have been shown to give a significant improvement in fretting fatigue life [4]. The application process and the material tend to be fairly inexpensive as the application can be as simple as inserting shims between the two surfaces. Usually working as a sacrificial shield between the two surfaces, this method is an effective solution as long as the applied normal load does not cause the coating to extrude, leaving the parent material unprotected [4]. 
Certain soft coatings, particularly those containing nickel $(\mathrm{Ni})$ or chromium $(\mathrm{Cr})$ are also used. These can aid in the formation of the protective oxide discussed in section 2.2.3 [3].

Due to their tendency to smear, soft coatings have a higher coefficient of friction, which increases the degradation rate of the coating [11]. In addition, most of the materials used for these types of coatings tend to oxidize at lower temperatures, therefore breaking down and becoming ineffective beyond a certain temperature limit of approximately $500{ }^{\circ} \mathrm{C}$ $\left(932{ }^{\circ} \mathrm{F}\right)[4]$.

\subsubsection{Hard Coatings}

In addition to having an increased surface hardness over the parent material they are protecting, hard coatings can usually be polished to reduce the surface's coefficient of friction. As stated in section 2.2.4, coatings that reduce the coefficient of friction are effective when the fretting wear mechanism is predominant $[11,33]$. Hard coatings such as plasma-sprayed WC-Co, $\mathrm{Al}_{2} \mathrm{O}_{3}-\mathrm{TiO}_{2}$ and $\mathrm{Cr}_{2} \mathrm{O}_{3}$ are commonly used for this purpose.

Hard coatings tend to have a morphology that is not directly compatible with the more ductile parent materials. Special care needs to be taken during the application of hard coatings to ensure an optimized interfacial bond between the two surfaces since a weak interface could lead to partial or full delamination of the coatings from the substrate. A delamination pocket presents an ideal site for fretting and may not be easily detected since the coating itself appears not to have failed [25]. As the hard coating and its oxide 
particles react with the softer substrate, sub-surface cracks may initiate and propagate to failure without visually being detected. However, if the interface bond is too strong, cracks that initiate in the coating easily transfer into the substrate. One method of prevention involves the addition of a third bond coating used to help transition the stress distribution between the hard coating and the more ductile parent material.

Hard coatings, though sometimes used, are not typically useful in fretting fatigue dominated situations [11]. The reason for this is two-fold. First, many of the hard coating application processes produce fatigue debits in the substrate by inducing residual tensile stresses and/or partially or fully relieving any induced compressive residual stresses imposed by cold working or shot peening $[11,34]$. Second, due to the typically brittle nature of the hard coating and the difference in ductility between it and the substrate, once cracks form, the coating tends to spall quickly, no longer offering any protection.

\subsubsection{Solid Film Lubricants}

Solid film coatings/lubricants are materials with inherent lubricating properties. Like the coatings previously discussed, they are firmly bonded to the surface of the substrate or an additional coating [9]. Application techniques include burnishing, mechanical impingement, sputtering, ion deposition or physical vapour deposition (PVD). Solid film lubricants are used extensively in the aerospace industry for several reasons including [29]:

1) strong adhesion to substrate material, 
2) effective protection over a wide temperature range $\left(-200^{\circ} \mathrm{C}\left(-328^{\circ} \mathrm{F}\right)\right.$ to 2000 $\left.{ }^{\circ} \mathrm{C}\left(3632^{\circ} \mathrm{F}\right)\right)$,

3) low coefficient of friction,

4) corrosion and chemical resistance, and

5) self regenerative nature.

The formulation of a solid film lubricant is broken into three distinct parts. The first is the lubricant base material. Common base materials include molybdenum-disulphide $\left(\mathrm{MoS}_{2}\right)$, graphite or fluorinated polymers. The base material must be carefully selected based on the intended environment and application since each material has its own advantages and disadvantages, some of which are outlined in Table 2.1. The second consideration is the resin or binder composition, which is typically introduced in conjunction with a carrier material during the application process. As the carrier evaporates, the resin cures by either air-drying or oven curing, binding the solid coating particles to the surface of the component. Curing is usually performed at lower temperatures in order to minimize stress relief and damage to the underlying material. The final component is an additional material, used to improve the properties of the coating or lubricant, such as chromium or copper to improve corrosion or wear resistance in fluorinated polymers.

Some solid film lubricants such as $\mathrm{MoS}_{2}$, oxidize readily and are susceptible to moisture absorption. This breaks down the binder and reduces its effectiveness. Using sputter 
deposition, $\mathrm{MoS}_{2}$ affinity for moisture can be reduced. Other techniques include multilayering or co-deposition with another metal sulphide [35].

\subsubsection{Mechanical Hardening}

Mechanical hardening is used to increase component life when fatigue is the dominant failure mechanism. Introducing compressive residual stresses to the surface of a component susceptible to cracking has been proven to increase the time to crack initiation and therefore extend the life of the part $[36,37]$. Many types of mechanical hardening processes are available. These include shot peening, dual shot peening and laser shock peening.

The shot peening process makes use of small spherical objects fired at the surface of the component at a high velocity. The spheres are typically made of steel or plastic depending on the desired energy to be impacted on the target surface. At higher energy levels, shot peening changes the surface condition by work hardening, which produces compressive residual stresses and an increase in hardness [9]. This increased hardness and compressive residual stress increases the resistance to plastic deformation, which is required for crack initiation and propagation. It also provides an increase in the keying mechanism that some coatings use to bond to the surface [5]. Varying the shot size, shot type and impact energy can control the residual stress state, surface finish and the depth of penetration. Lower energy shot peening is often used as a surface pretreatment for coatings as it removes oxides and produces a fresh surface finish [1]. Although this 
outlines the basic shot peening process and some of its uses, a more detailed description can be found in Reference 38 .

Previous investigations of fatigue testing, conducted as early as 1963 , reveal that a dual peening process produces a greater improvement to fatigue life than a single peening process as indicated in Figure 2.9 and Figure 2.10 [36, 39]. Dual peening simply applies a second shot peened layer of lesser intensity over the first, tending to improve the surface finish.

Laser shock peening consists of mechanically hardening the surface of a material by rapidly heating an opaque absorbent material, usually paint or tape, applied to the target part's surface. The part is then covered with a thin translucent liquid, usually water or oil. As the pulse laser passes through the liquid, it vapourizes a small portion of the absorbent material. The vapour then uses the remaining laser light to generate plasma and form a pocket between the surface and the liquid. As the pressure builds, the plasma generates sufficient energy to compress the surface. Laser shock peening typically produces a superior surface finish in terms of homogeneity and reduced roughness and provides an inert process since shot peening, depending on process parameters, can deposit some of the shot on the treated material's surface.

In general, some form of mechanical hardening, usually shot peening, in combination with a protective coating has become standard practice for increasing the fretting fatigue life of engine components $[4,9,15]$. Besides inducing a compressive residual stress 
state, shot peening causes an increase in surface roughness, which, as stated in section 2.2.1, improves fretting fatigue resistance [5]. However, application of both the mechanical hardening process and the coating must be controlled as uncontrolled peening can lead to localized micro cracking and high temperature coating applications such as plasma-sprayed or high velocity oxy-fuel (HVOF) can lead to compressive stress relief $[9,40]$.

\subsubsection{Anodizing}

Used with both aluminum and titanium, the anodizing process converts naturally occurring titanium or aluminum oxide on the surface of the material into an extremely hard, stable and well-bonded oxide finish. The reinforced surface provides excellent abrasion and corrosion resistance [4]. Depending on the type of anodizing process used, the new surface is approximately $30 \%$ thicker than the material it replaces [41]. Because of this increase in volume and therefore reduced density, anodized surfaces allow infusion of materials for lubrication to increase wear resistance.

There are several anodizing processes available, the choice of which one to use depends on the material and/or finish desired. Both Aerospace Materials Specification (AMS 2488) and Military Specifications (MIL-A-8626, MIL-A-63576) outline the procedure to be used in order to ensure quality control. 


\subsection{MATERIAL CHARACTERISTICS}

The following section describes some of the material characteristics of titanium alloy Ti6242 that are related to fretting fatigue. It also describes those characteristics, which may contribute to titanium's susceptibility to fretting fatigue.

\subsubsection{Titanium 6242}

Titanium and its alloys are classified into three categories depending on the microstructural phases present. The classifications are [42]:

1) alpha, $\alpha$, a hexagonal close-packed structure (hcp),

2) beta, $\beta$, a body-centred cubic structure (bcc), and

3) alpha-beta

Titanium 6242 (Ti-6242) is a super-alpha alloy with a total alloy content optimized to produce an ideal combination of creep strength, tensile strength, toughness and stability to $565^{\circ} \mathrm{C}\left(1050^{\circ} \mathrm{F}\right)$. It has excellent creep properties for extended periods of time at temperatures up to $427^{\circ} \mathrm{C}\left(800^{\circ} \mathrm{F}\right)$ and is less susceptible to stress corrosion than Ti-6Al4V [43]. A small amount of silicon ( $\mathrm{Si}$ ) which aids in increasing beta precipitates is sometimes added to the Ti-6242 alloy to improve its properties at high temperatures. The Ti-6242 alloy is generally used in the compressor sections of jet engines and airframe skin components.

Various types of annealing, solution treating and aging treatments are used to achieve selected mechanical properties. Stress relieving and annealing are applied to prevent 
preferential chemical attack in some corrosive environments, to prevent distortion or to condition the metal for subsequent forging and fabrication operations [44]. The Ti-6242 alloy is noted for its attractive mechanical properties in both the duplex and triplex annealed condition. Duplex and triplex refer to the specific heat treatment process used during manufacturing. Reference 45 outlines these heat treatments. A time - temperature - transformation (TTT) diagram outlining the effects of heat treatment temperatures on the phase morphology of Ti-6242 is shown in Figure 2.11 [45].

Stress relieving is commonly conducted after a component has been machined or manufactured. For the Ti-6242 alloy, a $593{ }^{\circ} \mathrm{C}\left(1100{ }^{\circ} \mathrm{F}\right), 2$ hour stress relief cycle provides nearly $100 \%$ relief of residual stresses (Figure 2.12) [45]. Depending on availability and furnace capabilities, stress relief at lower temperatures for a longer duration may be satisfactory.

The American Society for Testing and Materials (ASTM) has developed accepted standards for performing room temperature tensile tests (ASTM E-8), including methods for calculating the material properties [46]. Tensile tests provide material strength and ductility data in terms of load versus displacement from which basic material properties including: yield strength $\left(\sigma_{y s}\right)$, modulus of elasticity (E), ultimate tensile strength (UTS), elongation and reduction of area (RA) can be determined. Yield stress is determined using the intercept given at the 0.2 percent offset strain on the stress-strain curve, while the slope of this offset is used as an estimate of the modulus of elasticity. Ultimate tensile strength is defined as the maximum stress achieved for each specimen and is 
found by dividing the maximum withstood load by the initial cross-sectional area of the coupon. The specimen elongation and reduction of area are both calculated as a percentage of their original values, using the gauge length and cross-sectional area measured before and after testing.

The annealed properties of Ti-6242 required by the OEM for tensile test specimens at room temperature are given below [47]:

$\begin{array}{ll}\text { Tensile Strength, MPa } & 896(130,000 \mathrm{psi}) \\ \text { Yield Strength (0.2\% offset), MPa } & 827(120,000 \mathrm{psi}) \\ \text { Elongation (\% over 4 diameters) } & 10 \\ \text { Reduction in Area, \% } & 25\end{array}$

The crack propagation characteristics of a material include its resistance to crack growth and its load carrying ability in the presence of stress concentrations. Fracture mechanics assumes the pre-existence of flaws, inhomogeneities and discontinuities in a material. It is from these flaws that cracks often nucleate and grow under cyclic load $[48,49]$. The prediction of crack nucleation and propagation is beyond the scope of this thesis, however, it must be recognized that any local geometry, physical or metallurgical (welds, cutouts, notches, impact cracks, etc.), which intensify the stress are a prospective site for fatigue crack initiation. 


\subsubsection{Titanium's Susceptibility to Fretting Fatigue}

Titanium alloys are commonly used in rotating gas turbine engine components because of their high specific strength and excellent corrosion resistance $[10,12,13]$. Unfortunately, titanium and its alloys are particularly susceptible to wear and fretting fatigue damage $[6,11,14]$. This susceptibility may be due to two causes. First, the protective oxide layer naturally formed on titanium, which protects it in a corrosive environment, is typically very thin $(\sim 30 \mathrm{~nm}(1 \mu \mathrm{in}))$ [22]. The constant wear caused by fretting continuously disturbs this layer and provides little protection, allowing metal-tometal contact to occur. This contact, as discussed in section 2.1.3, will eventually lead to crack initiation and ultimately, failure of the component. Second, titanium has relatively poor thermal conductivity. High temperatures at the fretting surface contact points and lack of heat dissipation cause a transitional state at the surface from $\beta$-phase (body centered cubic (bcc) structure) titanium to $\alpha$-phase (hexagonal close-packed structure (hcp) structure) titanium. This leads to a greater probability of surface cracking since the microstructure of $\alpha$-phase titanium is more brittle than its $\beta$ counterpart [22]. 


\section{THESIS OBJECTIVES AND SCOPE}

The objective of this thesis is to design a fretting fatigue test rig and associated test specification to aid in the evaluation, through coupon testing, of potential processes to improve Ti-6242 resistance to fretting fatigue. This protective process must produce results "better than" the current fretting fatigue resistant solution used by the OEM in service.

The fretting fatigue rig previously developed at Orenda Aerospace Corporation, in cooperation with the Institute for Aerospace Research (IAR) at the National Research Council (NRC) is redesigned to represent the service conditions of a simulated blade and disc combination and used as a screening test for potential fretting resistant processes. Since there are no set standards (ASTM, AMS, AGARD) for fretting fatigue testing, a specification based on existing standards relative to fatigue testing is produced. This specification also outlines the equipment modifications and the test matrix to be used. To narrow potential processes down to one, additional tests are conducted on specimen coupons with the developed processes along with the current OEM process to determine if either have any detrimental effects on basic material characteristics. These additional tests include low cycle fatigue (LCF) testing, notch sensitivity testing and metallurgical analysis. Also, residual stress measurements are taken to determine if there is a direct correlation between compressive residual stress and fretting fatigue resistance. 


\section{DEVELOPMENT OF THE TEST PROGRAM}

The following section outlines the work completed in the design and modification of the fretting fatigue test rig and associated test specification. It also includes the development process and logic of the fretting fatigue test matrix. The fretting fatigue tests are used for isolating the best potential fretting fatigue resistant process to proceed to the additional material characterization tests mentioned in section 3.0.

\subsection{DESIGNING THE FRETTING FATIGUE TEST RIG}

When qualifying repairs or treatments, the evaluation tests developed must simulate service conditions as closely as possible. Most evaluation tests, such as low cycle fatigue, tensile or creep, have standard ASTM or Military Specifications, which outline the test procedure, limiting parameters and specimen design $[46,50,51,52]$. As mentioned earlier, there are currently no published standards, test methods or standard test equipment for fretting fatigue qualification $[1,45]$.

Investigations into fretting fatigue reveal that many factors influence the life expectancy of components exposed to fretting fatigue. These factors, several of which were discussed in section 2.2, include: material, environment, surface finish, surface hardness, normal load, axial load, relative displacement, oscillatory frequency, area of contact and environment. With all these factors affecting results, a successful test rig that produces unbiased and repeatable results, must restrain most of these factors and allow only 1 or 
possibly 2 , if unavoidable, to vary at any given time in order to determine resistance improvement with various surface modifications.

Facilities at the IAR of the NRC in Ottawa included a Material Testing System (MTS) loading frame type 810 capable of exerting $100 \mathrm{kN}(22,500 \mathrm{lbs})$ force. This frame is the same one used for previous fretting fatigue test programs and is used frequently for standard LCF tests.

The design of the fretting rig, the apparatus that applies the normal load, is the result of several revisions. Previous to the design used for this thesis, flat bridges and square specimens as shown in Figure 4.1 and Figure 4.2 were used. Analysis of the square design of the bridge and specimen, conducted at Orenda Aerospace Corporation, revealed stress concentrations or edge effects leading to premature failure at the points of contact [53]. A redesign was completed and led to an elliptical bridge (Figure 4.3) and dogbone specimen design (Figure 4.4), which reduced the edge effects.

A system of disc springs (conical washers), which allows the rig to maintain a relatively constant contact pressure with small bridge displacements, was incorporated. These discs reduced the number of adjustments that needed to be made during the test. They also have the flexibility to be stacked either in series (alternating), which increases the maximum displacement, or in parallel (single column), which increases the maximum load. A combination of both, with discs stacked in parallel and then stacked in series, optimised the desired loading characteristics. This spring design was more compact and 
more easily modified than using a similar coil spring. A complete picture of the current fatigue test rig is given in Figure 4.5 (note that the springs are located behind the heat shield on the left).

Included in the design of the test rig was a closed loop control system, which allows the user to leave the test running unattended. This control system maintains a given cyclic axial load, a set temperature and shuts itself down if the specimen fails or if the temperature exceeds pre-defined range limits.

An MTS force transducer model \# 680.01B-01 load cell capable of producing $100 \mathrm{kN}$ $(22,500 \mathrm{lbs})$ force is used to monitor and maintain the axial loading on the fretting rig.

To equally distribute the normal load over the four bridge pads, two strain gauges were added to each bridge, giving a total of four strain gauges (Figure 4.6). These strain gauges are monitored with a strain gauge conditioner and amplifier system, supplied by InterTechnology Inc. It is broken down into two parts; the first is a power supply, model\# 2110A and second, two conditioners model \# 2120A capable of conditioning up to four gauges collectively. The conditioners use a three-line input to compensate for any strain variation due to thermal conditions. However, due to the high temperatures of the tests $\left(454{ }^{\circ} \mathrm{C}\left(850^{\circ} \mathrm{F}\right)\right)$, the strain gauges are typically operational only during room temperature loading and become inoperative during the initial ramp up to temperature. Very few of the strain gauges survived the tests performed during research for this thesis, 
and therefore the strain gauge data retrieved by the computer during cycling was considered unreliable.

To maintain a given constant thermal environment, several methods of heating were considered for the test set-up including induction, furnace and radiant light. Radiant light was selected as the easiest and most economical means to provide uniform and controllable temperatures within the test area. The closed loop quartz lamp heating system selected provided rapid response to temperature fluctuation and closed loop control. Heat is supplied by two quartz light parabolic strip heaters, model \# 5305-A, which are orientated perpendicular to the fretting rig. These lights were manufactured by Research Inc., and each produce 1000 Watts at full power. The temperature of the tests was $454{ }^{\circ} \mathrm{C}\left(850^{\circ} \mathrm{F}\right)$ and was maintained within $\pm 3{ }^{\circ} \mathrm{C}\left( \pm 5^{\circ} \mathrm{F}\right)$. The Power Control Series 663, model \# 663F-11-331-00, can supply up to 25 amps at 120 volts, which is sufficient for successful full range operation of these lights. To control the output power of the lights, an ARROW 8630 heat controller with an RS-485 interface was integrated into the system not only for closed loop control of the output power of the lights but to shut them off in case of a test stoppage. A test stoppage is defined as failure of a specimen, temperature out of range, hydraulic failure or manual override.

Due to extended periods of operation at high temperature, the MTS frame, grips and the fretting rig, need to be cooled since only the test specimen and test bridges are capable of surviving these high temperatures for the duration of the test. The cooling system consists of two parts; a constant water flow system that cools the fatigue test frame grips, 
the fretting rig bridge plates and the load cell monitoring the normal load, and a forced air cooling system, which maintains the disc springs within acceptable temperature limits.

The normal load or contact force is monitored for the duration of the test using an ACCUDATA amplifier with a specialized load cell design. The load cell was manufactured such that a cooling insert could be added to maintain acceptable temperatures.

To allow the user to leave the test running, a data acquisition system was added to monitor the test. This data acquisition system included several components. The computer used to run the tests is a Compaq Deskpro 386/25e with $16 \mathrm{Mb}$ of random access memory (RAM), interfaced with the TESTSTAR workstation model \# 490.01 . The software running the tests is TESTSTAR, Version 1.4C. The system is capable of storing strain gauge, normal load and axial load readings and loading cycles at a preset number or time count specified by the user.

The specimen grips were manufactured from MAR-M247, a material capable of withstanding temperatures and loadings far greater than those induced by these tests. The grips are pre-loaded to prevent the backlash effects of a threaded connection. Extra specimen grips were manufactured due to the number of tests that were to be run to prevent down time in the event of a grip failure. Figure 4.7 shows the complete set-up of the fretting fatigue test facility. 


\subsection{DESIGNING THE SCREENING PROCESS AND TEST MATRIX}

As discussed in section 2.3, different anti-fretting fatigue improvement techniques can be used in conjunction with each other. However, care must be taken in selecting the processes for combination. For example, enriching a hard coating with a lubricant in an attempt to reduce the coefficient of friction may seem the best solution, but the application of the lubricant may damage the coating or assist in delaminating it from the parent surface.

Before selecting processes to screen, the service environment, including the material has to be fixed. The material selected for both the compressor blade and disc is Ti-6242 to the material requirements specified by the OEM [47]. The service conditions, determined in consultation with the OEM and with consideration to the facilities available, are as follows:

$$
\begin{array}{ll}
\text { Temperature: } & 454{ }^{\circ} \mathrm{C}\left(850{ }^{\circ} \mathrm{F}\right) \\
\text { Contact Stress (normal load): } & 337.8 \mathrm{MPa}(49 \mathrm{ksi}) \\
\text { Vibratory stress: } & 55.2 \mathrm{MPa}(8 \mathrm{ksi}) \\
\text { Relative displacement: } & 38 \mu \mathrm{m}(0.0015 \mathrm{in})
\end{array}
$$

Once the environment is understood and potential candidates selected, the coatings and/or processes must be placed into respective groups, which compare similar traits (e.g. mechanical hardening, soft and hard coatings, lubricants). After the groups are identified a test matrix can be developed. The matrix must ensure that the coating or treatment is isolated such that the benefits or detriments can be confirmed without interference from 
external influences. External influences, which could alter results, include: different material lots for specimen manufacturing, test equipment variance and variance in test operators. By reducing the number of outside variables, the process performance can be fairly evaluated.

With this type of test apparatus the dogbone specimen represents the failing component and the bridge the component causing the damage. The failure criteria is complete fracture of the dogbone specimen or five million cycles. The best result is considered those processes that produce the highest number of cycles to failure.

Some of the coatings or surface processes have "line of sight" restrictions. "Line of sight" coatings or processes refer to those that must be applied directly in line of the area to be treated without any impedance. For ease of application in service and in testing, the dogbone specimen represents the compressor blade and the bridges represent the disc since complete coverage of the dovetail slot was not possible because of "line of sight" restrictions.

Based on the industry and literature review, as presented in section 2.0 , and prior pin on disc wear tests, external to this thesis research, several potential fretting resistant processes are identified and sorted into a test matrix (next page). Phases within the matrix are designed to screen several candidates of each type of process, as well as combinations of processes, which may produce better results. 
Fretting Fatigue Test Matrix:

\begin{tabular}{|l|l|l|l|}
\hline SPECIMEN (blade) & BRIDGES (disc) & \# OF TESTS & SERIES \\
\hline \multicolumn{5}{|c|}{ PHASE I } \\
\hline BARE & BARE & 6 & 1 \\
\hline \multicolumn{5}{|c|}{ PHASE II } \\
\hline SP & SP & 6 & 2 \\
\hline DSP & DSP & 6 & 3 \\
\hline LSP & LSP & 6 & 4 \\
\hline \multicolumn{5}{|l|}{ PHASE III } \\
\hline SP+CuNiIn+DAG** & SP** & 6 & 5 \\
\hline SP+Met 33+RJ 143 & SP & 6 & 6 \\
\hline SP+Hast B+LOB & SP & 6 & 7 \\
\hline SP+O.C.1 & SP & 6 & 8 \\
\hline SP+O.C.T.+O.C.C. & SP+O.C.T.+O.C.C. & 6 \\
\hline \multicolumn{5}{|c|}{ PHASE IV } \\
\hline SP+O.I.T.+O.C.C. & SP+O.C.C. & 6 & 9 \\
\hline SP+O.C.T.+O.C.C1 & SP+O.C.T.+O.C.C1 & 6 \\
\hline
\end{tabular}

**Current OEM solution

The Phase I test specimens were manufactured from the as received parent material, Ti6242. These tests were performed to provide a benchmark to measure the relative improvement of the fretting fatigue resistant coatings and processes.

Phase II was designed to select a mechanical hardening technique. It consisted of shot peening (SP), dual shot peening (DSP) and laser shock peening (LSP). The SP process was the current peening specification used on the blade, MI 110, 4-8 A, total coverage. MI 110 describes the size and quality of metal shot used and 4-8 A describes the intensity. As discussed in section 2.3 .4 , dual peening can potentially produce better 
results than single peening. Previous work completed at Orenda Aerospace Corporation verified this and dual shot peening was added to Phase II [53]. The exact specifications of the second peening process can be found in the aforementioned reference. Laser shock peening was added to compare different mechanical hardening processes. The mechanical hardening processes that provided the best results are used in Phase III.

Phase III was designed to find the most effective coating or surface protection process. All processes were used in combination with the best mechanical hardening process from Phase II. Data obtained in earlier projects showed that shot peening, CuNiIn coating, $\mathrm{MoS}_{2}$ solid film lubricant (DAG) and an anodizing and chemical process (OCT), proprietary to Orenda Aerospace Corporation, improved fretting fatigue life in the fan section [53]. CuNiIn and $\mathrm{MoS}_{2}$ are still used by the OEM for the compressor stage and were therefore included. It was indicated by the vendor that the solid film lubricant used in the previous program by Orenda Aerospace Corporation, was known to be unable to sustain long exposure in the service environment discussed above [53]. A new solid film lubricant (OCC) was therefore developed. Details of the development of the Orenda Chemical Coating (OCC) can be found in section 4.2.1. Phase III also included 3 hard coatings. Metcolly 33 (Met 33) and Hastelloy B (Hast B) are both metallic powder based coatings applied using the HVOF process whereas the Orenda Coating (OC1), a chromium carbide coating, is applied using a super detonation gun process. Both RJ 143 and LOB $1800 \mathrm{G}$ (LOB) are proprietary solid film lubricants. Originally, it was intended that the combined process producing the best results would be compared with the current solution used by the OEM in the additional material testing. However, midway through 
testing another promising surface treatment, Orenda Ion Treatment (OIT), was developed and there was further modification of the Orenda Chemical Coating. This additional modification (OCC1) is also discussed in section 4.2.1. To allow testing of these new processes and modifications, Phase IV was added.

The OIT process consists of depositing a thin layer of coating using ion sputtering combined with the original Orenda Chemical Coating (OCC). A modification in the curing temperature of the Orenda Chemical Coating1 (OCC1) was added to reduce its susceptibility to water absorption without negatively affecting the test results from Phase III. This susceptibility is discussed in section 4.2.1.

The original OEM design of the blade and disc interface allows for an anti-fretting fatigue coating while minimizing vibration and displacement. However, without this coating, a gap between the two is created, allowing the tip of the blade to move further toward the shroud during rotation of the disc. The geometrical impact of the removal and of the CuNiIn and solid film lubricant from the dovetail of the blade and replacement with a thinner coating was considered. Analysis, prior to testing, was conducted and is discussed in section 4.2.2.

\subsubsection{Design of the Orenda Chemical Treatment and Solid Film Lubricant}

As described in section 2.3, processes can be combined for greater fretting fatigue resistance. Initial concepts were to combine a shot peened surface, coating and solid film lubricant since this had been successful in the past [53]. The driving forces for the 
selection were the amount of improvement, the ease of application and the cost of application per component. The OEM currently uses CuNiIn as the anti-fretting fatigue solution. CuNiIn has a known thermal limit of $343^{\circ} \mathrm{C}-399^{\circ} \mathrm{C}\left(650^{\circ} \mathrm{F}-750^{\circ} \mathrm{F}\right)$. The service environment of the third-stage compressor is $454{ }^{\circ} \mathrm{C}\left(850^{\circ} \mathrm{F}\right)$, which is much higher than this thermal limit. It was therefore believed that the OEM solution would fail prematurely in testing and that another solution would have to be found. Contact with the vendor resulted in an anodizing type solution and a solid film lubricant alternative to the $\mathrm{MoS}_{2}$ used in the previous program. The anodizing type solution offered several advantages. The process itself did not affect the dimensions of the specimen and could therefore be used in conjunction with other coatings. In addition, there would be no stress relieving of the shot peening since the anodizing could be performed at room temperature. Vendor tests showed a reduction in surface roughness in comparison to the untreated material. Based on this information, specimens isolating the effects of the Orenda chemical treatment and solid film lubricant were tested in Phase III.

Although this new lubricant could withstand higher temperatures, it was found to break down in the presence of water. To mitigate this, several tests were conducted with respect to susceptibility to humidity and water absorption by the vendor under supervision, by the author, to optimize the application process of the new solid film lubricant. Tests were carried out over a range of curing temperatures and film adhesion was monitored. The new curing temperature produced a solid film lubricant with improved resistance to water absorption and humidity. This modified solid film lubricant (OCC1) was added to Phase IV. 


\subsubsection{Geometric Impact Analysis}

Regardless of coating applied to the disc dovetail region, new and replacement thirdstage compressor blades are pre-ground and coated to meet the following blade-to-shroud clearance [54]:

Clearance requirements for new and replacement blades:

\begin{tabular}{|l|l|l|}
\hline HPC STAGE & MINIMUM & MAXIMUM \\
\hline 3 & $0.037^{\prime \prime}$ & No longer than longest installed blade \\
\hline
\end{tabular}

The minimum clearance is required in order to prevent contact damage to the shroud and/or the tip of the blade during engine operation. The maximum clearance is to aid in balancing the disc and refers to the difference between the new or replacement blade and the longest currently installed blade. Since there was no numerical maximum clearance given, a previous fan and compressor stage value of 0.008 " maximum difference between the replacement blade and the longest installed blade was used [53]. Using this information, the removal of the CuNiIn and $\mathrm{MoS}_{2}$ could not allow the replacement blade to exceed these limits.

Of all the combined processes, the Orenda Chemical Treatment (OCT) and Orenda Chemical Coatings (OCC or OCC1) had the greatest geometric impact since the combination of the two had the minimum coating/process thickness associated with them. Therefore, this combination was used in the analysis. 
In General Electric specifications F50TF13, for the CuNiIn coating, and F50TF33, for the solid film lubricant, the following coating thickness ranges were determined:

Coating thickness ranges:

\begin{tabular}{|l|l|l|}
\hline HPC STAGE & CuNiIn & $\begin{array}{l}\text { Solid film lubricant } \\
\text { (DAG) }\end{array}$ \\
\hline 3 & $\begin{array}{l}2.5^{\prime \prime} \\
4.5^{\prime \prime}\end{array}$ & $0.5^{\prime \prime}-1.5^{\prime \prime}$ \\
\hline
\end{tabular}

Note: all measurements are in $(0.00 \mathrm{x})$ inches.

From the blade drawings, the incline of the dovetail was found to be $45^{\circ}$ and the following tip displacement increase due to coating removal were calculated:

Tip displacement due to coating removal:

\begin{tabular}{|l|l|l|l|l|l|l|}
\hline & \multicolumn{2}{|l|}{ CuNiIn } & \multicolumn{2}{l|}{ DAG } & \multicolumn{2}{l|}{ TOTAL } \\
\hline HPC STAGE & MIN & MAX & MIN & MAX & MIN & MAX \\
\hline 3 & 3.5 & 6.4 & 0.7 & 2.1 & 4.2 & 8.5 \\
\hline
\end{tabular}

Note: all measurements are in $(0.00 \mathrm{x})$ inches.

This means that if the OEM coating of CuNiIn and solid film lubricant were completely removed, the blade tip could displace a maximum of 0.0085 inches, which could potentially exceed the maximum allowable difference of 0.008 inches.

Although the OCT process does not have a thickness associated with it, the OCC and the modified OCC1 lubricants both have a thickness of 0.0003-0.0005 inches. This would 
give a maximum tip displacement reduction of $0.00042-0.00071$ inches. Theses numbers can then be subtracted from the total impact of the removal of the CuNiIn and solid film lubricant from the blade. The minimum and maximum tip displacement increase is then calculated to be:

Tip displacement due to $\mathrm{OCT}$ and $\mathrm{OCC} / \mathrm{OCC} 1$ processing:

\begin{tabular}{|l|l|l|}
\hline HPC STAGE & MIN CHANGE & MAX CHANGE \\
\hline 3 & $3.5^{\prime \prime}$ & $8.1 "$ \\
\hline
\end{tabular}

Note: all measurements are in $(0.00 \mathrm{x})$ inches.

Although the maximum change still exceeds the project imposed 0.008 inch limit, it was accepted that the removal and replacement of the CuNiIn and solid film lubricant with the new Orenda process would have little impact since even in the worst case these changes in dimensions are less than what the total removal of the CuNiIn and DAG would cause and still be within tolerances given in the original OEM document [54]. 


\section{TESTING AND ANALYSIS PROCEDURES}

The following section describes the tests and the post-test analysis conducted for this project.

\subsection{FRETTING FATIGUE TESTING AND ANALYSIS}

Section 3, stated that there is a need for a standard procedures produced for fretting fatigue testing and that this project would attempt to fill this need. In the design of the proposed fretting fatigue test procedure, ASTM and AMS guidelines were followed when applicable.

In the tests, the temperature, normal load, relative displacement (slip amplitude) and material were selected to reproduce service conditions. The specimen and bridge materials, as described in section 4.2, were both made from Ti-6242, representative of the third-stage compressor blade and disc combination used by the OEM.

The initial testing parameters were determined based on the service conditions outlined in section 4.2. The fixed testing parameters were:

$$
\text { Temperature: } \quad 454{ }^{\circ} \mathrm{C}\left(850^{\circ} \mathrm{F}\right)
$$

Normal load (contact load): $337.8 \mathrm{MPa}(49 \mathrm{ksi})$

Relative displacement (slip): $38 \mu \mathrm{m}$ (0.0015 in) 


\subsubsection{Calibration of the Axial Stress}

To produce the required relative displacement (amplitude of slip), the fretting rig depends on a certain amount of strain on the specimen caused by the application of the axial load. To determine this value, a calibration test was performed using a gold sputtered specimen. The specimen was placed in the fretting rig at room temperature and at the contact load given in section 5.1. A traveling microscope was used to measure the bridge pads before testing and the average of these measurements were taken. After allowing the test to run for a small number of cycles (less than 3,000 ), the contact surfaces on the specimen were measured and the difference between the specimen contact points and the average bridge value was taken to calculate relative displacement. If a relative displacement of less than $38 \mu \mathrm{m}\left(0.0015^{\prime \prime}\right)$ was achieved, the specimen was polished to remove any surface damage and then recoated with gold. The calibration continued, adjusting the axial load, until a relative displacement of $38 \mu \mathrm{m}\left(0.0015^{\prime \prime}\right)$ had been reached. Using the following to calculate the cross-sectional area of the specimen:

$$
X-\text { SectionalArea }=\frac{t}{2} * \sqrt{\left(w^{2}-t^{2}\right)}+\frac{w^{2}}{2} * \arcsin \left(\frac{t}{w}\right)
$$

where: $t$ is the thickness of the specimen

$\mathrm{w}$ is the width of the specimen

the axial stress was calculated. This axial stress value was used for the remaining fretting fatigue tests. 


\subsubsection{Fretting Fatigue Tests}

A total of 66 tests were performed as outlined in section 4.2. The results of these tests can be found in Figure 6.1 or individually in Table 6.1 and are discussed in detail in section 6.1 .

\subsubsection{Control Specifications}

Each test was run maintaining a constant maximum and minimum load with an R-ratio of 0.25 , at a frequency of $5 \mathrm{~Hz}$ using a sine wave pattern. The values of maximum and minimum stress were calculated using the cross-sectional area before processing. An Rratio is the minimum applied stress divided by the maximum applied stress. A frequency of five (5) $\mathrm{Hz}$ was selected to reduce the frequency effects discussed in section 2.2.6 while maintaining a test duration of approximately 1-10 hours. The sine wave was selected as the best representation of actual loading conditions encountered in service.

\subsubsection{Normal or Contact Load Application}

Using a load cell and strain gauges, it was ensured that an evenly distributed contact load was applied to each specimen. However, due to the thermal limits of the strain gauges, the readings were monitored and recorded only at the beginning of each test, prior to thermal loading. These initial readings were kept for potential future study.

\subsubsection{Post-Test Analysis}

Each specimen, once tested, underwent the following analytic procedures for classification and documentation. 


\subsubsection{Optical Microscopy}

An optical (light) microscope was used to determine the severity of fretting fatigue surface damage. It was also used to classify and document the types of damage that occurred (crack location, failure mechanisms, etc.), and how each test performed on a visual basis. Results of the optical microscope analysis can be found in section 6.4.

\subsubsection{SEM (Scanning Electron Microscope) Analysis}

The scanning electron microscope was used to verify the optical observations in determining the fretting fatigue surface damage. The SEM also allowed the observer to check for and document such things as galling, fatigue striations and material transfer, all of which are common in fretting fatigue (section 2.3). Results of the SEM analysis can be found in section 6.4 .

\subsubsection{Surface Profilometry}

Using a surface profilometer, a general outline of penetration due to fretting fatigue was obtained. Results of the surface profile analysis can be found in section 6.4.

\subsection{LOW CYCLE FATIGUE TESTING AND ANALYSIS}

Low Cycle Fatigue (LCF) tests were carried out on the process found to be most successful in Phases III and IV of the fretting tests as well as the current OEM process of shot peening, CuNiIn and molybdenum-disulphide $\left(\mathrm{MoS}_{2}\right)$. The objective was to verify that the processes used to improve fretting fatigue life did not reduce the base material's 
low cycle fatigue properties. OCT combined with OCC1 was selected from Phases III and IV.

The low cycle fatigue (LCF) test equipment used met ASTM E467 and ASTM E606 requirements. The test equipment included, but was not limited to, the following:

1) material test machine powered by hydraulic system,

2) specimen fixture system,

3) loading transducers,

4) automated control unit,

5) function generator, and

6) data acquisition and recording system.

An MTS servo-hydraulic $100 \mathrm{kN}$ test frame installed at the IAR/NRC was used for the LCF testing. The frame was calibrated to MTS and ASTM specifications prior to testing.

All tests were conducted and maintained at $454{ }^{\circ} \mathrm{C} \pm 3{ }^{\circ} \mathrm{C}\left(850 \mathrm{~F} \pm 5{ }^{\circ} \mathrm{F}\right)$ using a split-shell furnace with close loop control.

\subsubsection{LCF Axial Stress}

All LCF tests were conducted to the point of specimen fracture or $10^{6}$ cycles at an R-ratio of 0.1. LCF testing was conducted at three different stress levels. These levels were calculated to give a minimum cycle life based on material characteristics listed in 
Reference 47. The points were then plotted to represent a portion of a standard $\mathrm{S}-\mathrm{N}_{\mathrm{f}}$ curve. The initial stress levels were determined to be:

Initial Stress Levels for LCF testing:

\begin{tabular}{|c|c|c|}
\hline $\begin{array}{c}\text { Test } \\
\#\end{array}$ & $\begin{array}{c}\text { Estimated Minimum Cycles to Failure } \\
\left.\mathbf{( N}_{\mathbf{f}}\right)\end{array}$ & $\begin{array}{c}\text { Maximum Stress Level } \\
(\mathbf{S})\end{array}$ \\
\hline 1 & 50,000 & $579 \mathrm{MPa}(84 \mathrm{ksi})$ \\
\hline 2 & 30,000 & $607 \mathrm{MPa}(88 \mathrm{ksi})$ \\
\hline 3 & 10,000 & $662 \mathrm{MPa}(96 \mathrm{ksi})$ \\
\hline
\end{tabular}

Note: These stress levels were subject to change upon completion of the first test.

\subsubsection{LCF Tests}

The LCF test specimen was of the standard ASTM "hourglass" configuration with button head ends. Details of the specimen geometry are given in Figure 5.1. LCF testing was conducted at three different stress levels to compare the most successful Phase III/IV process and the OEM process. The applied load was calculated based on the preprocessed cross-sectional area. For each process and stress level three specimens were tested for a total of 18 specimens. The test matrix is outlined below:

LCF Test Matrix:

\begin{tabular}{|l|l|l|l|}
\hline MATERIAL & PROCESS & \# OF TESTS & SERIES \\
\hline Ti-6242 & SP+CuNiIn+DAG $* *$ & 9 & 1 \\
\hline Ti-6242 & SP+O.C.T.+O.C.C1 & 9 & 2 \\
\hline
\end{tabular}

$* *$ Current OEM process 
The results of these tests can be found in Figure 6.2 or individually in Table 6.2 and are discussed in detail is section 6.2 .

\subsubsection{Control Parameters}

Each test was run maintaining a constant maximum and minimum load with an R-ratio of 0.1 , at a frequency of $5 \mathrm{~Hz}$ using a sine wave pattern. The values of maximum and minimum stress were calculated using the cross-sectional area before processing. A frequency of five (5) $\mathrm{Hz}$ was selected to reduce the frequency effects discussed in section 2.2.6 while maintaining a test duration of approximately 1-10 hours. The sine wave was selected as the best representation of actual loading conditions encountered in service.

\subsubsection{Post-Test Analysis}

Each specimen, once tested, went through the following analytic procedures for classification and documentation.

\subsubsection{Optical Microscopy}

An optical (light) microscope was used to classify and document the type and location of failure. Results of the optical analysis can be found in section 6.4 .

\subsubsection{SEM (Scanning Electron Microscope) Analysis}

A scanning electron microscope was used to verify the optical observations and to allow the observer to check for and document any unusual failure conditions. Results of the SEM analysis can be found in section 6.4 . 


\subsection{NOTCH SENSITIVITY TESTING AND ANALYSIS}

Notch sensitivity tests were carried out on the most successful process of Phases III and IV of the fretting tests and the current OEM process of shot peening, CuNiIn and molybdenum-disulphide $\left(\mathrm{MoS}_{2}\right)$. The objective was to verify that the processes used to improve fretting fatigue life did not increase the base material's notch sensitivity properties. The OCT combined with OCCl was selected from Phases III and IV.

There are neither standard procedures nor specimen designs published by ASTM or AMS for notch sensitivity testing which could be used. However, the design of the test procedure and specimens used followed ASTM and AMS guidelines where applicable.

The notch sensitivity test equipment met ASTM E467 requirements. The test equipment included, but was not limited to, the following:

1) material test machine powered by hydraulic system,

2) specimen fixture system,

3) loading transducers,

4) automated control unit,

5) function generator, and

6) data acquisition and recording system.

The MTS servo-hydraulic $100 \mathrm{kN}$ test frame installed at the IAR/NRC used for the LCF testing was also used for the notch sensitivity testing. The frame was calibrated to MTS and ASTM specifications prior to testing. 
The tests were run at room temperature. In the represented service conditions, this is the most severe condition for notch sensitivity in titanium since notch sensitivity is generally inversely proportional to ductility, which increases with temperature.

\subsubsection{Axial Stress}

All notch sensitivity tests were conducted to the point of specimen fracture or $10^{6}$ cycles at an R-ratio of 0.1 as in the LCF evaluation tests. Notch sensitivity testing was conducted at varying stress levels. These levels were calculated based on the minimum reduced area of the specimen, prior to processing, to give a range of failures typically below 50,000 cycles. Since the effect of the notch was difficult to predict without detailed analysis, several calibration tests were conducted.

\subsubsection{Notch Sensitivity Tests}

The specimens were machined with two stress concentration $\left(\mathrm{K}_{\mathrm{t}}\right)$ values, one set at 1.52 and one set at 2.6. A total of 36 tests were performed as follows:

Notch Sensitivity Test Matrix:

\begin{tabular}{|l|l|l|}
\hline SPECIMEN & Kt value & \# OF TESTS \\
\hline SP+CuNiIn+DAG** & 1.52 & 9 \\
\hline SP+CuNiIn+DAG ${ }^{* *}$ & 2.6 & 9 \\
\hline SP+O.C.T.+O.C.C1 & 1.52 & 9 \\
\hline SP+O.C.T.+O.C.C1 & 2.6 & 9 \\
\hline
\end{tabular}

** Current OEM solution

Note: These numbers do not include the tests required for calibration. 
The results can be found in Figure 6.3. Individual test data can be found in Table 6.3 for $\mathrm{K}_{\mathrm{t}}=1.52$ and Table 6.4 for $\mathrm{a} \mathrm{K}_{\mathrm{t}}=2.6$ and are discussed in detail in section 6.3 .

\subsubsection{Control Parameters}

Each test was run maintaining a constant maximum and minimum load with an R-ratio of 0.1 , at a frequency of $5 \mathrm{~Hz}$ using a sine wave pattern. The values of maximum and minimum stress were calculated using the cross-sectional area before processing. A frequency of five (5) $\mathrm{Hz}$ was selected to reduce the frequency effects discussed in section 2.2.6 while maintaining a test duration of approximately $1-10$ hours. The sine wave was selected as the best representation of actual loading conditions encountered in service.

\subsubsection{Post-Test Analysis}

Each specimen, once tested, went through the following procedures for classification and documentation.

\subsubsection{Optical Microscopy}

An optical (light) microscope was used to classify and document the type and location of failure. Results of the optical inspection can be found in section 6.4 .

\subsubsection{SEM (Scanning Electron Microscope) Analysis}

A scanning electron microscope verified the optical observations and allowed the observer to check for and document any unusual failure conditions. Results of the SEM inspection can be found in section 6.4. 


\subsection{METALLURGICAL ANALYSIS}

Basic optical metallurgical analysis, outlined below, was carried out on selected specimens after the testing of each set was complete (after initial testing it was clear that certain process configurations were unacceptable and only those that proceeded to the additional evaluation tests were studied.) Metallurgical analysis was conducted on the following sets:

1) Bare: Baseline, bare Ti-6242, as received (Phase I, Series I)

2) SP: Shot Peened (Phase II, Series 2)

3) Shot Peened + CuNiIn + DAG (current OEM process) (Phase III, Series 5)

4) OCT+OCC1: Orenda Chemical Treatment and Modified Orenda Chemical Coating (lubricant) (Phase IV, Series 11)

As described in each test procedure, each of these groups of specimens underwent the following examination and documentation:

1) optical examination using a stereoscope to document fracture surface characteristics and wear pads,

2) SEM on the fracture and wear surfaces of three of the most representative specimens, and

3) surface profilometry of all of the specimens and bridges of the sets listed above and three from the remaining sets for comparison reasons.

Discussion of the metallurgical analysis can be found in section 6.4. 


\subsection{RESIDUAL STRESS ANALYSIS}

The NRC conducted surface residual stress tests on the failed specimens. Failed specimens were used to account for any relieving, which may have been caused through processing. A zone of the test specimen away from the fretting fatigue test region was used for the X-Ray analysis. A Rigaku D/MAX-2BX X-ray diffractometer was used for these measurements. The X-Ray was generated from $\mathrm{Cu} \mathrm{K}_{\alpha}$ radiation at $40 \mathrm{kV}$ and 30 mA. A Ni filter was placed at the receiving solar slit to suppress the $K_{\beta}$ and background radiation. The measurements were conducted by continuous scan at $0.3 \% \mathrm{~min}$ with a data acquisition interval of $0.02^{\circ}$. The residual stress values produced were used to determine a correlation between residual stress and cycles to failure.

Three specimens were taken from each of the 11 series and readings were taken between the fretting pads from both sides for a total of six readings from each series except from Series 11 (SP+OCT+OCC1), in which all specimens (6) were examined. Note that results from Series $8(\mathrm{SP}+\mathrm{OC} 1)$ are not included since the thick coating prevented any reading on the substrate. The results can be found in Table 6.5 or graphically represented using error bars (the error bars are derived from 1 standard deviation) in Figure 6.4. Further discussion can be found in section 6.5.

\section{RESULTS AND DISCUSSION}

The following section discusses in detail the results of the fretting fatigue, LCF and notch sensitivity testing as well as the analysis that was conducted post-failure. 


\subsection{FRETTING FATIGUE TESTS}

Shot peening results from Phase II differed slightly from previous programs in that dual peening (Series 3) did not show a noticeable improvement (Table 6.6). In Phase II, standard shot peening as per GE specifications showed a nearly a $25 \%$ improvement over laser shock peening (Series 4) and an over 60\% improvement over dual shot peening (Series 3). All three hardening processes (SP, DSP, LSP) increased the fretting fatigue life over the untreated material from $38-125 \%$. This increase in fretting fatigue life supports the discussion of the benefits of induced compressive residual stress states presented in sections 2.2 .2 and 2.3.4.

From the results in Phase II, standard shot peening proceeded to Phase III. The Orenda coating (OC1, Series 8) and the Orenda Chemical Treatment (OCT, Series 9), together with the shot peening process from Phase II were tested against the current OEM configuration of shot peening, CuNiIn and molybdenum disulphide (SP+CuNiIn+DAG) represented by Series 5. Two other alternatives suggested by the OEM, Metcolly 33 (MET 33, Series 6) and Hastelloy B (Hast B, Series 7) with proprietary solid film lubricants RJ 143 and LOB $1800 \mathrm{G}$, were also tested.

It is understood that blade and disc failure of high-pressure compressors (HPC) is a fretting fatigue dominated failure. Therefore, as discussed in section 2.3 , those coatings that did not relieve the compressive residual stress induced by the shot peening would likely perform better. The OCT+OCC process is applied at room temperature and 
therefore minimizes stress relief, unlike Met 33, Hast B and OC1, which are all applied at high temperatures. This explains the more desirable performance of the Orenda Chemical Treatment (OCT), with the original Orenda Chemical Coating (OCC), which out-performed all other coatings by $35-440 \%$ and in particular the OEM solution by $35 \%$. Table 6.6 shows the improvement factor of all suggested solutions in the test matrix with respect to the OEM solution.

Phase IV was integrated to allow the testing of an ion plating process (OIT, Series 10) and a modification to the Orenda Chemical Coating (OCC1) (section 4.2.1). The ion treatment showed a marginal improvement of $6 \%$ over the original Orenda Chemical Treatment (OCT) and over 40\% improvement over the OEM solution. However, the Orenda Chemical Treatment with the modified lubricant (OCT+OCC1, Series 11) showed an almost $90 \%$ improvement over the CuNiIn+DAG, over $25 \%$ improvement over the ion plating process (OIT $+\mathrm{OCC}$ ) and an improvement of nearly $400 \%$ over the parent material (BARE). This additional improvement is contributed to its resistance to moisture absorbance during handling and during the setup prior to testing.

All but three of the 66 tests were included in the results. Test \#4 of Series 9 was not included due to a failure pattern that indicated uneven loading. This was further verified with the strain gauge readings. Tests \#5 and \#6 of Series 11 were also removed from the results. One of the bridges in test $\# 5$ displayed a large scratch in its surface. When the specimen was examined, the crack initiation was determined to be at the contact point of the scratch. Test \#6 was discarded due to a surface scratch found in the specimen, 
probably a result of the original machining. The failing crack was tracked back to its origin which was at the surface scratch. There were no unusual results in the observations of the fracture surfaces or wear pads other than those mentioned above.

\subsection{LOW CYCLE FATIGUE TESTS}

Inspection of the specimens processed using the OEM coating of CuNiIn+DAG revealed severe cracking and delamination from the parent material (Figures 6.5, 6.6 and 6.7.) This breakdown of the coating verified the coating's inability to sustain the compressor's higher temperatures as mentioned in section 2.3. The cracking in the OEM coating seemed to correspond to the multiple crack initiation sites in the specimen Figure 6.4. Optical photos of both the CuNiIn+DAG and the OCT $+\mathrm{OCC} 1$ show a typical fatigue crack growth to a ductile failure. Examples of these failures can be found in Figures 6.8 and 6.9.

A plot of maximum applied stress versus cycles to failure for Ti-6242 shows a dramatic improvement in low cycle fatigue life for $\mathrm{OCT}+\mathrm{OCC} 1$ (Series 2) in comparison to CuNiIn+DAG (Series 1) (Figure 6.2). The Orenda Chemical Treatment with modified lubricant show a relatively moderate but stable decline over the range of the test. The CuNiIn + DAG (Series 1) however, shows a drastic drop in fatigue life over the same test range. Based on fatigue analysis only, a possible explanation is the difference in the failure mechanisms against which CuNiIn protects. CuNiIn has very good wear properties, as discussed in section 2.3 , however, its fatigue strength is relatively poor. Due to the strength of adhesion to the parent material, once the coating fails in fatigue it 
promotes crack initiation into the parent material. Also, the application of CuNiIn is performed at a sufficiently high temperature to partially relieve the compressive residual stresses induced by shot peening. Conversely, the Orenda process increases the hardness of the surface in addition to reducing the surface roughness, both of which reduce the susceptibility to crack initiation and fatigue cracking. These results clearly indicate that the Orenda Chemical Treatment with the modified Orenda Chemical Coating (OCT+OCC1) dramatically improves the low cycle fatigue life of the coupons over the current OEM solution of CuNiIn+DAG.

\subsection{NOTCH SENSITIVITY TESTS}

Several of the initial tests, at a $K_{t}$ value of 1.52 , failed in the threads. Careful inspection of the thread roots indicated that machining flaws had caused a greater stress concentration in the thread root than in the notch. This was fixed by extending the grips to encompass the entire thread and then pre-stressing the threads using a hydraulic piston. The remaining Ti-6242 tests were run as follows:

\begin{tabular}{|l|l|l|l|l|}
\hline $\begin{array}{l}\text { Kt } \\
\text { Value }\end{array}$ & $\begin{array}{l}\text { Max Stress } \\
(\mathrm{ksi})\end{array}$ & $\begin{array}{l}\text { Min Stress } \\
(\mathrm{ksi})\end{array}$ & $\begin{array}{l}\text { Maximum } \\
\text { cycles }\end{array}$ & $\begin{array}{l}\text { Minimum } \\
\text { cycles }\end{array}$ \\
\hline 1.52 & 130 & 80 & 84,654 & 5,760 \\
\hline 2.6 & 100 & 60 & 148,136 & 5,330 \\
\hline
\end{tabular}

In both cases, all tests tended to fall within scatter of each other especially at a $\mathrm{K}_{\mathrm{t}}$ value of 1.52, where the results are almost identical. The results for the $K_{t}$ value of 2.6 show a slightly quicker stress decline over the range of cycles to failure of the OCT+OCC1 specimens but are still within scatter (Figure 6.3). These results indicate that the Orenda 
chemical treatment with the modified lubricant does not affect the parent materials' notch sensitivity characteristics any more than the current OEM solution.

\subsection{METALLURGICAL ANALYSIS}

Optical examination of the failed fretting fatigue specimens was performed with a stereoscope at up to $50 \mathrm{X}$ magnification. Only general characteristics of the surfaces, such as the crack growth region and the general crack initiation site, can be determined with this equipment. The examination predominately showed that all failures occurred from one of the fretted regions and usually near the outer edge of the fretting faces (Figure 6.10). This outer edge was located relatively close to the slip no slip transition area discussed in section 2.1.3. The fracture surface of each specimen revealed extensive crack growth regions (Stage II) perpendicular to the applied load (Figure 6.11). As discussed in section 2.1.4, Stage III crack growth resulted in a rapid failure, which occurred in ductile tension followed by quasi-cleavage under a partial bending of the specimen. This region is generally characterized by a dramatic change in the crack growth direction as the load axis is shifted off-centre for the remaining load-bearing material and results in "lipping." In addition, due to the reduction in the load-bearing cross-sectional area, the remaining overloaded material tends to fail in tensile shear at an angle of $\sim 45^{\circ}$ to the load direction. This is known as the shear plane and commonly produces a large spike on one fracture surface and a deep cleft in the other (Figure 6.10).

Using the optical examination as a guideline, three representative specimens from each set were chosen for further analysis with a Scanning Electron Microscope (SEM.) 
Initially, the analysis was conducted with a Novascan SEM, but once available was later conducted with a Hitachi S-570 SEM due to its increased resolution. The fracture surface of each of the selected specimens was examined to determine the crack initiation points and the crack growth patterns that resulted in failure (Figure 6.12). By tracing the cracks back to their initiation point, the cause of initiation can often be determined. In most cases, the initiation likely originated due to fretting wear as many of the characteristics discussed in section 2.1 were observed. Although they were not observed, other mechanisms such as flaws within the specimen may have been involved. Such flaws can be pores, pre-existing cracks, scratches caused by machining and inhomogeneities of the material. It is difficult to completely determine all possible contributions since fretting tends to severely damage the surface, covering any previous evidence of pre-test flaws.

After the fracture surface had been examined, the fretted faces were also examined for distinguishing characteristics discussed in section 2.1. As indicated above, characteristics such as galling troughs occurring parallel to the fretting direction as shown in Figure 6.13 can be compared to similar damage shown in Figure 2.5. Material transfer, discussed in section 2.1, is simply the breaking of asperities off of one surface and transferring to the other through localized welding. Smearing occurs when softer material is spread over a harder surface, which may or may not result in an actual bond. Both smearing and material transfer can be seen in Figure 6.14. Cracks forming perpendicular to the fretting direction are due to the fretting wear caused by high shear stress of the surface layers until cracking occurs (Figures 6.14 and 6.15). Fretting ridges 
form due to the pile up of debris welding together to create hardened ridges that form perpendicular to the fretting direction, or by the "rippling" of the harder surface over a softer under layer (Figure 6.16). In addition, near the crack initiation site at the edge of the fracture surface, a "tongue" or "chip" may be observed due to the direction the crack is prone to follow after initiation (Stage I crack growth) and prior to it altering direction to grow by fatigue perpendicular to the axial tensile load (Stage II crack growth). As discussed in section 2.1.4, this confirms that fretting fatigue does not affect the Stage I growth angle of a typical fatigue crack. The top of such a "tongue" is visible at the initiation site in Figure 6.12.

All of the above characteristics were observed on each of the four specimen sets examined. In addition, fatigue striations (Figure 6.17) were located on the crack growth surfaces, indicating that failure did occur ultimately due to fretting fatigue crack growth.

Further examination of the fracture surfaces with the SEM revealed that many of the specimen failures resulted from initiation sites directly beneath the surface of the specimens' fretting faces (Figure 6.12) and occurred between one-quarter and one-half of the distance from the edge of the specimen (Figure 6.11). These cracks grew by fatigue and eventually merged together, reducing the load bearing cross-sectional area by up to one-half prior to Stage III rapid failure. This is expected since the axial stress profile through the cross-section of the specimen results in a maximum just below the surface. 
Two of the specimens inspected had their crack initiation sites traced to single points on the undamaged rounded corner or side of the specimen. The corner of the specimens would be considered a stress raiser and in unfretted conditions would likely be the location of crack initiation. However, this would only be a crack initiation site in fretted conditions if an uneven loading of the specimen or a pre-existing flaw was located at or near that edge. In most of these cases, verification of strain gauge readings showed that initiation was likely due to uneven loading.

Surface profiles were taken using a Taylor Hobson Formtalysurf 120L (laser pick-up) profilometer. All 11 specimen sets had profiles generated. Three passes, in the axial direction, over each fretted face on both sides of the specimens were performed. An additional pass was also performed over each of the bridges' wear pads perpendicular to the fretting direction. Measurements of the depth of penetration were carried out on each profile taken. Results for the bridge damage can be found in Figure 6.18 and for the specimen damage in Figure 6.19 or tabulated in Table 6.1.

Due to the small area covered by the surface profilometry, conclusions can only be made on a general scale. The set with the greatest damage (wear depth) to both bridges and specimens was the CuNiIn+DAG, representing the current OEM configuration. As discussed previously, soft coatings such as CuNiIn and molybdenum-disulphide have a tendency to extrude. Since the profilometry results are based on the average high point to the average low point, this could lead to a larger value for this set. The bare material, LSP, SP, DSP, ion plated (OIT), and OCT+OCC1 specimens all fell within scatter of 
each other at the minimum depth of damage range. This verifies that the design of this fretting rig causes failure, which is dominated by fretting fatigue over fretting wear. The bridge fretting damage for all test Series fell within scatter of each other. This small variation in bridge scar depth can be explained by the fact that the bridges would only experience fretting wear (no axial loading component), in a fretting fatigue dominated situation. This allows any coatings or processes on the bridges to remain intact, reducing any potential damage caused by fretting wear.

Although, from a repair and overhaul point of view, it may be beneficial to correlate the amount of fretting damage to survived fretting fatigue cycle count, due to the limited amount of profilometry it was difficult to suggest a trend.

\subsection{RESIDUAL STRESS ANALYSIS}

The results indicated in Figure 6.4 and Table 6.5 shows that there is no direct relationship between the magnitude of compressive residual stress and number of cycles to failure. For example, in Figure 6.4, the dual shot peening process has a greater compressive residual stress than the single shot peening process but as discussed in section 6.1 , shot peening out-performed dual shot peening. This could be due to the large scatter of residual stress measurements within the same group. Some results were as expected. Processes that were expected to have detrimental effects on the compressive residual stress caused by application did show a reduced compressive residual stress or in some cases a tensile residual stress. These processes included: CuNiIn+DAG, Metcolly 33, Hastelloy B and the chromium carbide process OC1. It should be noted however, that 
although these processes may have relieved some of the pre-compressive states prior to testing, with the high temperature and long duration of the tests, the compressive residual stress would likely not have been completely relieved until some point during the test. In the case of the SP+OCT+OCC, the curing temperature of the OCC was higher than that of the OCC1, which may explain the differences in residual stress results. 


\section{SUMMARY AND CONCLUSIONS}

After designing a test rig and developing a test matrix, this study has evaluated several processes promising to reduce the effect of fretting fatigue on the third-stage HPC disc and blade coupling. These processes were evaluated through several tests including: 1) fretting fatigue, 2) low cycle fatigue, 3) notch sensitivity, 4) metallurgical analysis, 5) surface profilometry, and 6) surface residual stress. The conclusions for this study are summarized as follows:

1) Previous programs indicated that the Orenda Chemical Treatment (OCT) was successful in reducing the effects of fretting fatigue. This study further verified those results.

2) Previous programs showed that dual shot peening was more effective than single shot peening in extending the fatigue life of fan components. However, in the compressor test conditions, using Ti-6242, this was not the finding of this study.

3) After modifying the application of the Orenda Chemical Coating (OCC1), sensitivity to water was greatly reduced and the life to failure was increased.

4) The final configuration of shot peening, Orenda Chemical Treatment and the modified Orenda Chemical Coating increased the coupon life by nearly 2 times that of the current shot peened, CuNiIn and molybdenum-disulphide configuration used by the OEM. 
5) The LCF tests showed a dramatic increase in the fatigue life of Ti-6242, when treated with the modified Orenda process $(\mathrm{SP}+\mathrm{OCT}+\mathrm{OCC} 1)$, with respect to the current process used by the OEM.

6) The notch sensitivity tests showed that the notch fatigue life of Ti-6242 treated with the Orenda process was within test scatter with respect to the OEM's current solution.

7) Optical analysis determined that all failures were of a fretting fatigue nature with typical "lip" formations and shear planes of $\sim 45^{\circ}$.

8) Surface profiles showed that samples treated with the Orenda Chemical Treatment with modified chemical coating had significantly less depth of penetration (on average) than those coated with CuNiIn+DAG.

9) Surface profilometry does not allow for a correlation between depth of fretting damage and cycles to failure.

10) SEM analysis showed initiation sites were fairly standard across all specimens, confirming repeatability of results.

11) SEM provided evidence of gouging, material transfer and pitting. These are all characteristics associated with fretting fatigue.

12) Post-failure residual stress measurements do not relate to the cycles to failure of the specimen.

13) Residual stress measurements are too unstable to be used as an analysis tool to predict failure of the fretting fatigue coupons. 


\section{RECOMMENDATIONS AND FUTURE WORK}

Based on the information generated in this design and test program, the following recommendations are made:

1) Due to the positive results of the data obtained, the Orenda fretting fatigue resistant process should be further evaluated at the component level.

2) A better method of surface profilometry should be found to try and generate surface maps rather than individual lines. This may lead to a correlation between fretting fatigue damage and cycles to failure.

3) The following recommendations should be considered as future work to provide additional data in the characterization of this process:

a) Further metallurgy to investigate reasons for low depth of penetration and longer cycles to failure in the Orenda Chemical Treatment specimens.

b) Conduct spin-pit test to quantify the "added life" value of the Orenda Chemical Treatment on actual components. 


\section{REFERENCES}

[1] Koul, A.K., Xue, L., Wallace, W., Et A1., "An Investigation on Surface Treatments for improving the Fretting Fatigue Resistance of Titanium Alloys," 82nd Meeting of the AGARD SMP, May 1996.

[2] Ruiz, C., Boddington, P.H.B., Chen, K.C., “An Investigation of Fatigue and Fretting in a Dovetail Joint," Experimental Mechanics, pp 208 - 217, September 1984.

[3] Waterhouse, R.B., "Fretting Wear and Fretting Fatigue at Temperatures up to 600 ${ }^{\circ}$ C, AGARD, High Temperature Surface Interactions, 1989.

[4] Broszeit, E., Kloos, K.H., Schweighofer, B., "The Fretting Fatigue Behaviour of the Titanium Alloy Ti-6Al-4V," Proceedings of the Fifth International Conference on Titanium, Munich, West Germany, Vol. 4, pp 2171-2178, 1985.

[5] R.B. Waterhouse, "Fretting Fatigue," International Materials Review, Vol. 37, No.2, pp 77-97, 1992.

[6] Hamdy, M.M., Waterhouse, R.B., "The Fretting Fatigue Behaviour of the Titanium Alloy IMI 829 at Temperatures up to $600^{\circ} \mathrm{C}$," Fatigue of Engineering Materials and Structures, Vol 5., No. 4, pp 267-274, 1982. 
[7] Salkland, M.J., "Fretting Fatigue in Titanium Helicopter Components," Sikorsky Aircraft, Stanford, Connecticut.

[8] Fenner, A.J., Field, J.E., “Revue de Metallurgie," Vol. 55, pp 475-485, Paris, France, 1958.

[9] Chakravarty, S., Andrews, R.G., Patnaik, P.C., Koul, A.K., "The Effect of Surface Modification on Fretting Fatigue in Ti Alloy Turbine Components," JOM, pp 3135, April 1995.

[10] Antoniou, R.A., Radtke, T.C., "Fretting-Fatigue of Titanium Based Aircraft Turbine Materials," Defence Science and Technology Organisation, pp C296CC307, 1995.

[11] Privett III, H.M., Fujishiro, S., "Coating Studies for Prevention of Fretting Fatigue in Jet Engine Titanium Compressor Blade Dovetails," Minerals, Metals \& Materials Society, pp 401-410, 1994.

[12] Duncan, R.M., Blenkinsop, P.A., et al., "The Development of Gas Turbine Materials," Titanium Alloys, pp 63-87, 1981.

[13] Donachie, M.J., Jr., "Introduction to Titanium and Titanium Alloys," Titanium and Titanium Alloys-Source Book, pp 3-9, 1982. 
[14] Xue, L., "Surface Modification Treatments to Improve the Fretting Fatigue Resistance of Ti-6Al-4V," Doctorial Thesis, Carleton University, 1994.

[15] Xue, L., Koul, A, et al., "The Effects of Residual Stress and Fretting Bridge Geometry on Fretting Fatigue," Canadian Aeronautics and Space Journal, Vol. 41, No. 2, pp 78-84, June 1995.

[16] Bill, R.C., "Review of Factors that Influence Fretting Wear," ASTM STP 780, pp165-182, 1982.

[17] Elder, J.E., Patnaik, P., Thamburaj, R., "Life Extension of Titanium Alloy Gas Turbine Components by Ion Implantation," ASM International, 8712-001, pp 11$21,1987$.

[18] Fu, Y., Loh, N.L., Batchelor, A.W., et al., "Improvement in fretting wear and fatigue resistance of Ti-6Al-4V by application of several surface treatments and coatings," Surface and Coating Technology, No. 106, pp 193-197, 1998

[19] Koenen, A., Virmoux, Ph., Gras, R., et al., “A machine for fretting fatigue and fretting wear testing in cryotechnical and normal environment," Wear, No. 197, pp192-196, 1996. 
[20] Eden, E.M., Rose, W.N., Cunningham, F.L., "The Endurance of Metals," Process Institute for Mechanical Engineering, Vol. 4, pp 839-974, 1911.

[21] Iyer, K., Mall, S., "Analyses of Contact Pressure and Stress Amplitude Effects on Fretting Fatigue Life," Journal of Engineering Materials and Technology, ASME, Vol. 123, pp 85-93, 2001.

[22] Antoniou, R.A., Radtke, T.C., "Mechanisms of fretting-fatigue of titanium alloys," Materials Science and Engineering, A237, pp 229-240, 1997.

[23] Malkin, S., Majors, D.P., Courtney, H., "Surface Effects during Fretting Fatigue of Ti-6Al-4V," WEAR Magazine, No. 22, pp 235 - 244, 1972.

[24] Ruiz, C., Chen, K.C., "Fatigue of Engineering materials and structures," Institution of Mechanical Engineers, United Kingdom, pp 187- 194, 1986.

[25] Waterhouse, R.B., "Fretting Fatigue," Applied Science Publishers Ltd, pp.221$240,1981$.

[26] Bannantine, J.A., Comer, J.J., Handrock, J.L., "Fundamentals of Metal Fatigue Analysis," Prentice-Hall, New Jersey, USA, 1990.

[27] Sines, G., Waisman, J.L., et al, "Metal Fatigue," McGraw-Hill company, 1959. 
[28] Waterhouse, R.B. and Trowsdale, A.J., "Residual Stress and Surface Roughness in Fretting Fatigue," Journal of Physics D: Applied Physics, 25, 1A, pp A236-A239, 1992.

[29] Waterhouse, R.B., Iwabuchi, A., "The Composition and Properties of Surface Films Formed During the High Temperature Fretting of Titanium Alloys," Proceedings of the JSLE International Tribology Conference, Tokyo, Japan, pp 53 58, July 1985.

[30] Hibbeler, R.C., "Engineering Mechanics - Statics," $5^{\text {th }}$ Edition, MacMillan Publishing Company, 1989.

[31] Tsybanoj, G., Nalimov, J., "Elaboration of the Test Method and Lifetime Study for Compressor Blade Joints under Fretting Fatigue," National Academy of Sciences of Ukraine, Kiev, Ukraine, pp $287-298$.

[32] Mindlin, R.D., "Compliance of Elastic Bodies in Contact," ASME Journal of Applied Mechanics, Vol. 16, pp 259-268, 1949.

[33] Shen, G., Luo, J., Wang, S., Liang, Y., “The Surface Preventing Methods for Fretting Fatigue on TC11 Titanium Alloy," Titanium: Science and Technology, pp $2046-2052,1995$ 
[34] Bill, R., "Selected Fretting-Wear-Resistant Coatings for Titanium-6-PercentAluminum-4-Percent-Vanadium Alloy," NASA Technical Note D-8214, Washington, D.C., April 1976.

[35] E.W. Roberts, "The Efficacy of thin solid film Lubricants in LEO," Second International Space Forum, 1994.

[36] U.S. Patent 3,073,022, "Shot Peening Treatments," January 15, 1963.

[37] Waterhouse, R.B. and Sunders, D.A., "The Effect of Shot Peening on the Fretting Fatigue Behaviour of an Austenitic Stainless Steel and a Mild Steel," WEAR Magazine, No. 53, pp. 381-386, 1979.

[38] Metal Improvement Company, Inc., "Shot Peening Applications," Seventh Edition,

[39] General Electric Company, "Determination of Mechanism by Which Surface Treatment affects the Low Cycle Fatigue resistance of Advanced Disc Materials," October 1986.

[40] Sridhar, B.R., Ramachandra, K., Padmanabhan, K.A., "Effect of shot peening on the fatigue and fracture behaviour of two titanium alloys," Journal of Material Science, Vol. 31, pp $5953-5960,1996$. 
[41] Aluminum Anodizers Council, http://www.saf.com

[42] Cohen, H., Rogers, G.F.C., Saravanamuttoo, H.I.H., "Gas Turbine Theory," 3rd Edition, Longman Scientific \& Technical Publisher, England, 1987.

[43] Avallone, E.A., \& Baumeister III, T., "Mark's Handbook for Mechanical Engineers," Mc Graw Hill Company, 1987.

[44] Danforth, C.E., "Blade Vibration: Some Key Elements in Design Verification," J. Aircraft, Vol. 12, No.4, pp.33-342, April 1975.

[45] Shannon, J.L.. Jr., "Aerospace Material Specification for Ti-6242," CODE 3718, pp 1-95, June 1978.

[46] ASTM E 8M-89b, "Standard Test Methods for Tension of Metallic Materials," pp. $146-160$.

[47] Alloy Digest, "Ti-6Al-2Sn-4Zr-2Mo," Code: Ti-52, August 1967.

[48] Beards, S.F., "Vibrations and Control Systems," Allis Horwood limited, England, 1988. 
[49] MacBain, J.C., "Vibratory Behaviour of Twisted Cantilevered Plates," J. Aircraft, Vol.12, No.4, pp.343-349, April 1975.

[50] ASTM E 466-82, "Standard Practice for Conducting Constant Amplitude Axial Fatigue Tests of Metallic Materials," pp. 543-547.

[51] ASTM E 606-80, "Standard Recommended Practice for Constant Amplitude LowCycle Fatigue Testing," pp. 609-621.

[52] ASTM STP91-A, "A Guide For Fatigue Testing and the Statistical Analysis of Fatigue Data," 2nd Edition, 1964.

[53] Orenda Aerospace Corporation, "Fretting Fatigue Life Improvement of F404GE-400 Stage 3 Fan Blade/Disc Couple," \#ES92/10.48, 1994

[54] General Electric, "Intermediate Maintenance Inspection Manual," A1-F404AMMI-211, Section 06200

[55] EM Coatings, http://www.emcoatings.com/services/solidfilm.

[56] Cortez, R., Mall, S., et al, "Interaction of High-Cycle and Low-Cycle Fatigue on Fretting Behavior of Ti-6-4," ASTM STP 1367, pp 183 - 198, 2000. 
[57] Hutson, A.L., Nicholas, T., "Fretting Fatigue Behavior of Ti-6Al-4V against Ti6Al-4V under Flat-on-Flat Contact with Blending Radii," ASTM STP 1367, pp $308-321,2000$

[58] Goss, G.L., Hoeppner, D.W., “Characterization of Fretting Fatigue Damage by SEM Analysis," WEAR Magazine, No. 24, pp 77 - 95, 1973.

[59] Sridhar, B.R., Ramachandra, K., Padmanabhan, K.A., "Effects of cyclic stressing, heat treatment and shot-peening pressure on the residual stress distribution in two titanium alloys," Journal of Material Science, Vol. 31, pp 4381 - 4385, 1996.

[60] Shigley, J.E., Mischke, C.R., "Mechanical Engineering Design," $5^{\text {th }}$ Edition, McGraw-Hill company, 1989.

[61] Attia, M., Waterhouse, R.B., "Standardization of Fretting Fatigue Test Methods and Equipment," ASTM STP 1159, 1992.

[62] Armstrong, E.K., Crowcroft, R.S., \& Hunt, T.M., "Fatigue Life of Compressor Blading," Applied Mechanics Convention, IME, Cambridge, April 1966.

[63] Carek, G.A., "Shot Peening for Ti-6Al-4V Alloy Compressor Blades," NASA Technical Paper 2711, 1987. 
Table 2.1 Advantages and Disadvantages of Select Solid Film Lubricant Base Materials [55]

\begin{tabular}{|c|c|c|}
\hline Solid Film Base Material & Advantages & Disadvantages \\
\hline $\begin{array}{l}\text { Molybdenum Disulfide } \\
\left(\mathrm{MoS}_{2}\right)\end{array}$ & $\begin{array}{l}\text { High Load carrying } \\
\text { capacity (over } 100 \mathrm{ksi} \\
(689 \mathrm{MPa})) \\
\text { Wide temperature } \\
\text { range }\left(\text { cryo }-750^{\circ} \mathrm{F}\right. \\
\left.\left(398^{\circ} \mathrm{C}\right)\right) \\
\text { Low coefficient of } \\
\text { friction }(0.2 \text { to } 0.6)\end{array}$ & $\begin{array}{l}\text { - Susceptible to } \\
\text { moisture } \\
\text { - Starts to oxidize at } \\
750^{\circ} \mathrm{F}\left(398^{\circ} \mathrm{C}\right) \text { in } \\
\text { air } \\
\text { - Does not lubricate } \\
\text { well at low loads }\end{array}$ \\
\hline Graphite & 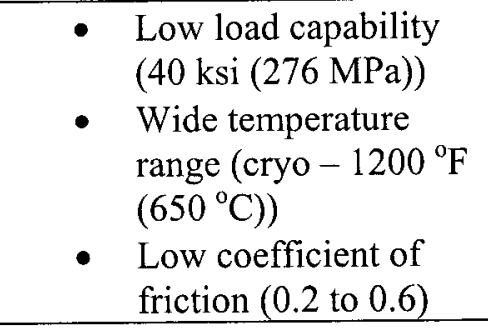 & $\begin{array}{l}\text { Provides poor } \\
\text { corrosion resistance } \\
\text { Moisture and air } \\
\text { must be present for } \\
\text { lubrication }\end{array}$ \\
\hline Fluorinated Polymers & $\begin{array}{l}\text { Low load capability } \\
\text { (10 ksi (69 MPa)) } \\
\text { Highly chemically } \\
\text { inert } \\
\text { - Electrically non- } \\
\text { conductive } \\
\text { - Low coefficient of } \\
\text { friction } \\
\text { - Can be incorporated } \\
\text { into corrosion } \\
\text { resistant coatings } \\
\text { Lubricates without } \\
\text { shedding } \\
\end{array}$ & $\begin{array}{l}\text { Limited } \\
\text { Temperature range } \\
-150^{\circ} \mathrm{F}\left(-100^{\circ} \mathrm{C}\right)- \\
500^{\circ} \mathrm{F}\left(260{ }^{\circ} \mathrm{C}\right) \\
\text { Suitable only for } \\
\text { low speed } \\
\text { applications }\end{array}$ \\
\hline
\end{tabular}




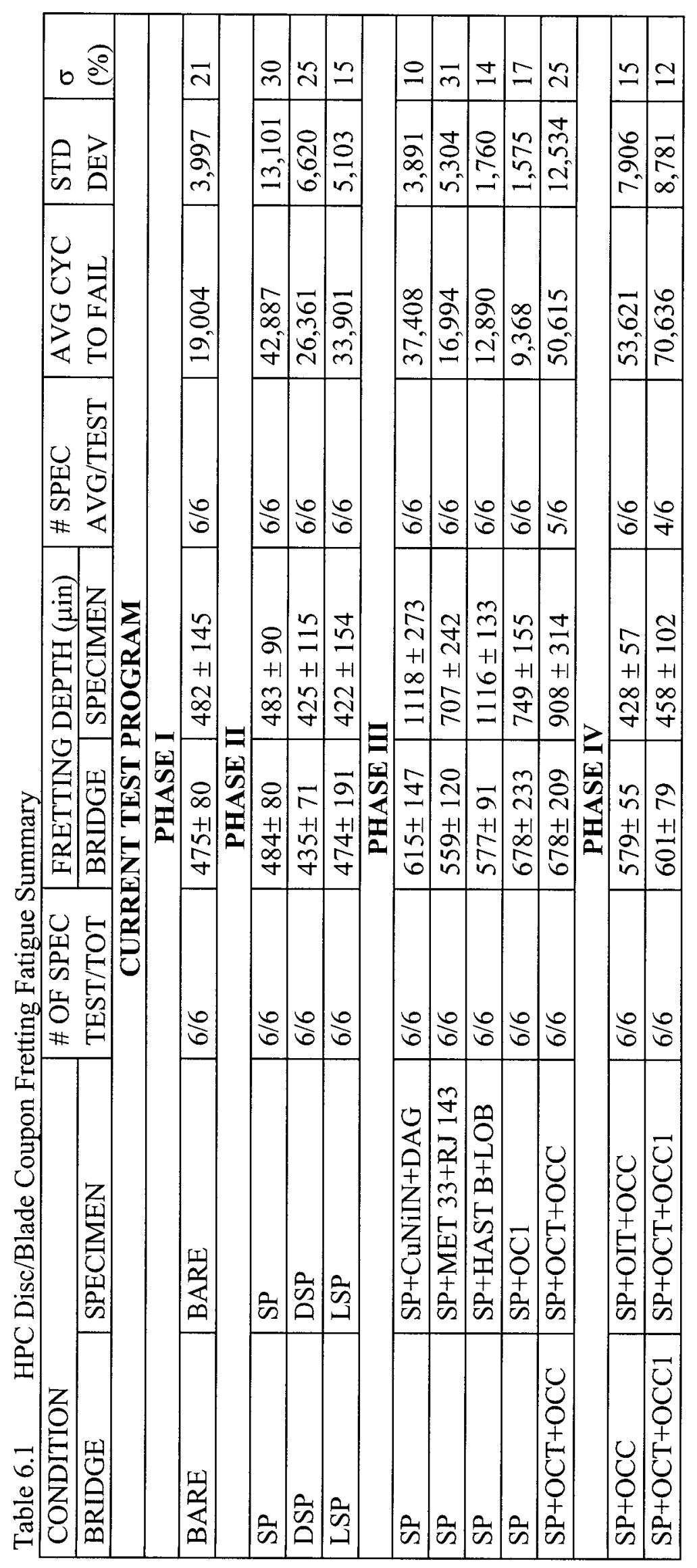




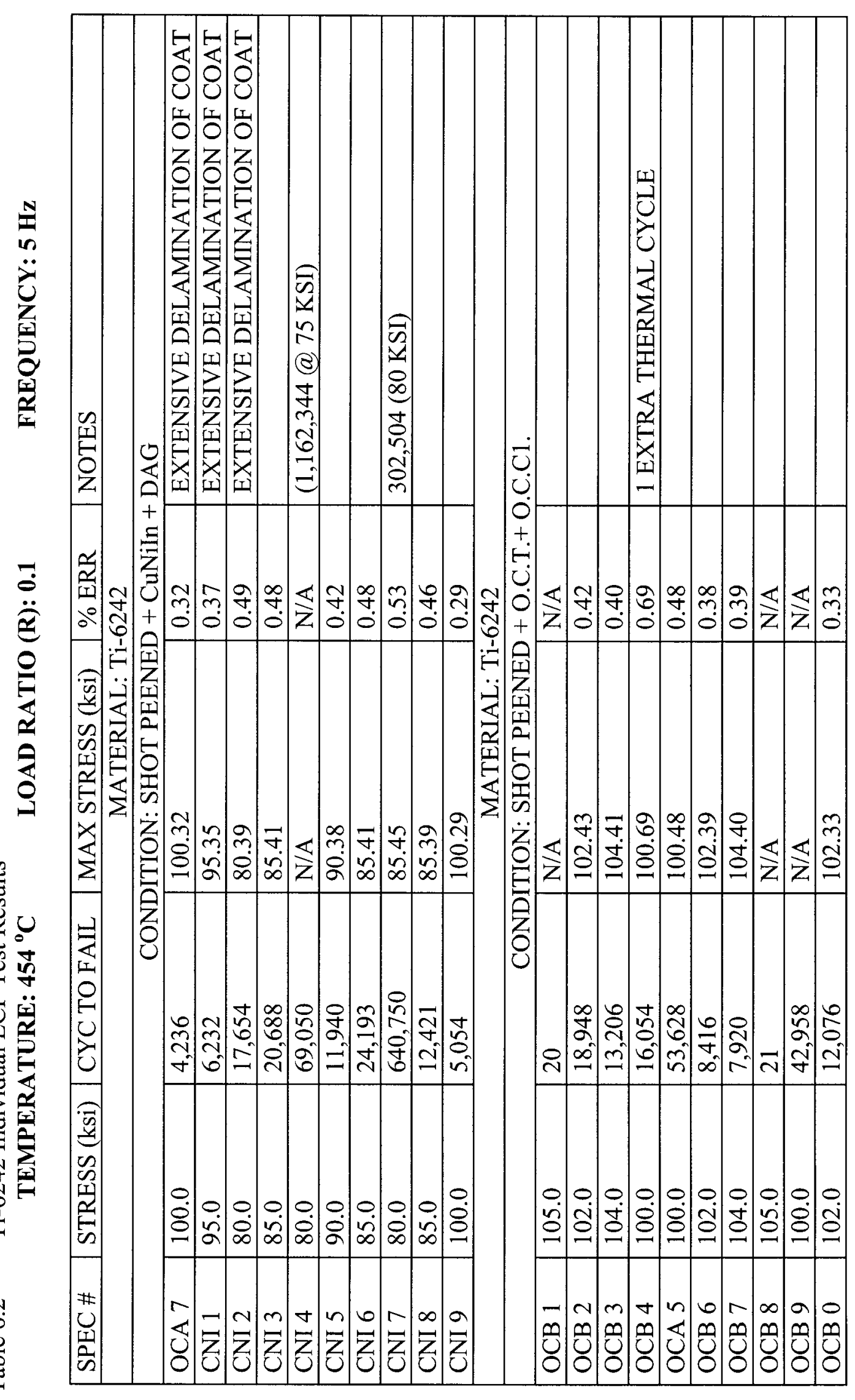




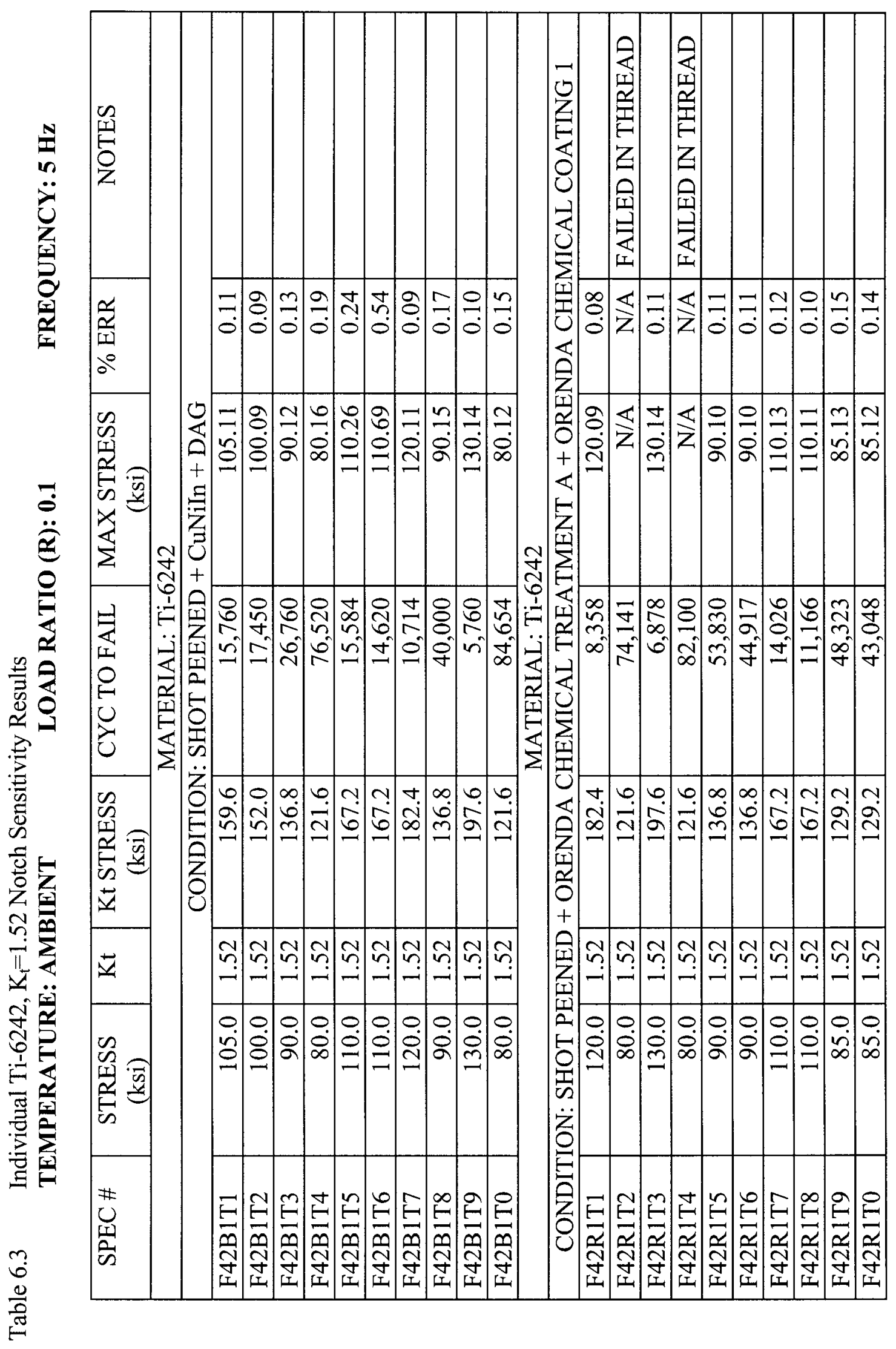




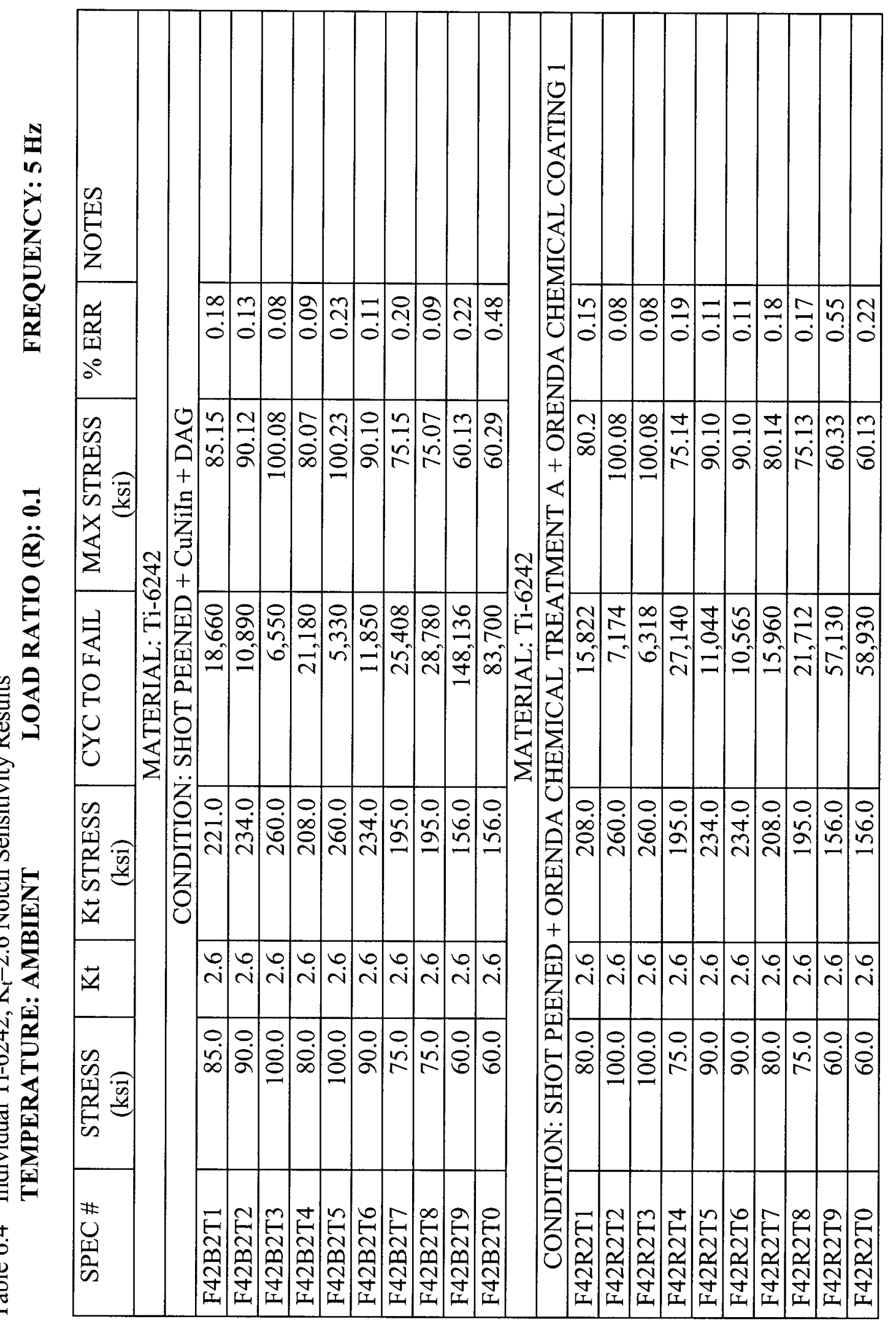




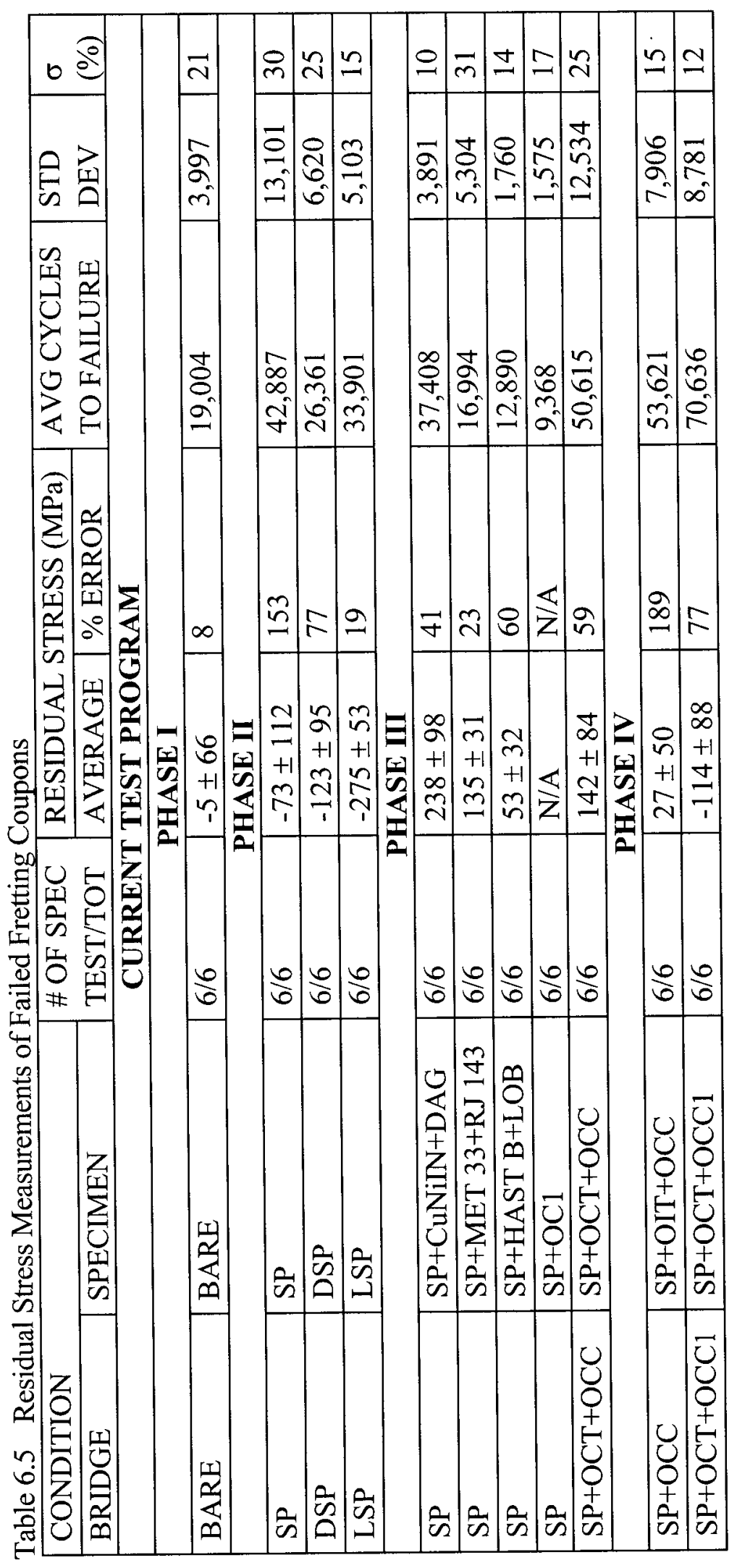


Table 6.6 Improvement Factor for HPC Fretting Results

\begin{tabular}{|l|l|l|l|}
\hline SPECIMEN (Blades) & BRIDGES (disc) & SERIES & $\begin{array}{l}\text { IMPROVEMENT } \\
\text { FACTOR }\end{array}$ \\
\hline SP+OCT+OCC1 & SP+OCT+OCC1 & $\mathbf{1 1}$ & $\mathbf{1 . 8 9}$ \\
\hline SP+OIT+OCC & SP+OCC & 9 & 1.43 \\
\hline SP+OCT+OCC & SP+OCT+OCC & 10 & 1.35 \\
\hline SP & SP & 2 & 1.15 \\
\hline SP+CuNiIn+DAG** & SP+DAG** & $\mathbf{5}$ & $\mathbf{1 . 0}$ \\
\hline LSP & LSP & 4 & 0.91 \\
\hline DSP & DSP & 3 & 0.70 \\
\hline Bare & Bare & 1 & 0.51 \\
\hline SP+MET 33+RJ 143 & SP & 6 & 0.45 \\
\hline SP+HAST B+LOB & SP & 7 & 0.34 \\
\hline SP+OC1 & SP & 8 & 0.25 \\
\hline
\end{tabular}

**Current OEM solution 


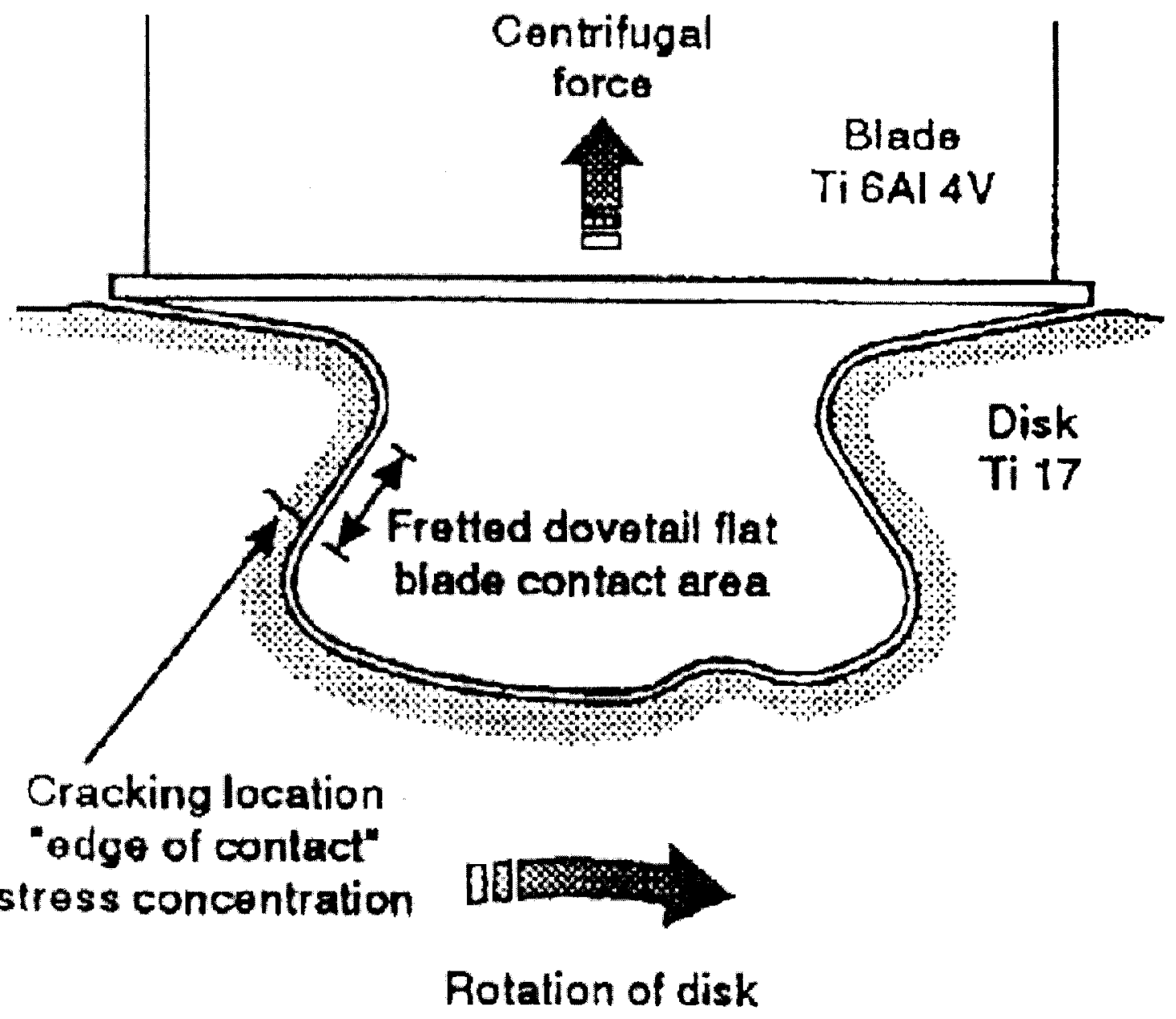

Figure 1.1 Blade-Disc Dovetail Orientation [10] 


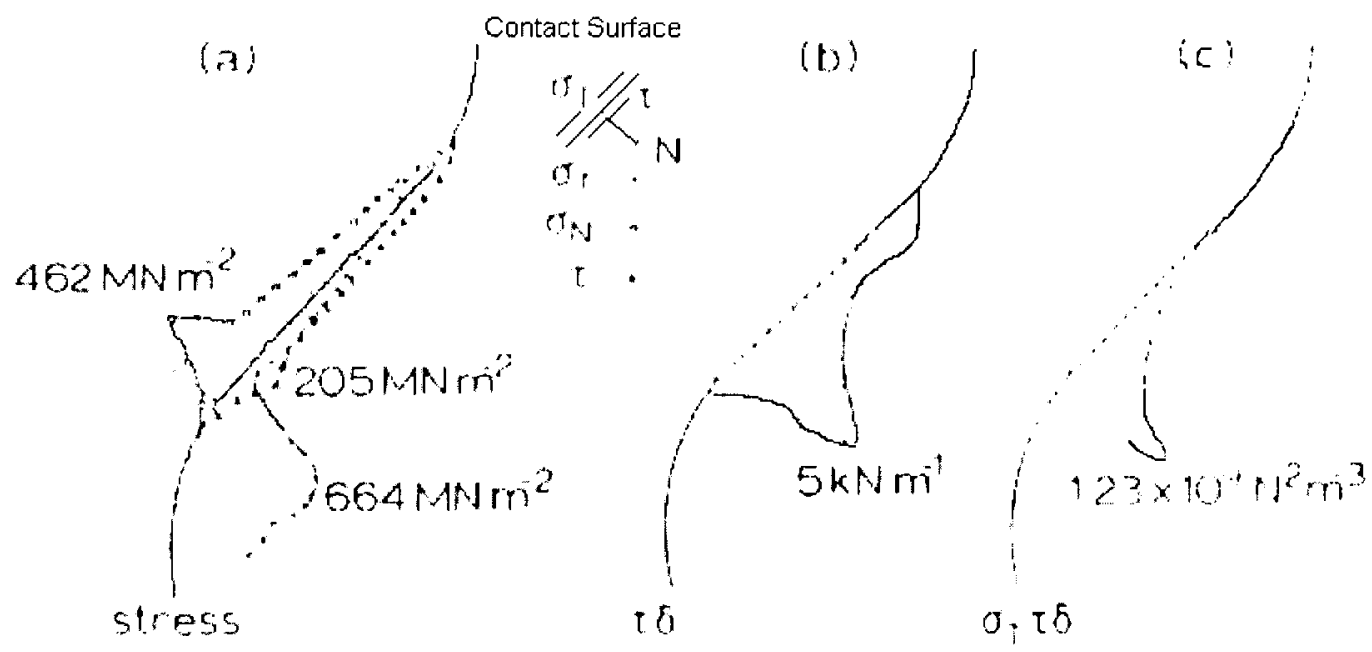

a stresses, b frotting damage lactor: c combined fatigue/tretting damage factor, 10 inttation parameter

Figure 2.1 Distribution of Stresses in Dovetail Joint (Blade/Disc) and Ruiz Criterion $[2,5]$ 


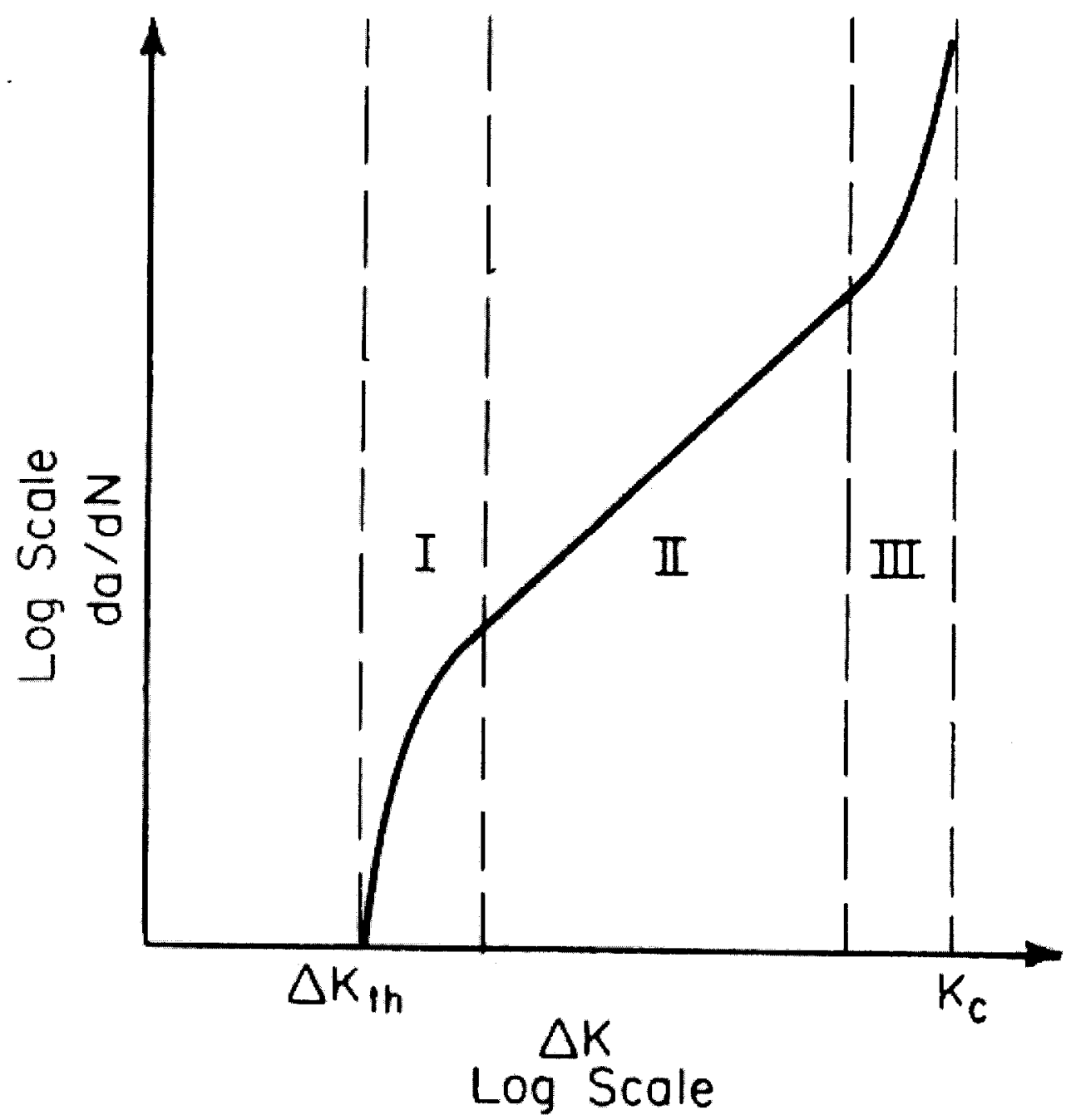

Figure 2.2 Three Regions of a Crack Growth Rate Curve [26] 


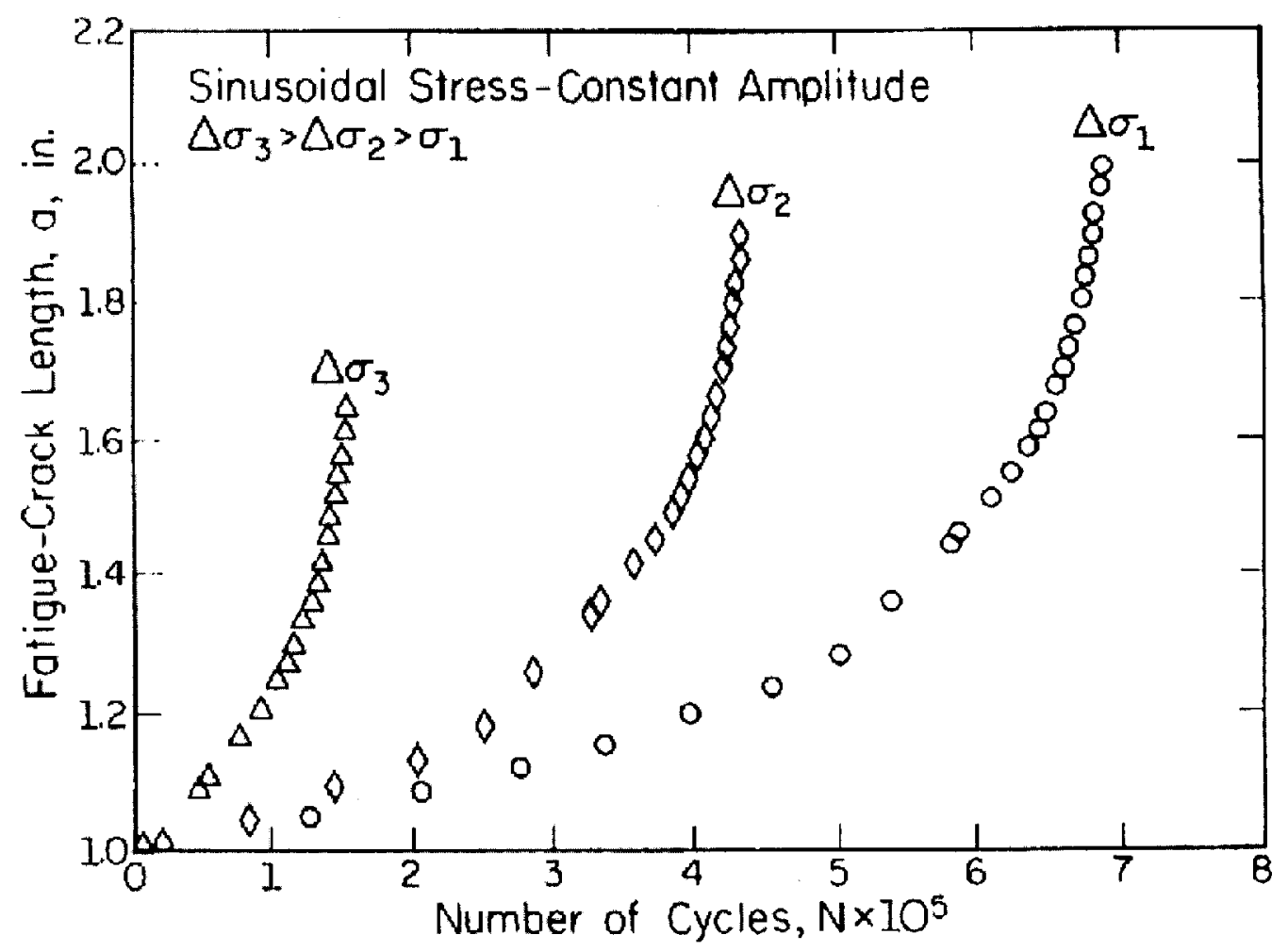

Figure 2.3 Constant Amplitude Crack Growth Data [26] 


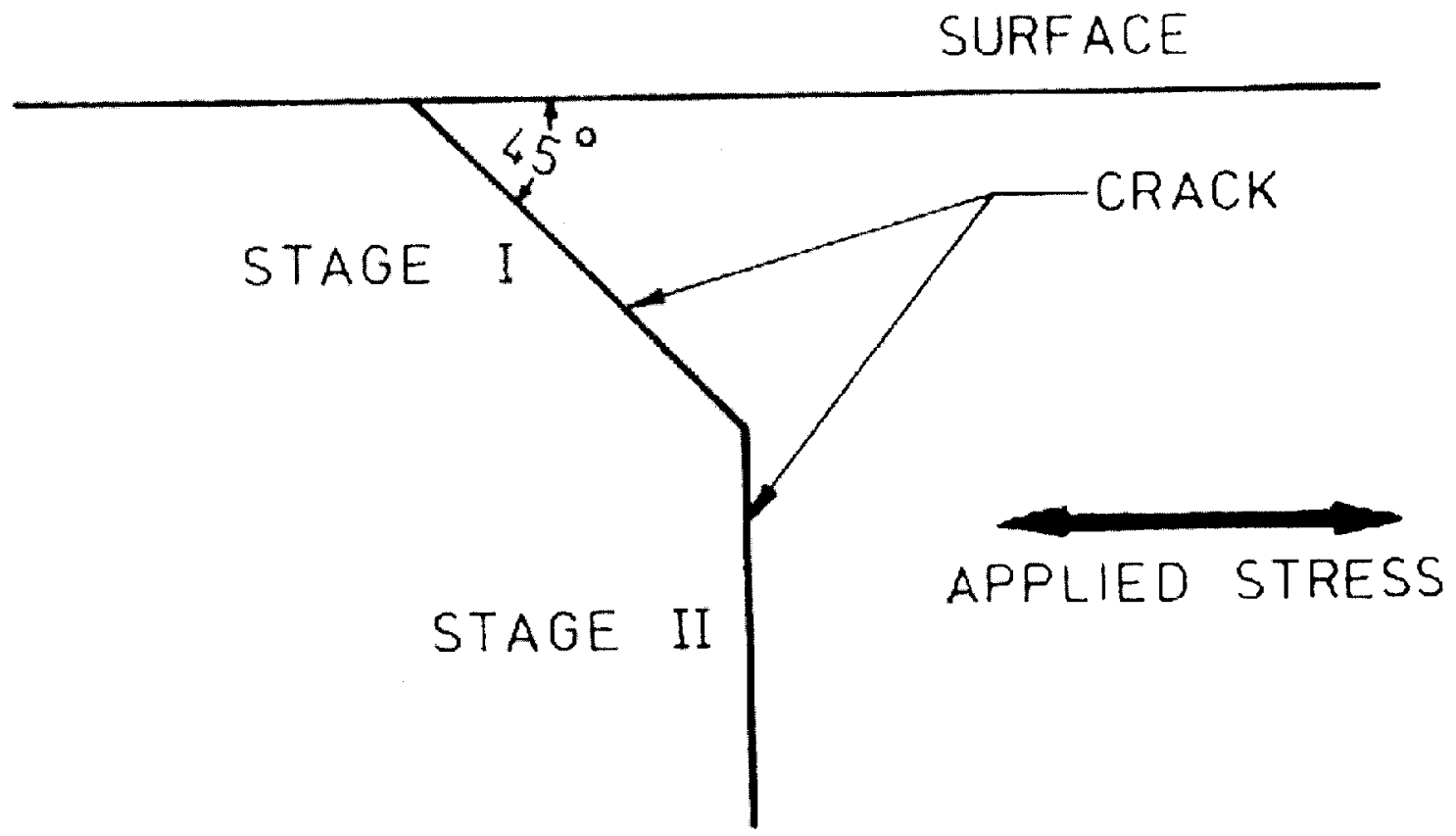

Figure 2.4 Stage I and Stage II Development of a Propagating Fatigue Crack [25] 


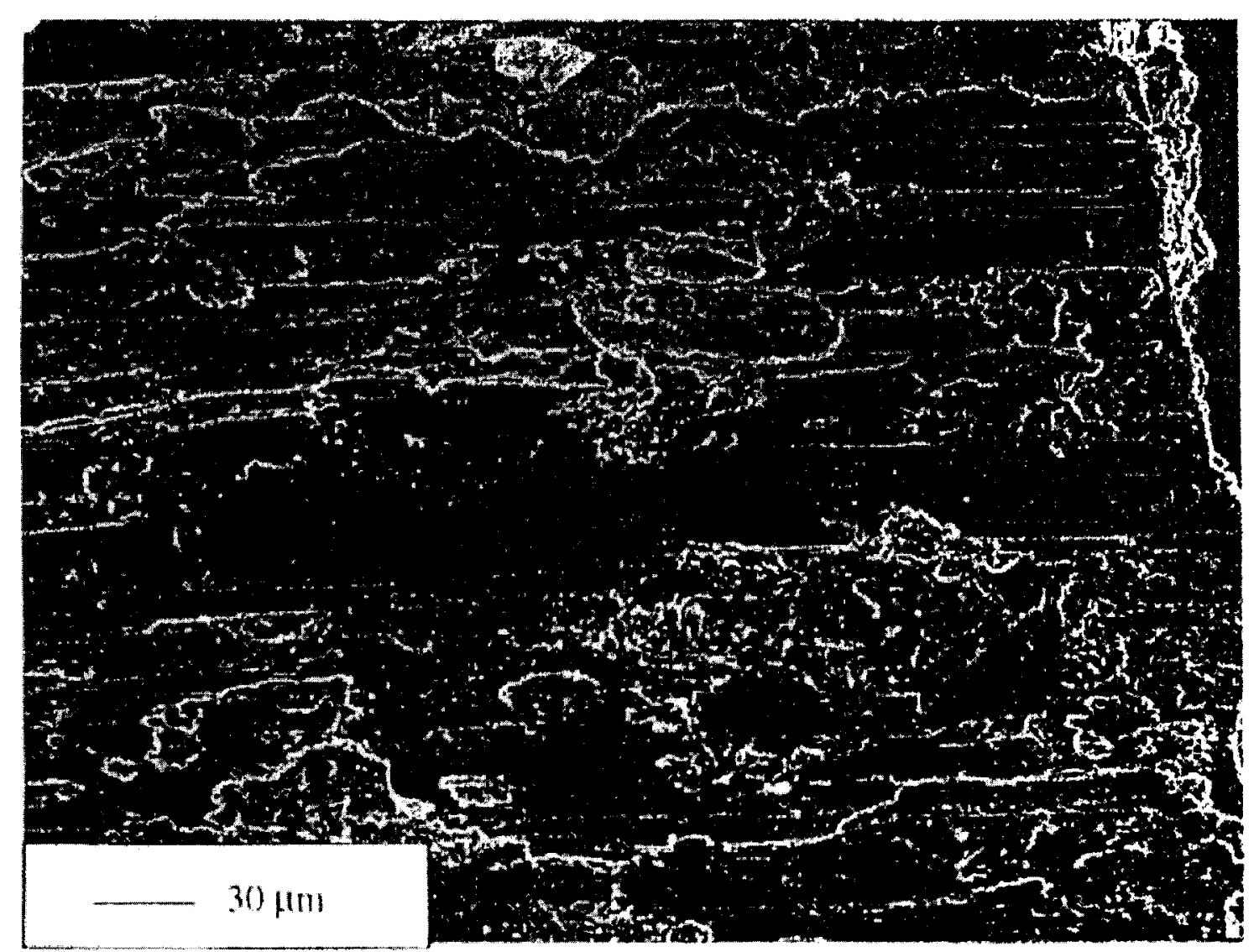

Figure 2.5 SEM Micrographs of Fretting Surfaces Illustrating Galling [56] 


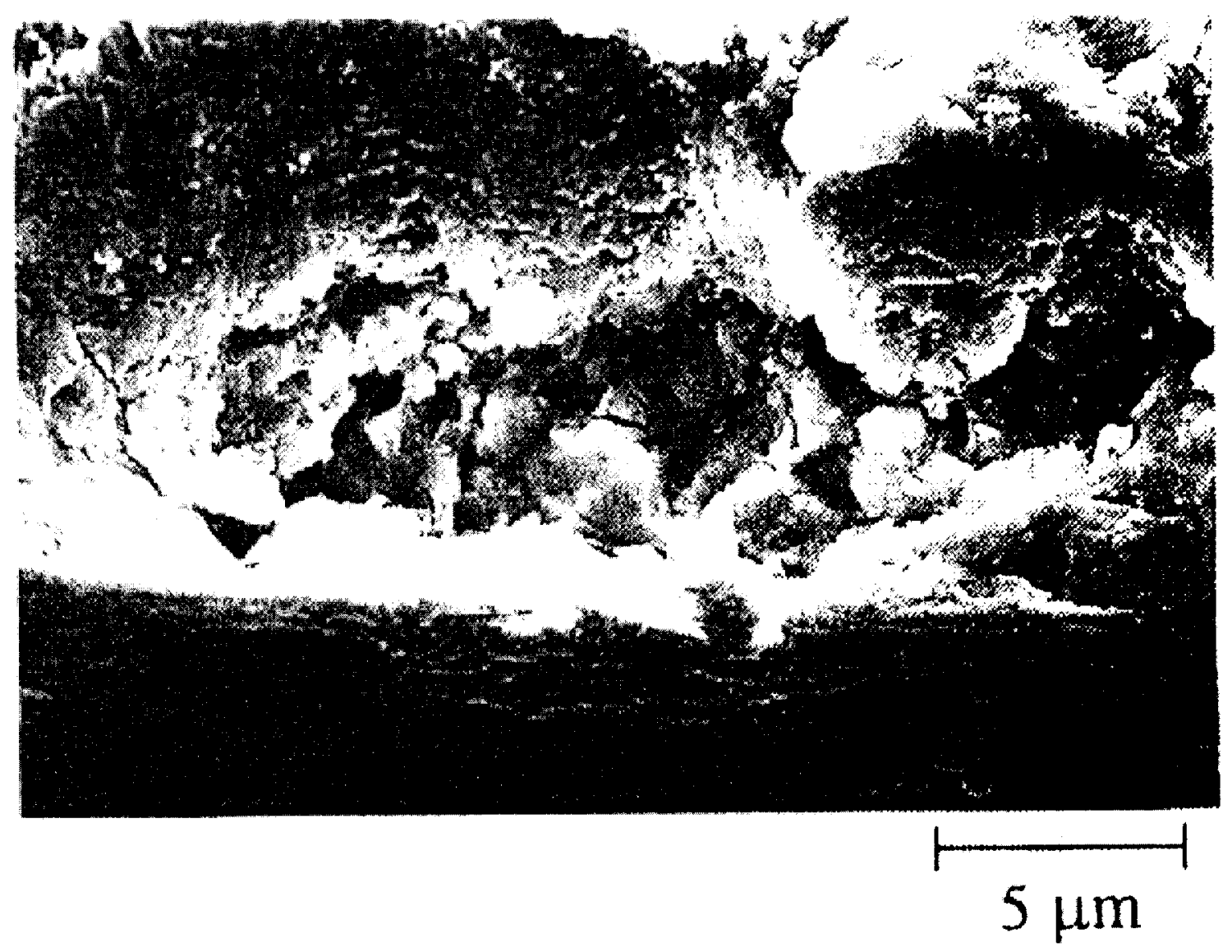

Figure 2.6 Fracture Surface Photos Showing Presence of Material Smearing [57] 


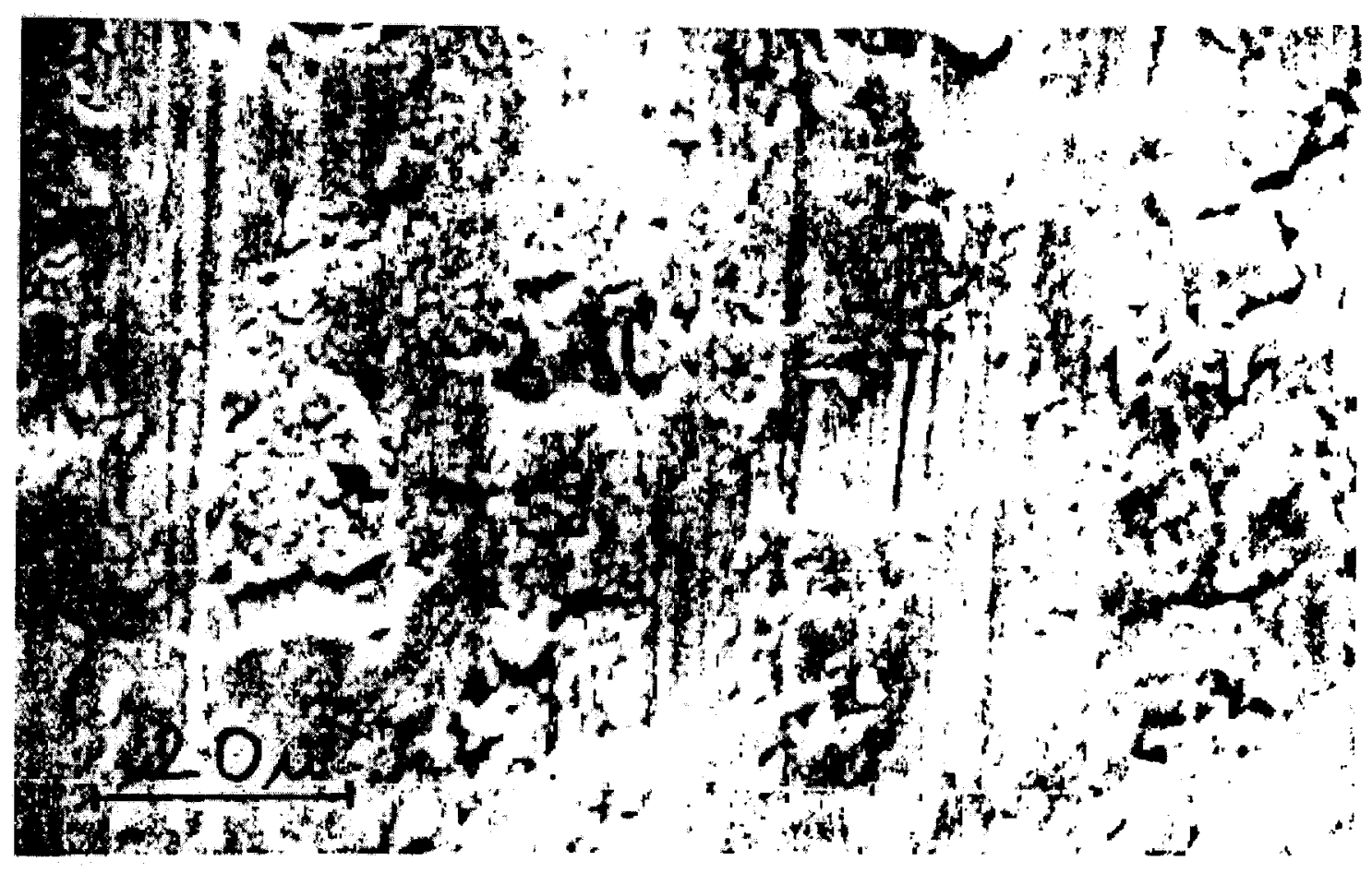

Figure 2.7 Fretting Scar Photos of a Titanium Alloy Showing Smearing and Delamination [6] 


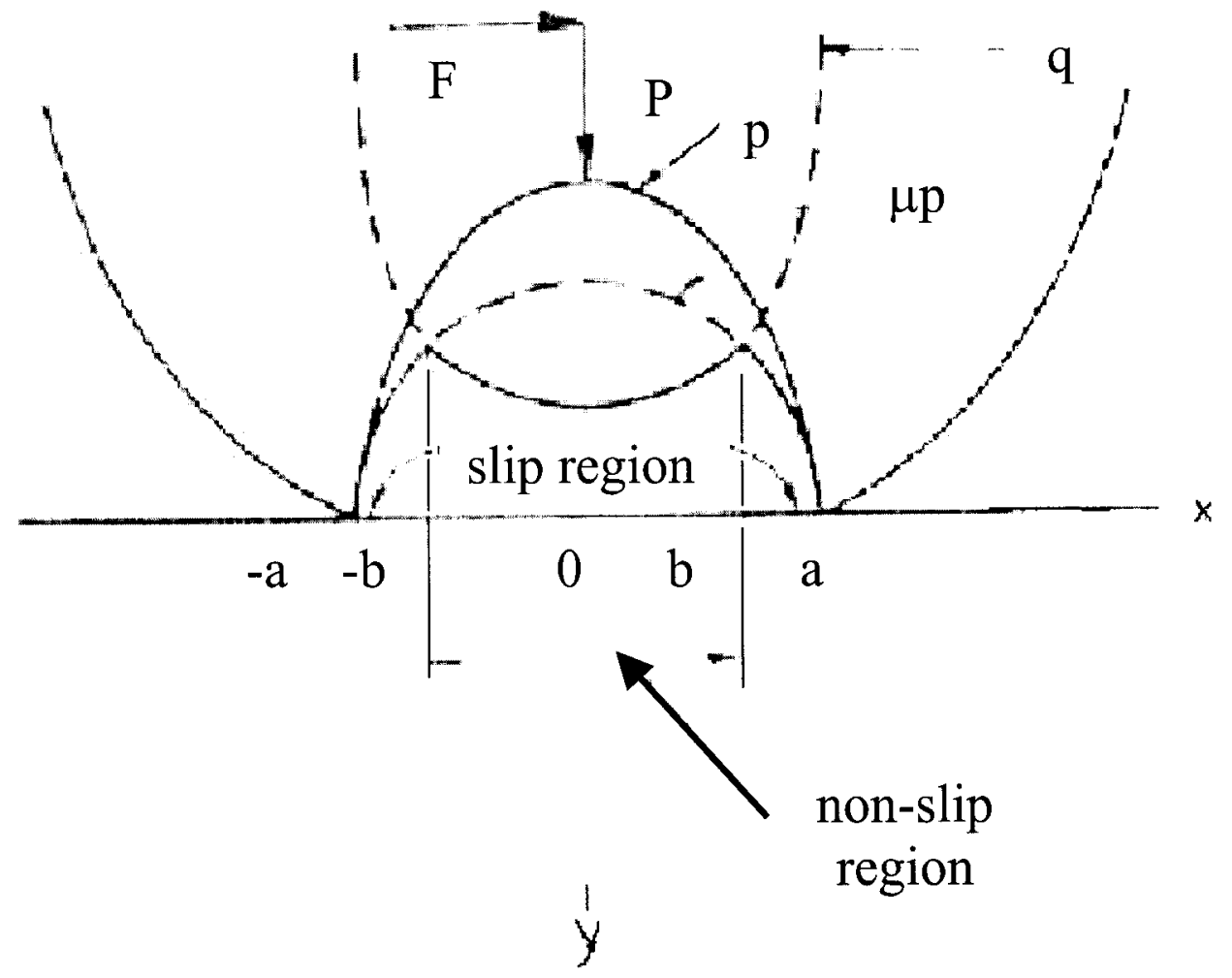

Figure 2.8 Mindlin Diagram Showing Central Locked Region Surrounded by Annulus of Slip for Sphere in Contact with Plane [5, 32] 


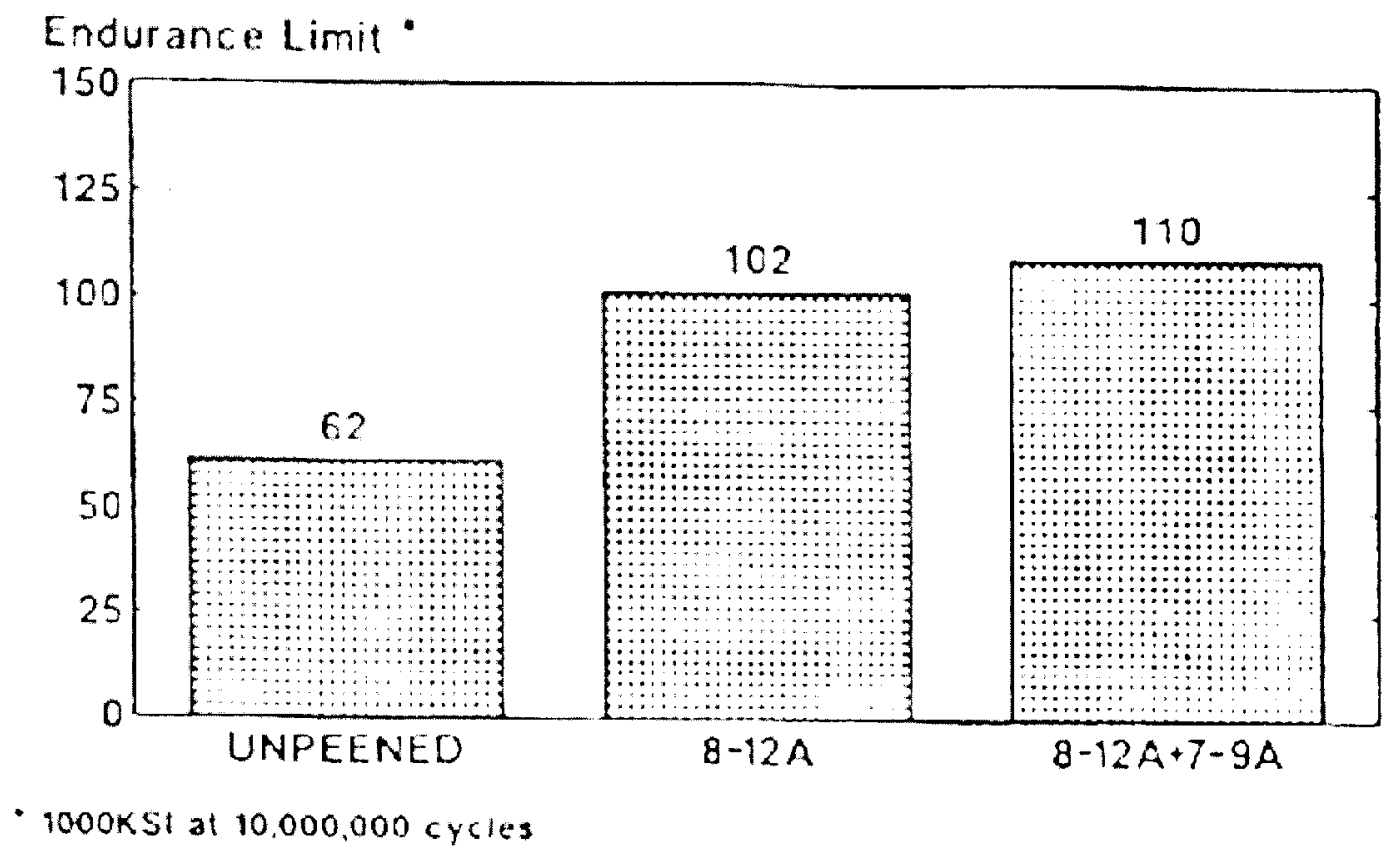

Figure 2.9 Dual Peening Rene 95 Specimens [38] 


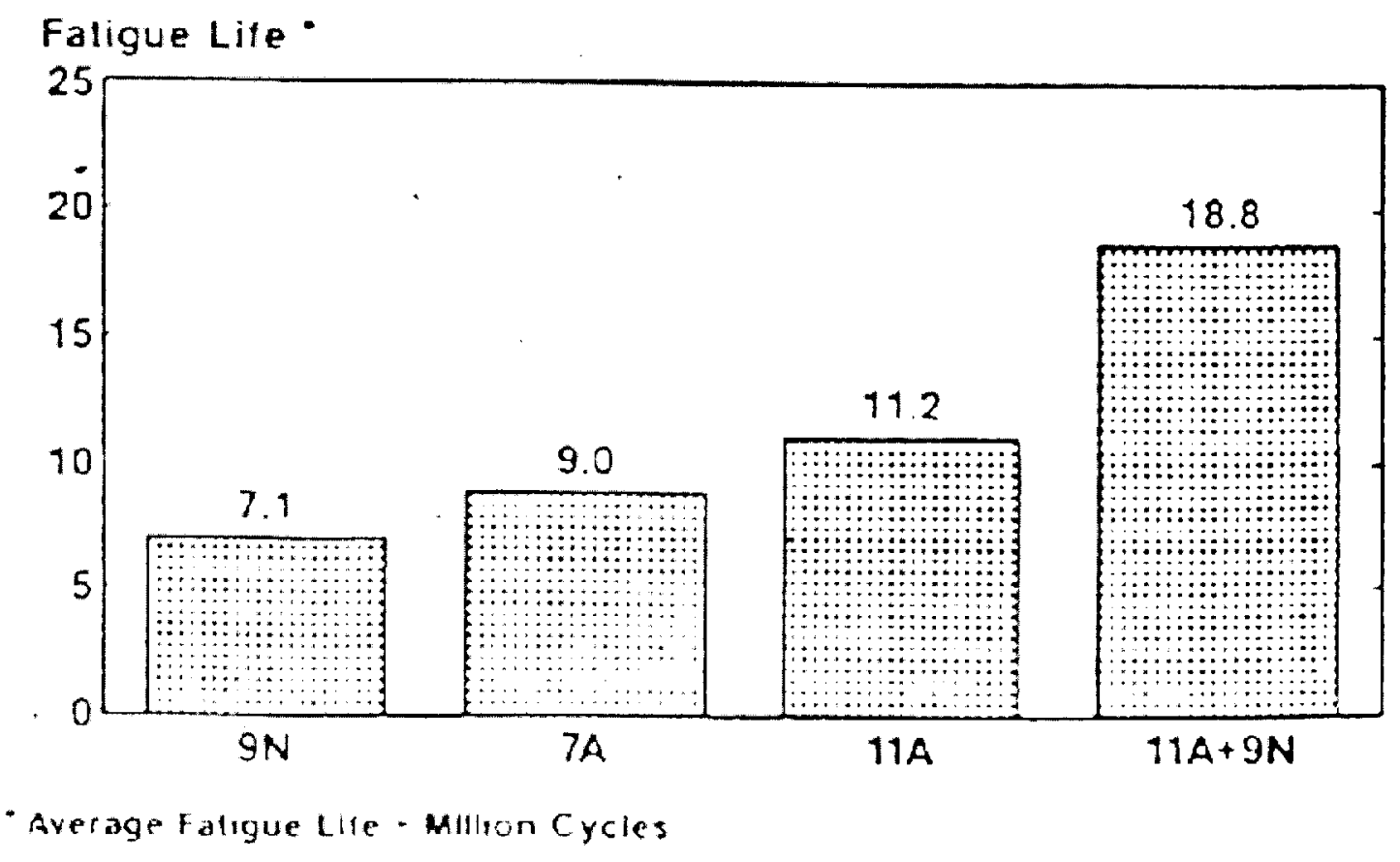

Figure 2.10 Dual Peening Ti-6Al-4V Blades [38] 


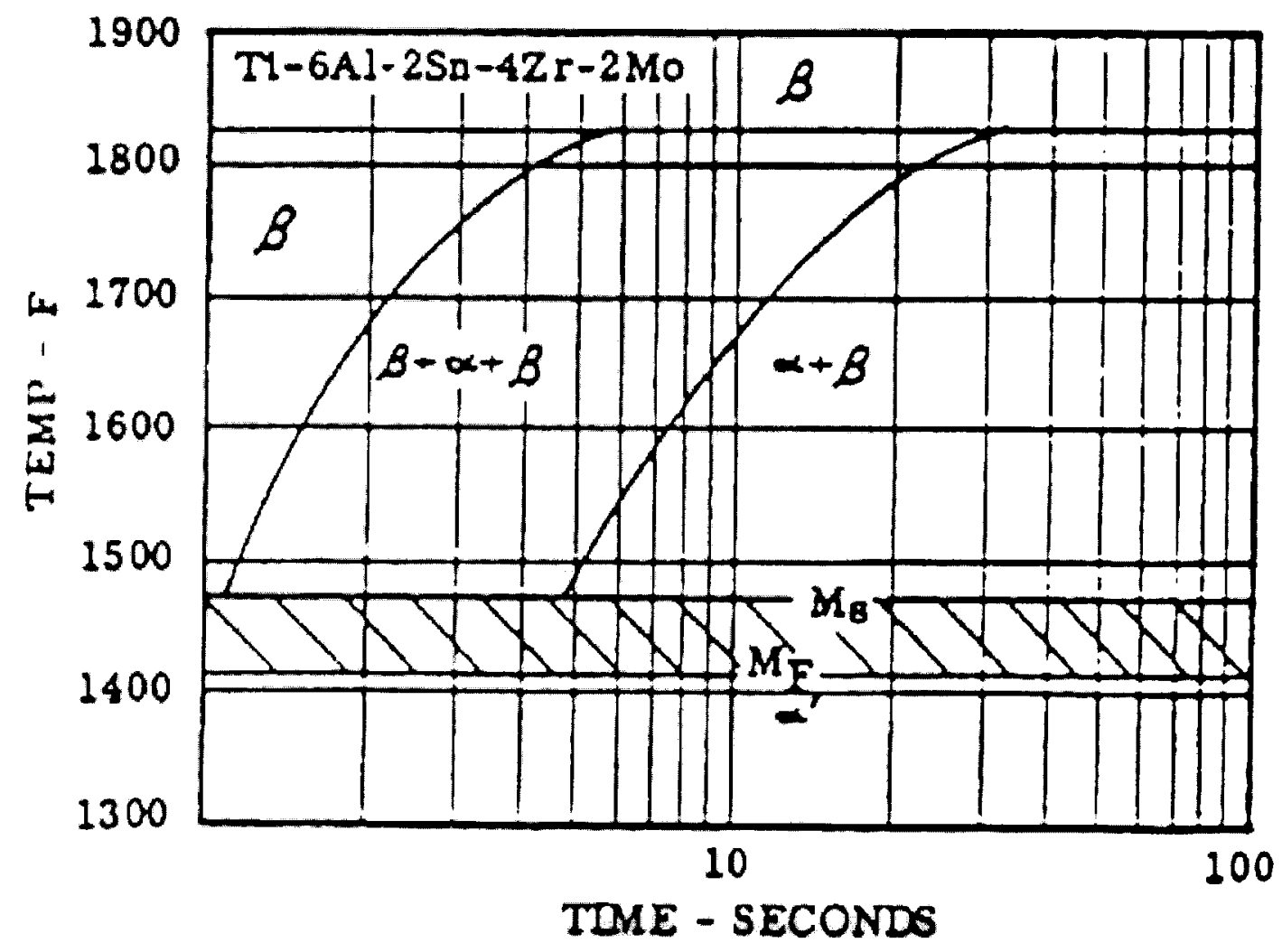

Figure 2.11 Isothermal Time-Temperature-Transformation (TTT) Diagram for Ti-6Al2Sn-4Zr-2Mo [45] 


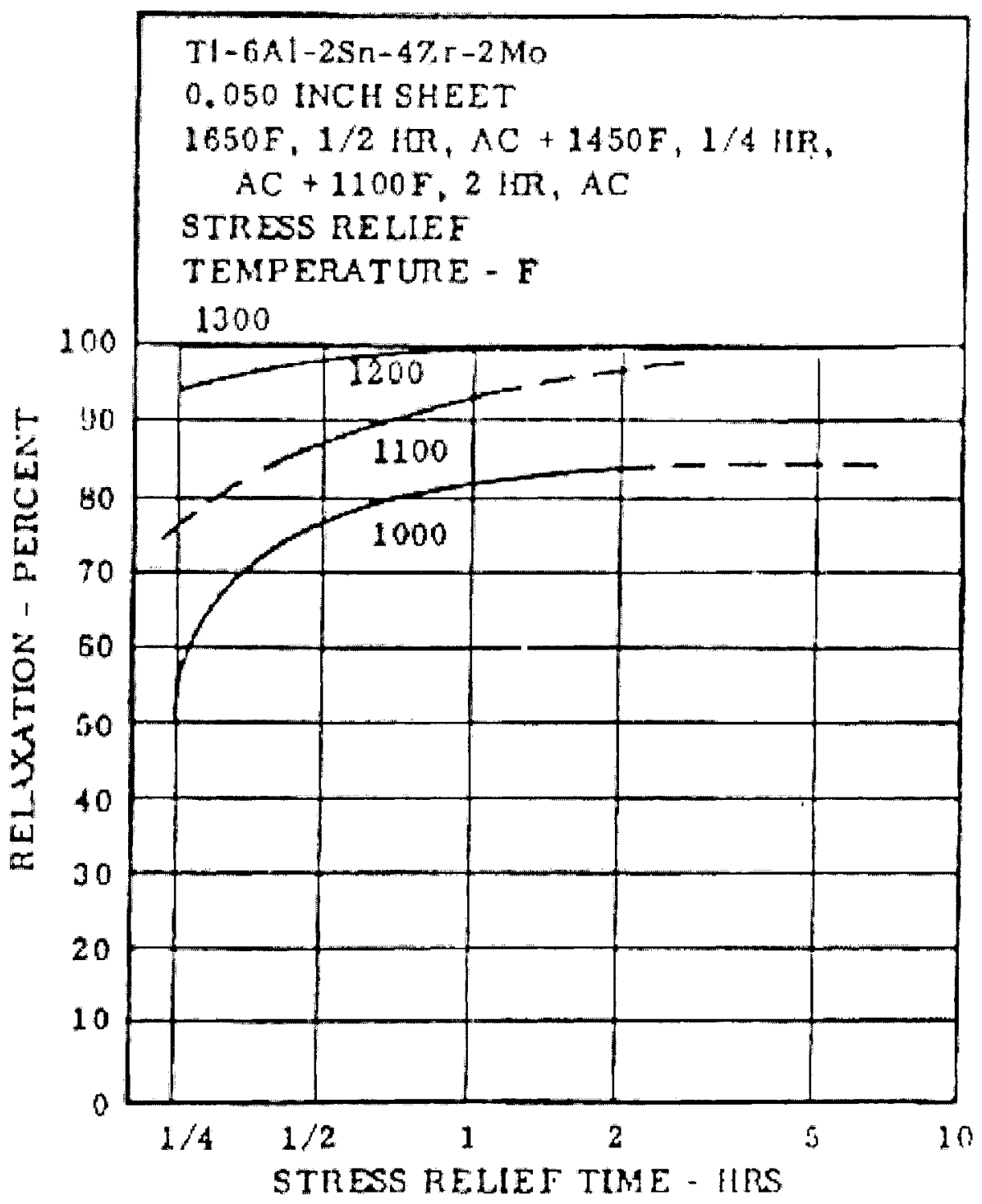

Figure 2.12 Effect of Stress Relief Time and Temperature on Relaxation of Restrained Bend Specimens of Triplex Annealed Sheet [45] 


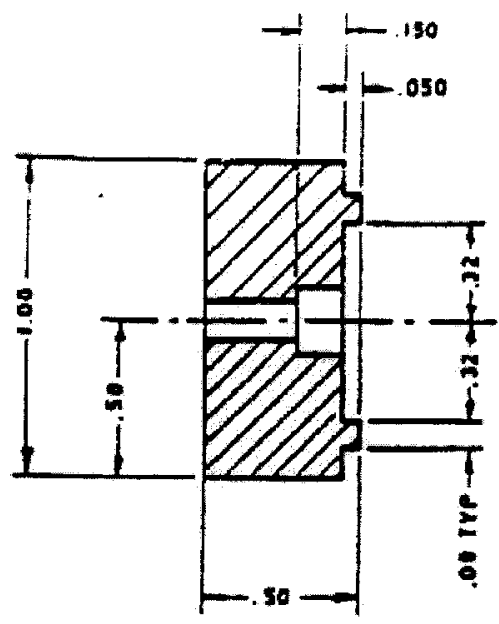

SECT. A-A

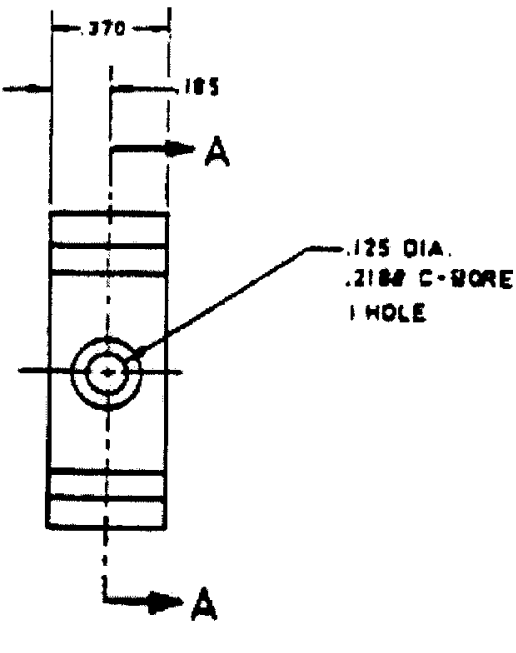

MoTE: AG OMENSIONS ARE IN INOHES.

Figure 4.1 Original Bridge Design of the Fretting Fatigue Test Rig [53] 

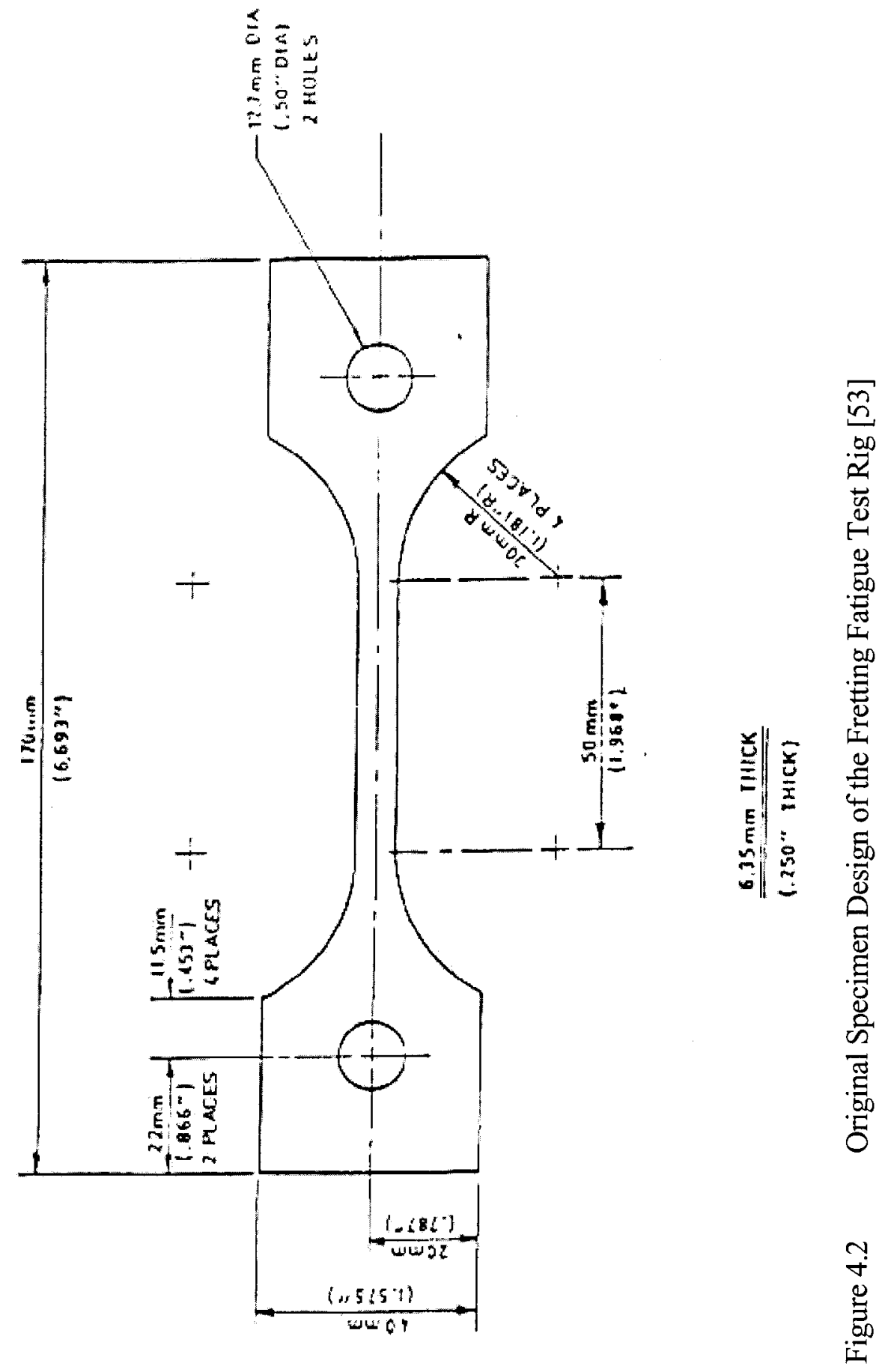

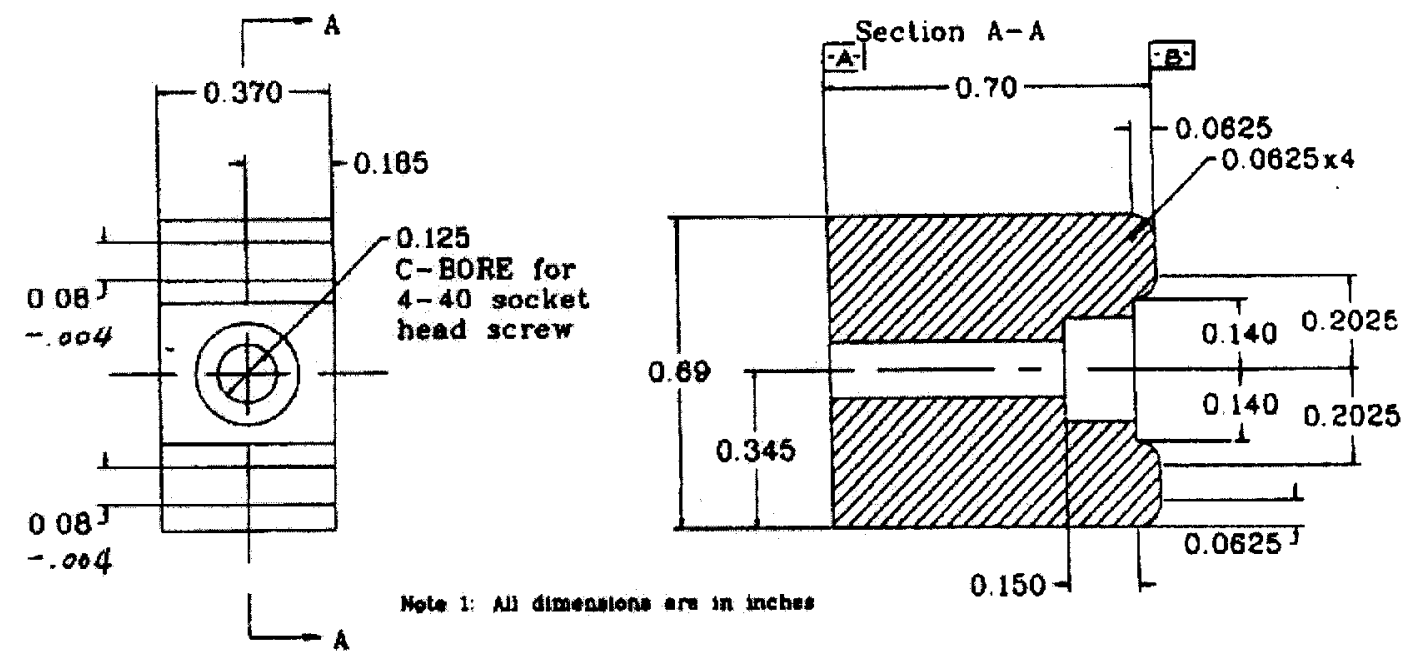

Figure 4.3 New Bridge Design of the Fretting Fatigue Test Rig 


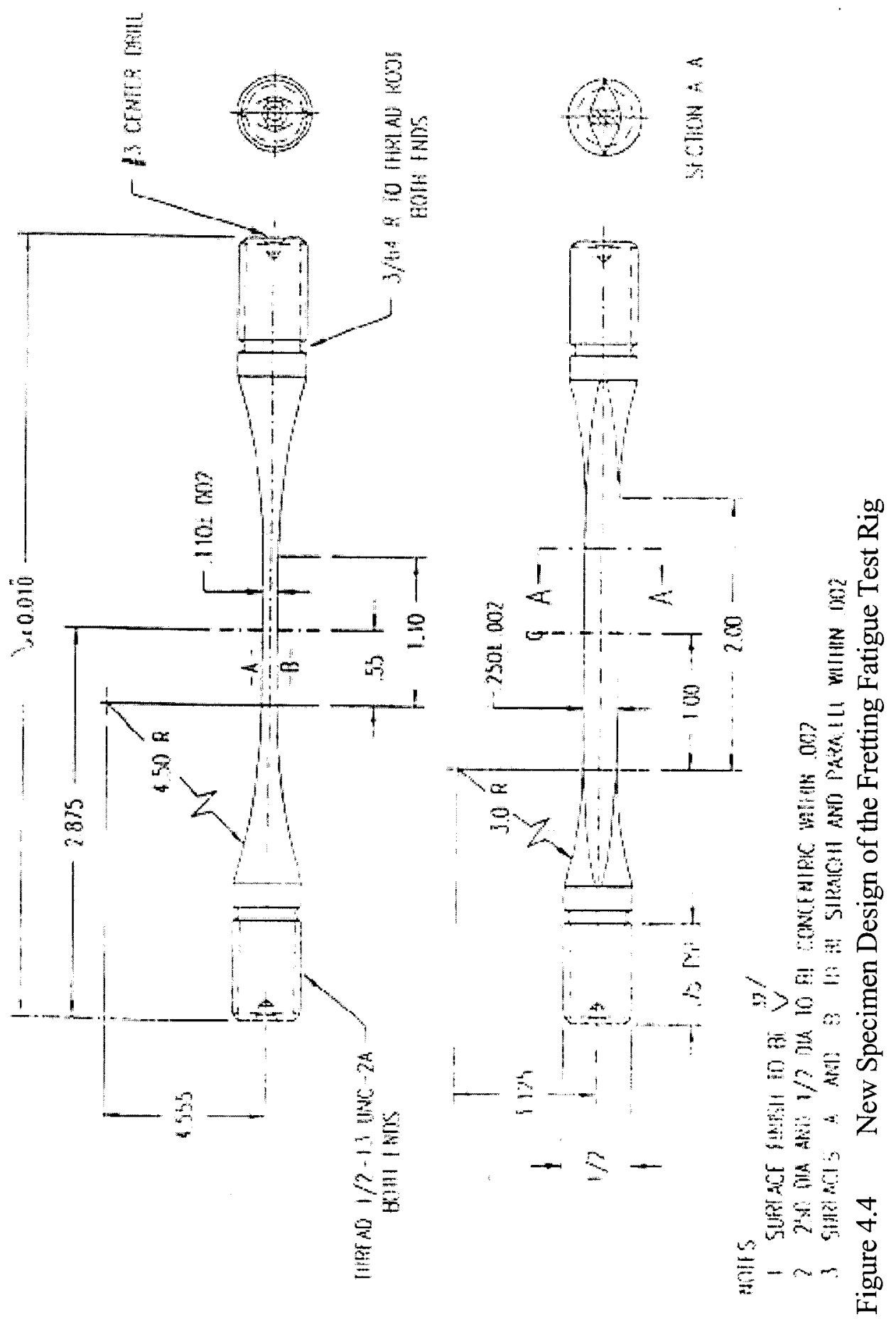




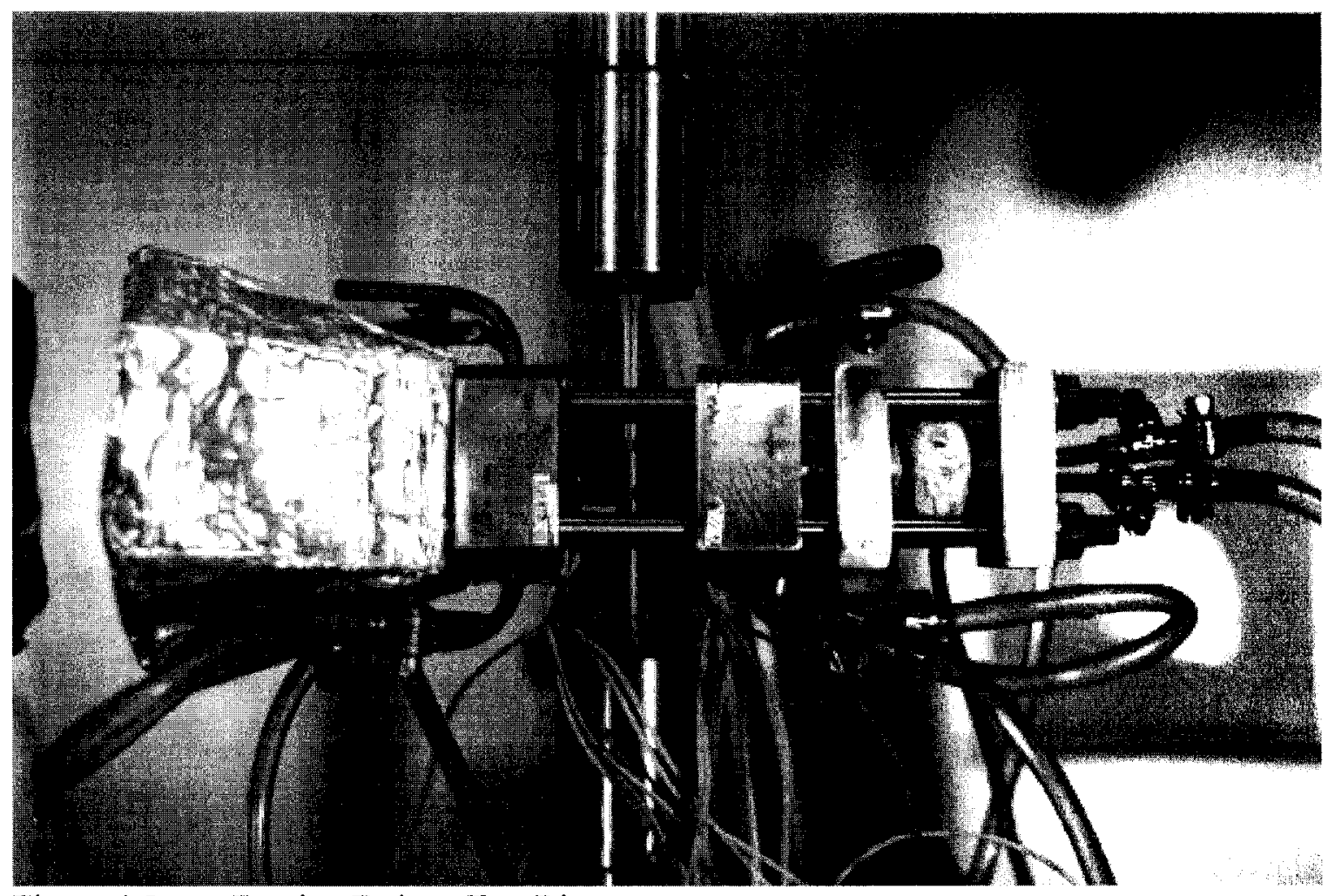

Figure 4.5 Fretting Fatigue Test Rig 


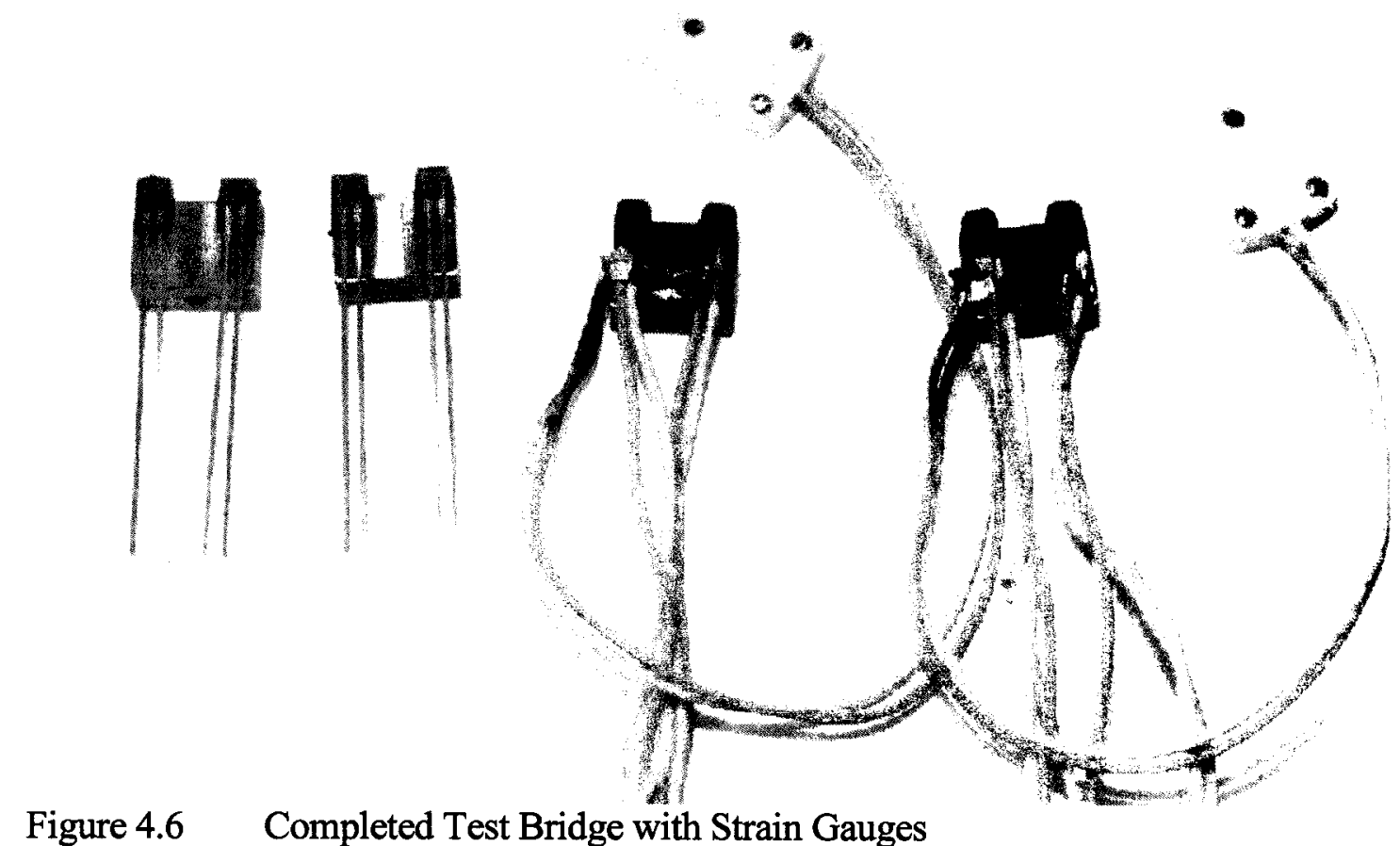

Figure 4.6 Completed Test Bridge with Strain Gauges 


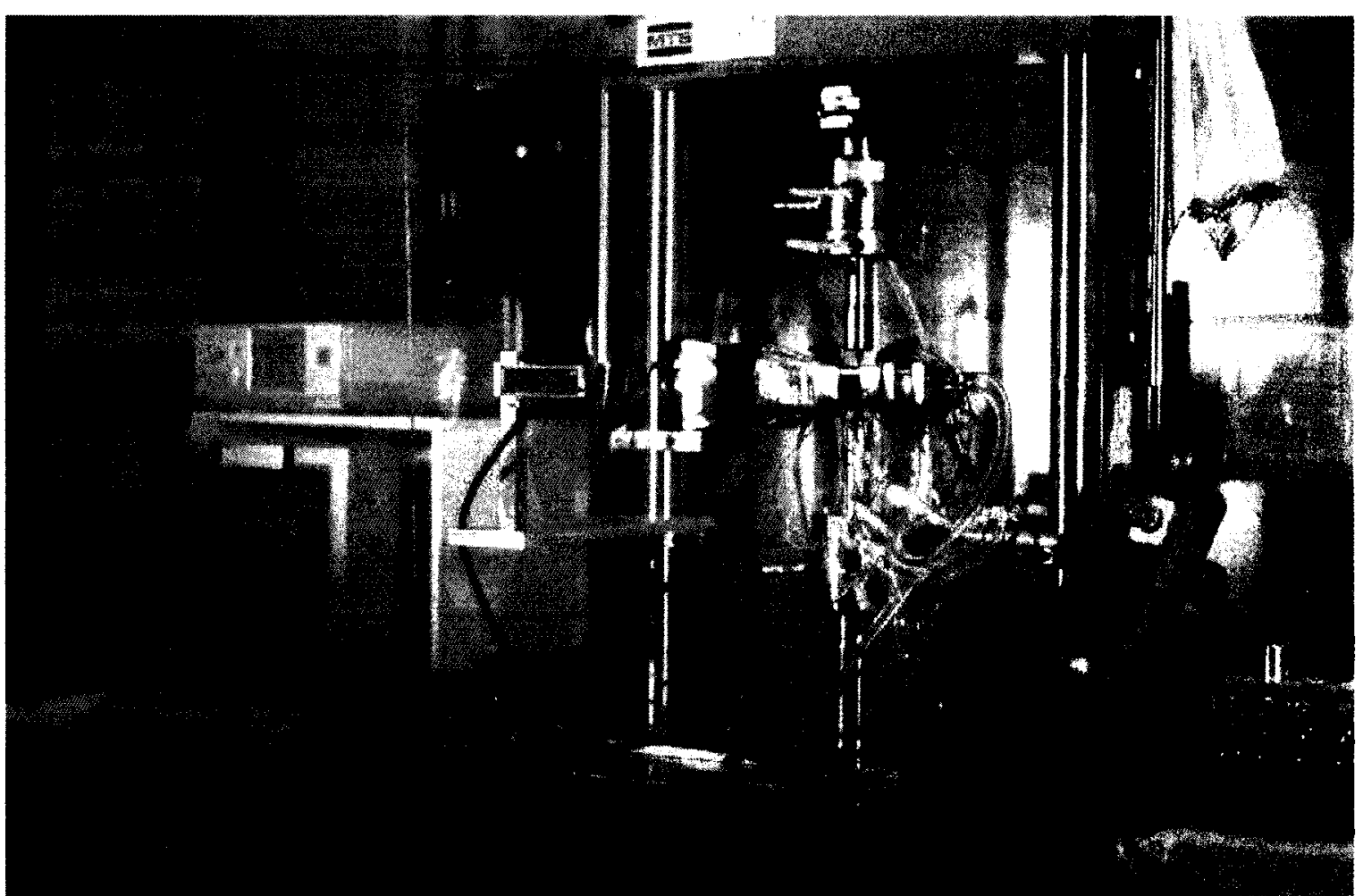

Figure 4.7 Fretting Fatigue Test Facility 


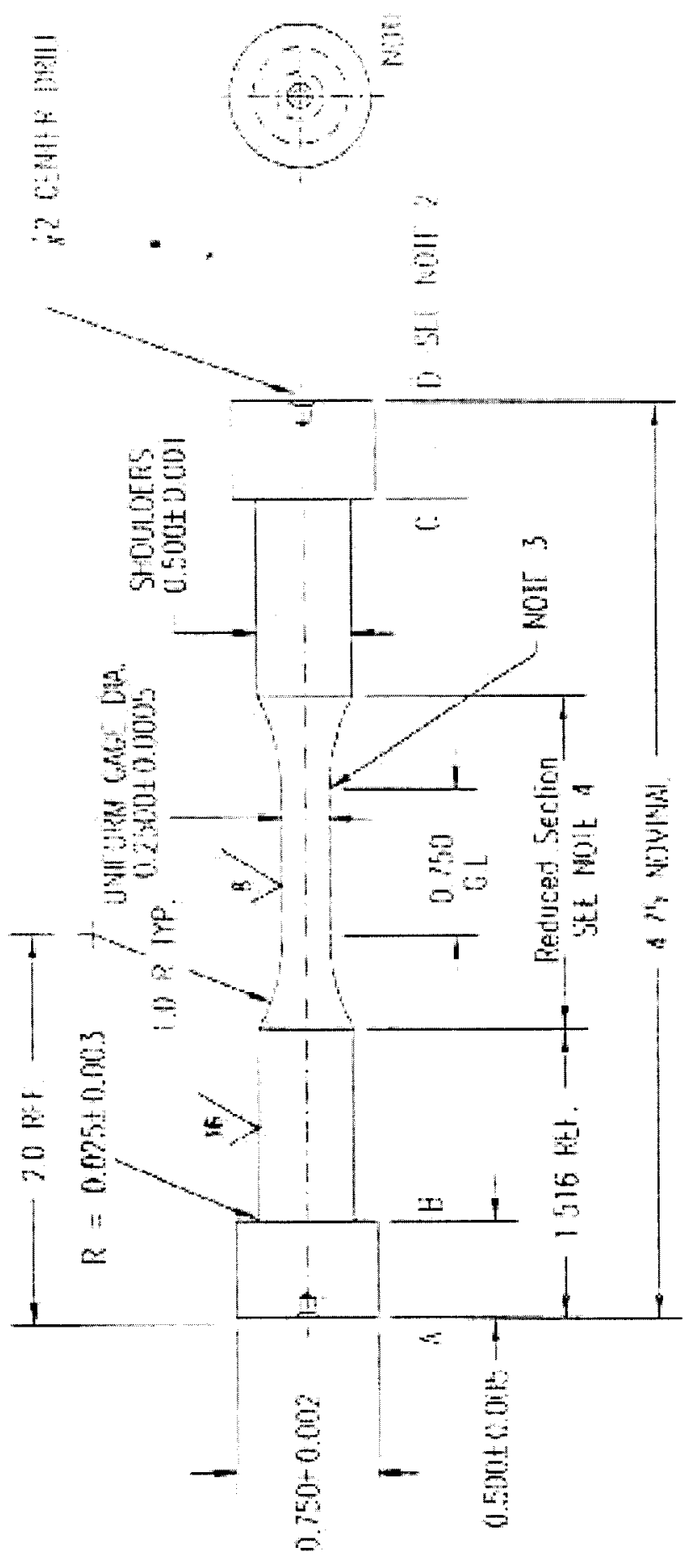

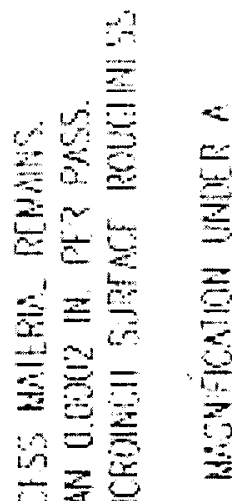

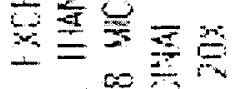
60 플 事产竞 $z=$ $\equiv \div 20$

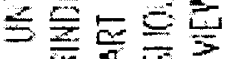
m昰

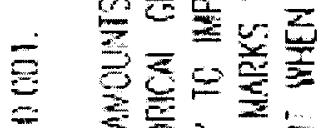

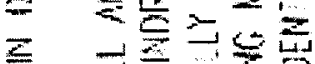

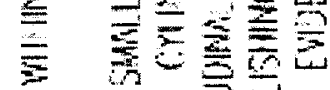

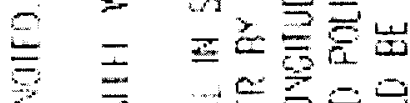
$\equiv \equiv$

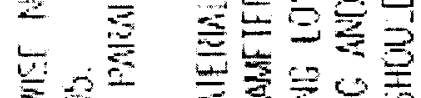

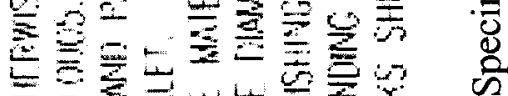

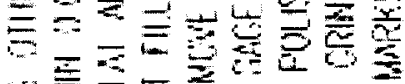

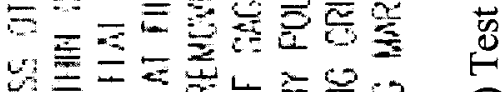

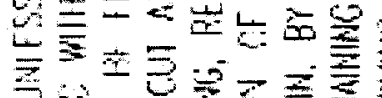

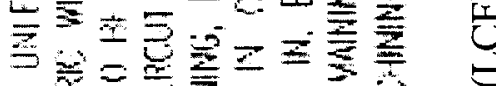

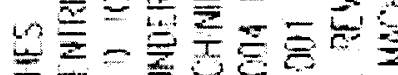
E气

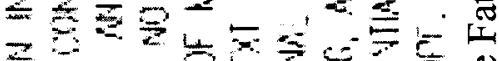
$\Xi-1.20$

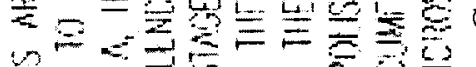
20:

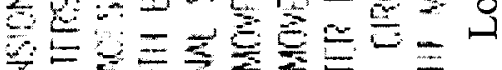
늘을 裳 

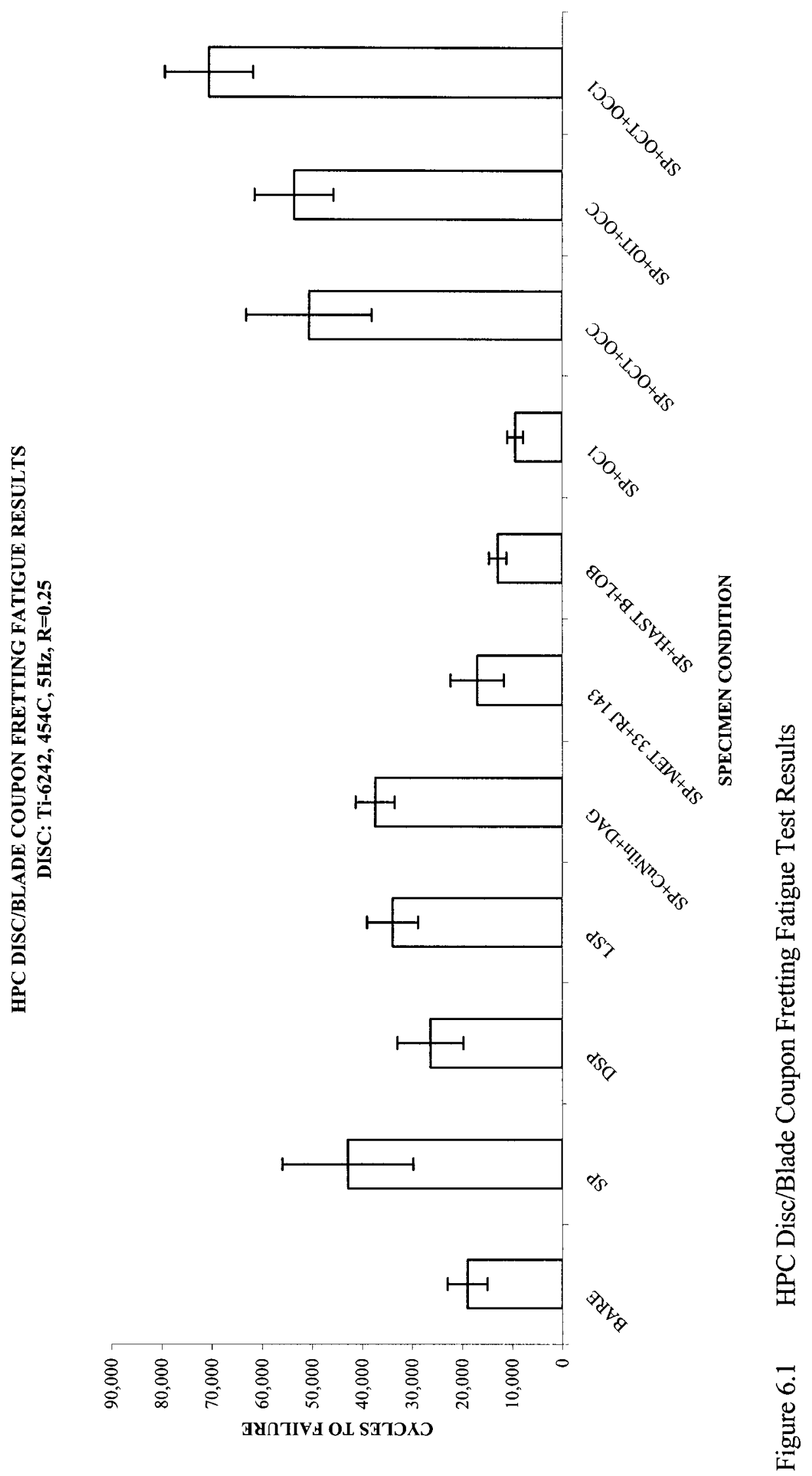


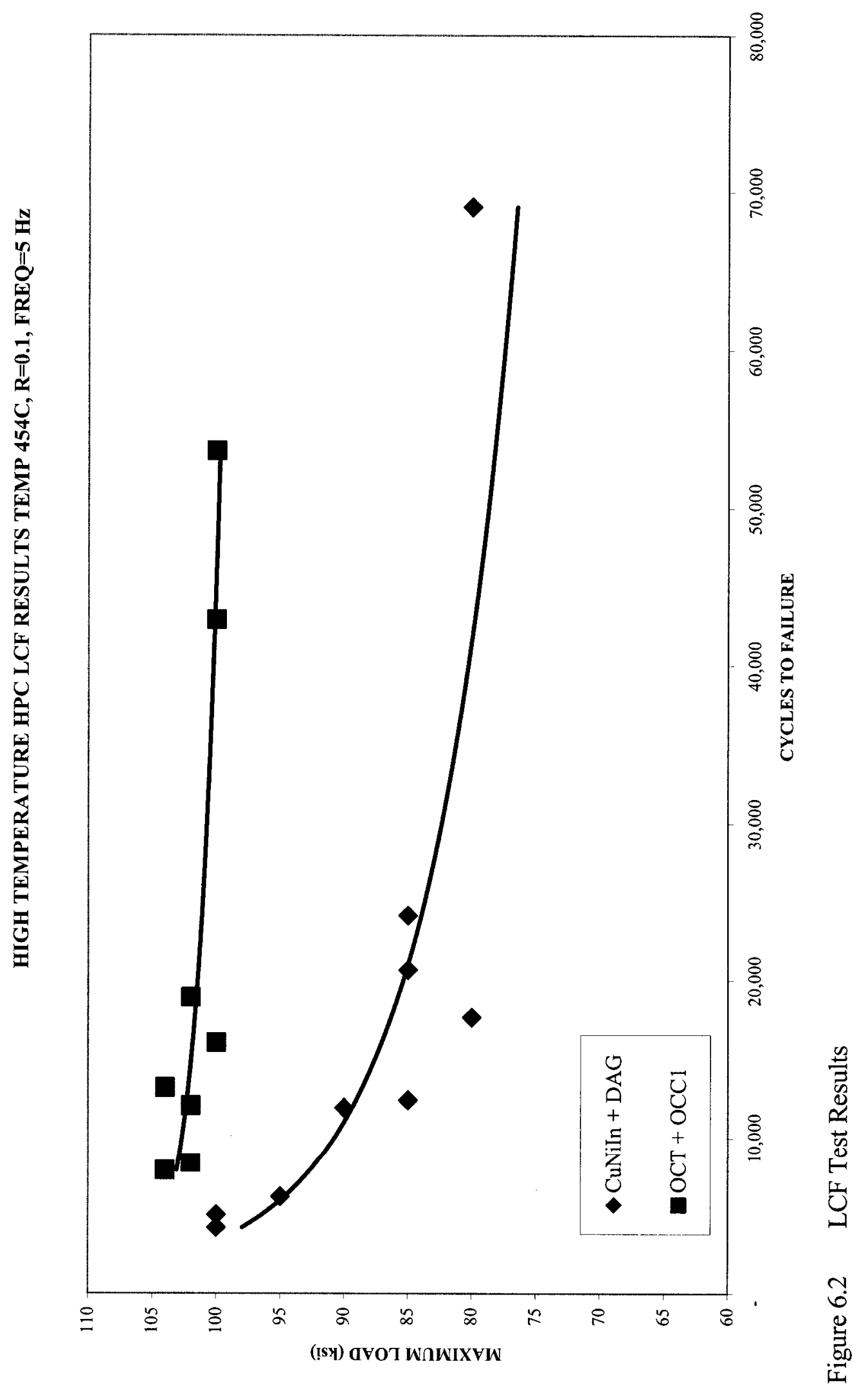




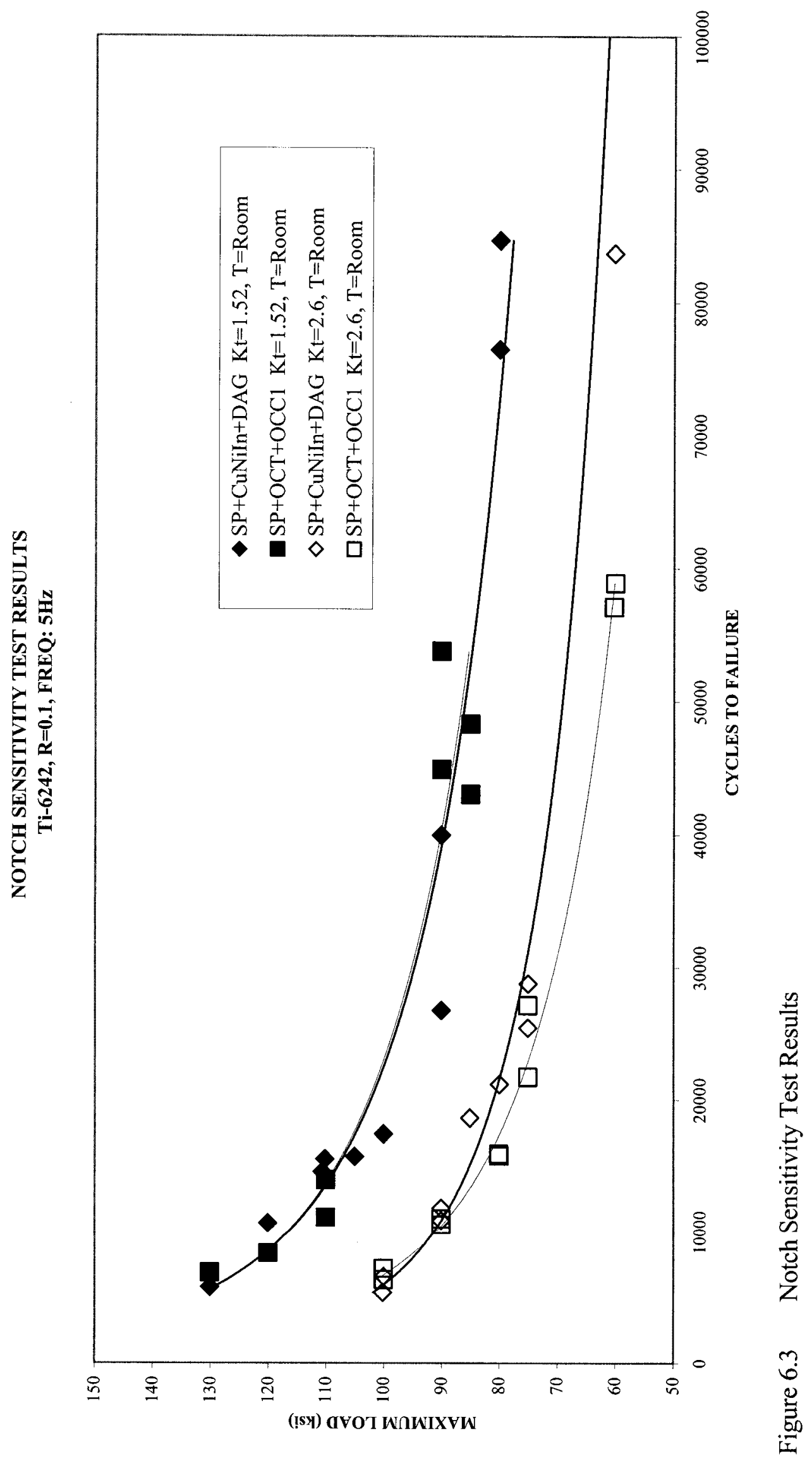




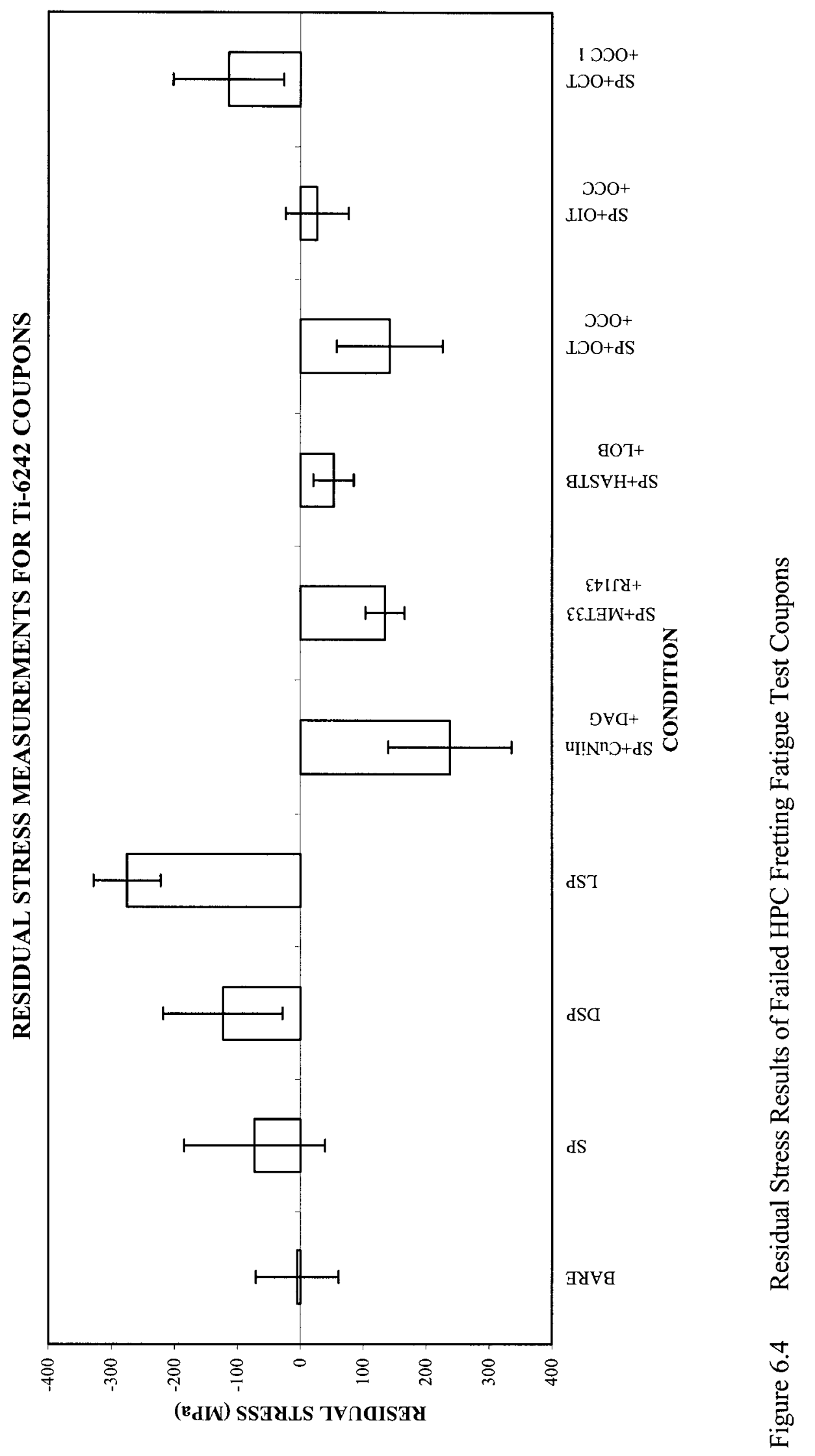




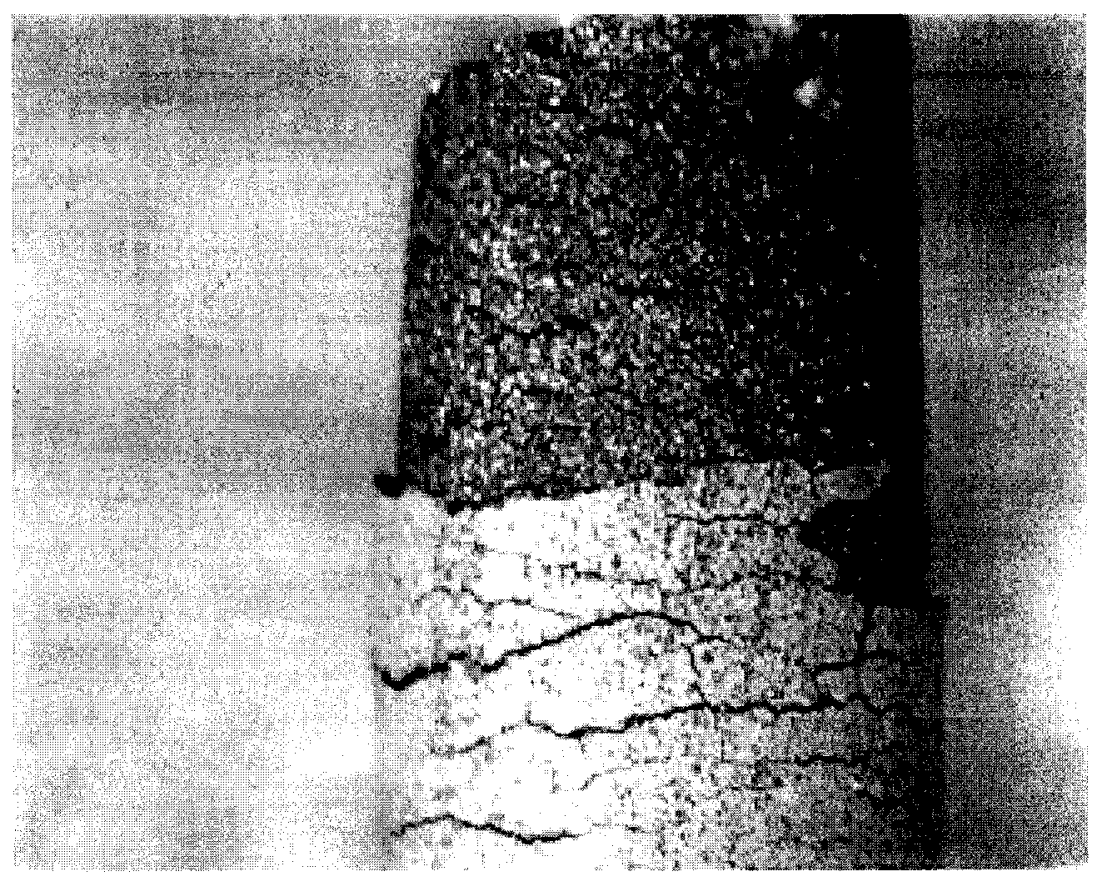

Figure 6.5 Multiple Crack Initiation Sites for Ti-6242 CuNiIn +DAG LCF Specimen 


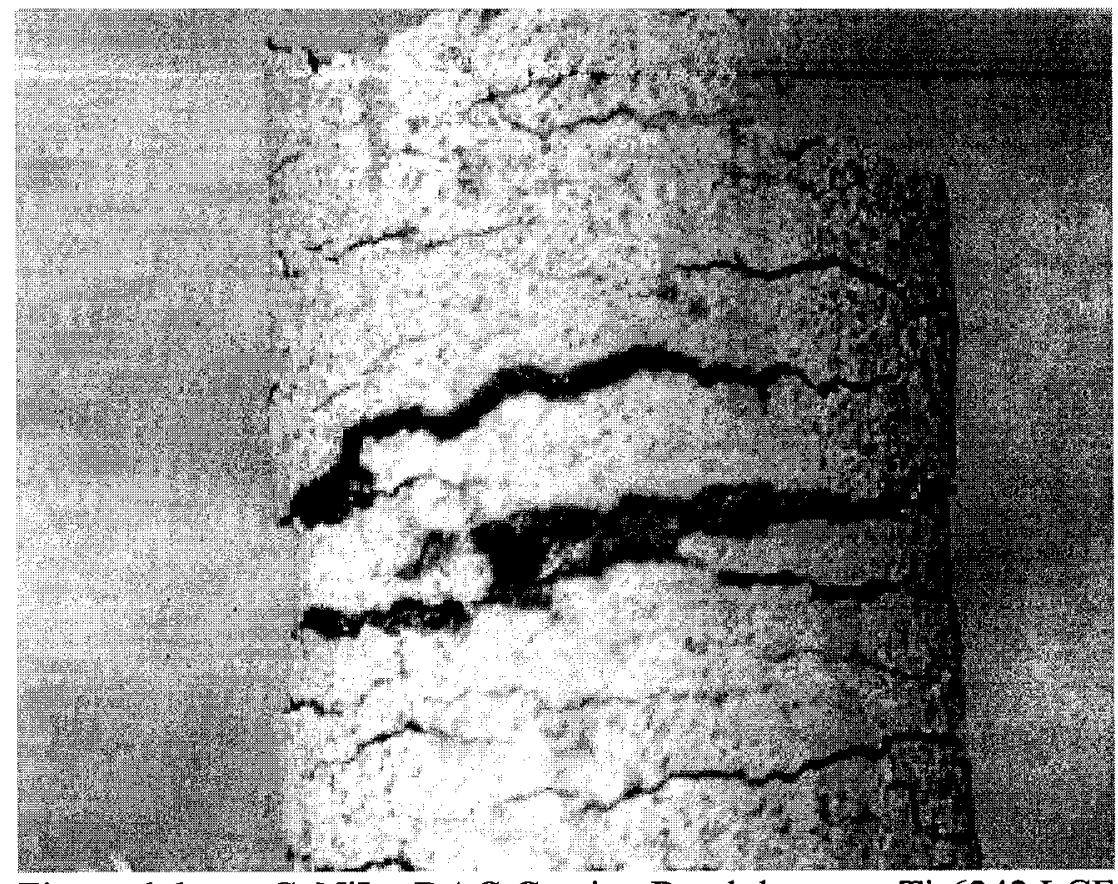

Figure 6.6 CuNiIn+DAG Coating Breakdown on Ti-6242 LCF Specimen 


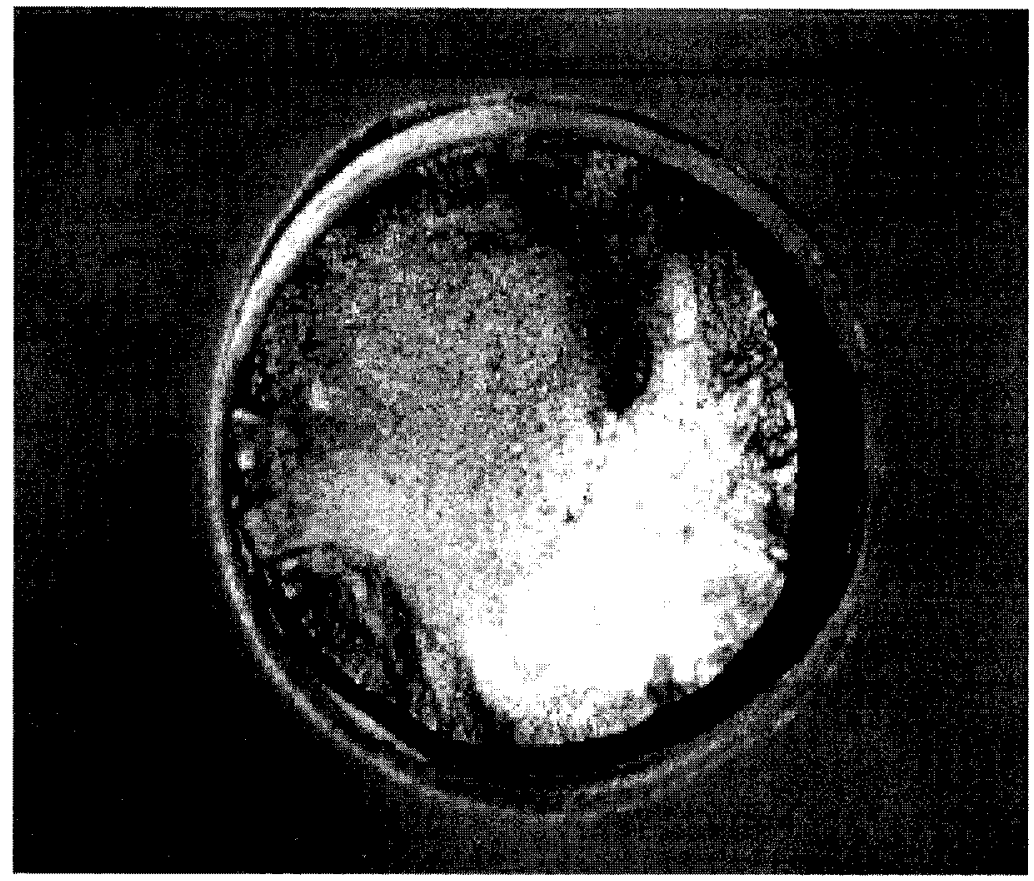

Figure 6.7 Delamination of CuNiIn+DAG on Ti-6242 LCF Specimen 


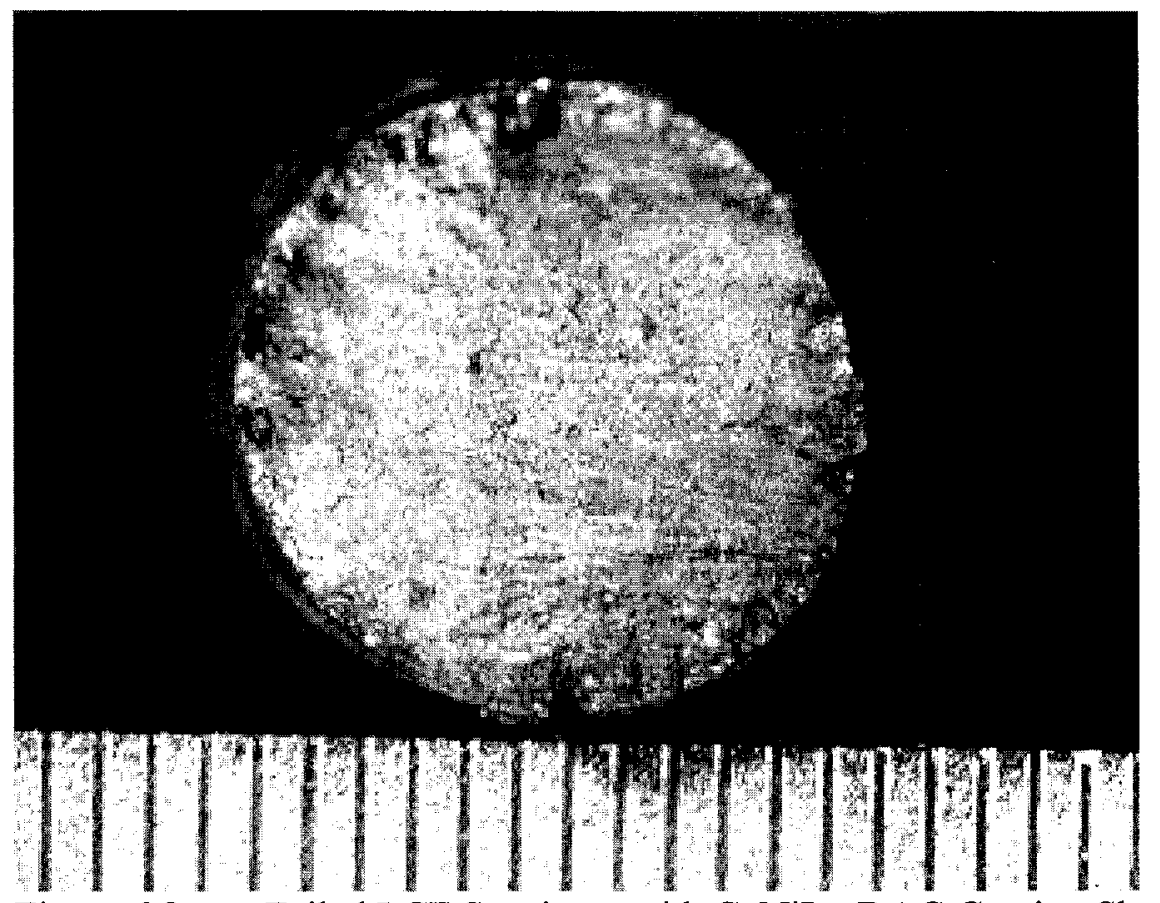

Figure 6.8 Failed LCF Specimen with CuNiIn+DAG Coating Showing Multiple Initiation Sites 


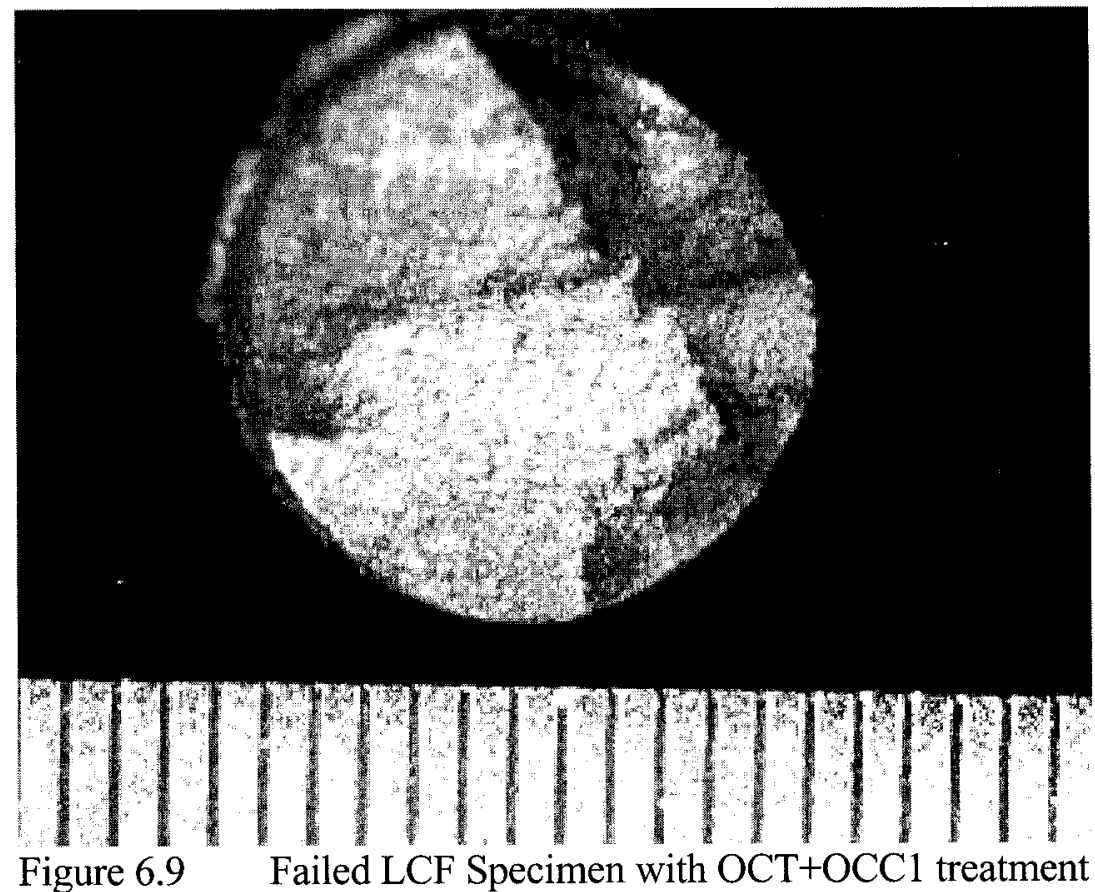




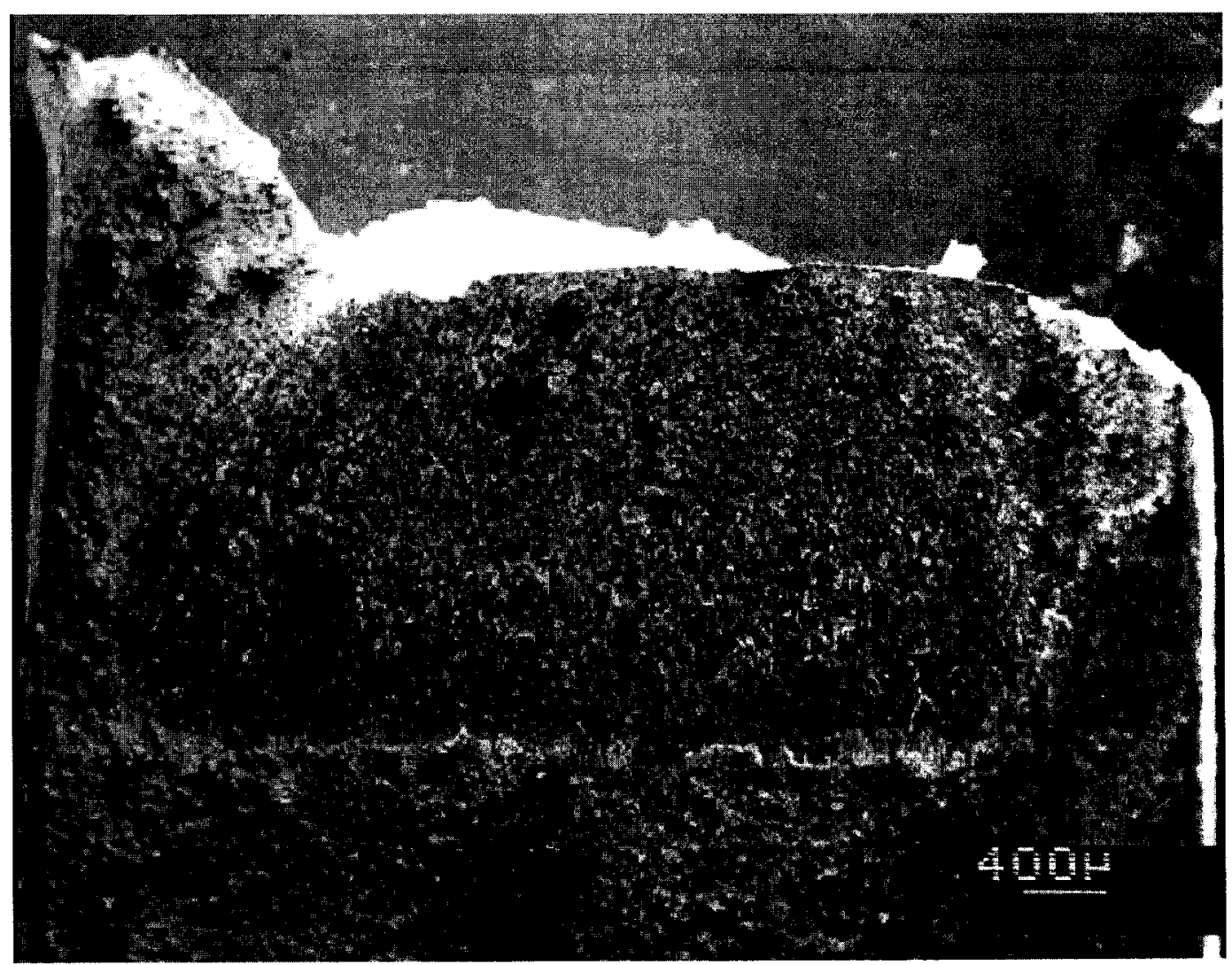

Figure 6.10 Fretting Specimen Surface Scar SP+OCT+OCC1, Spec. 2 


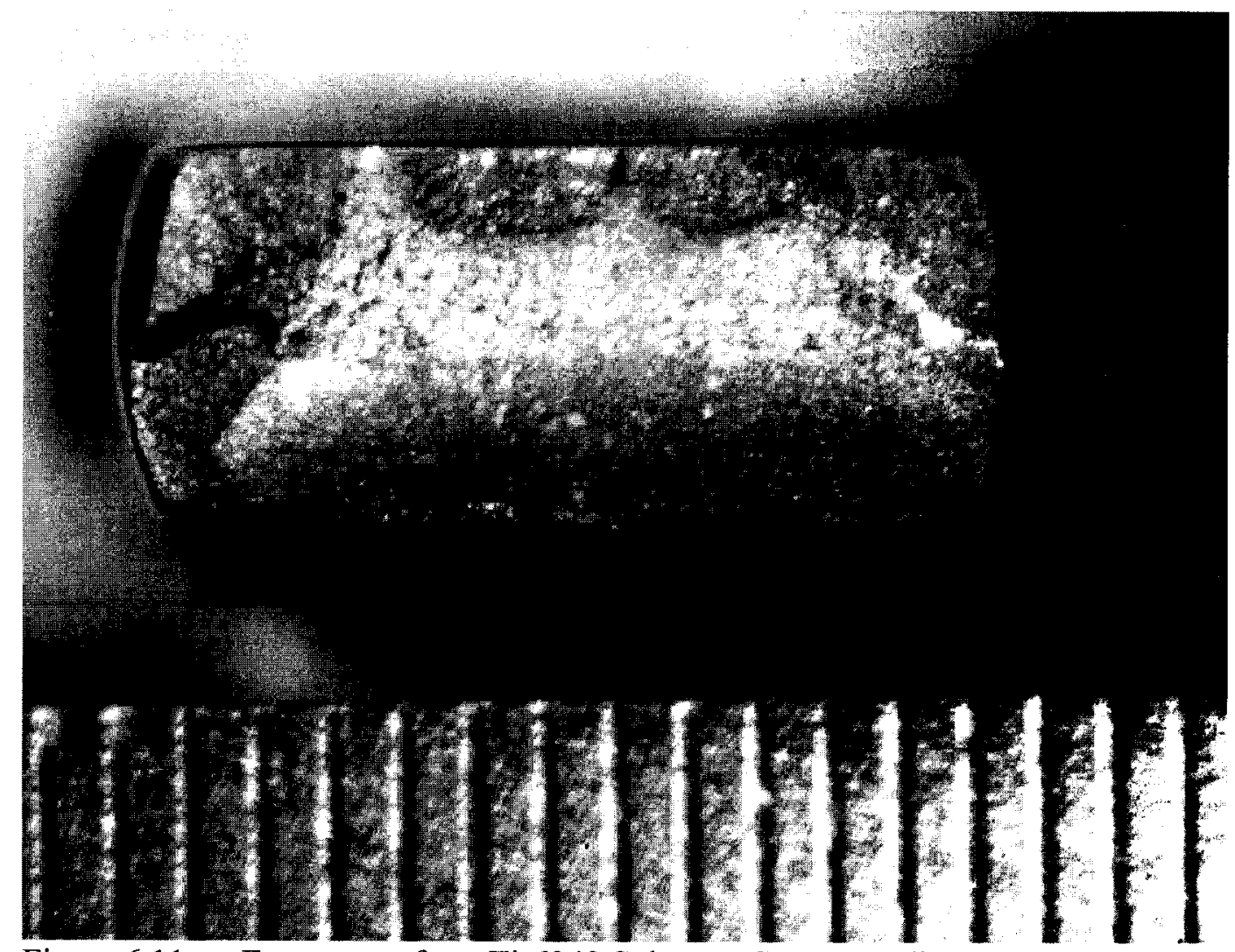

Figure 6.11 Fracture surface, Ti-6242 Substrate Spec. 5,1 div. $=1 / 2 \mathrm{~mm}$ 


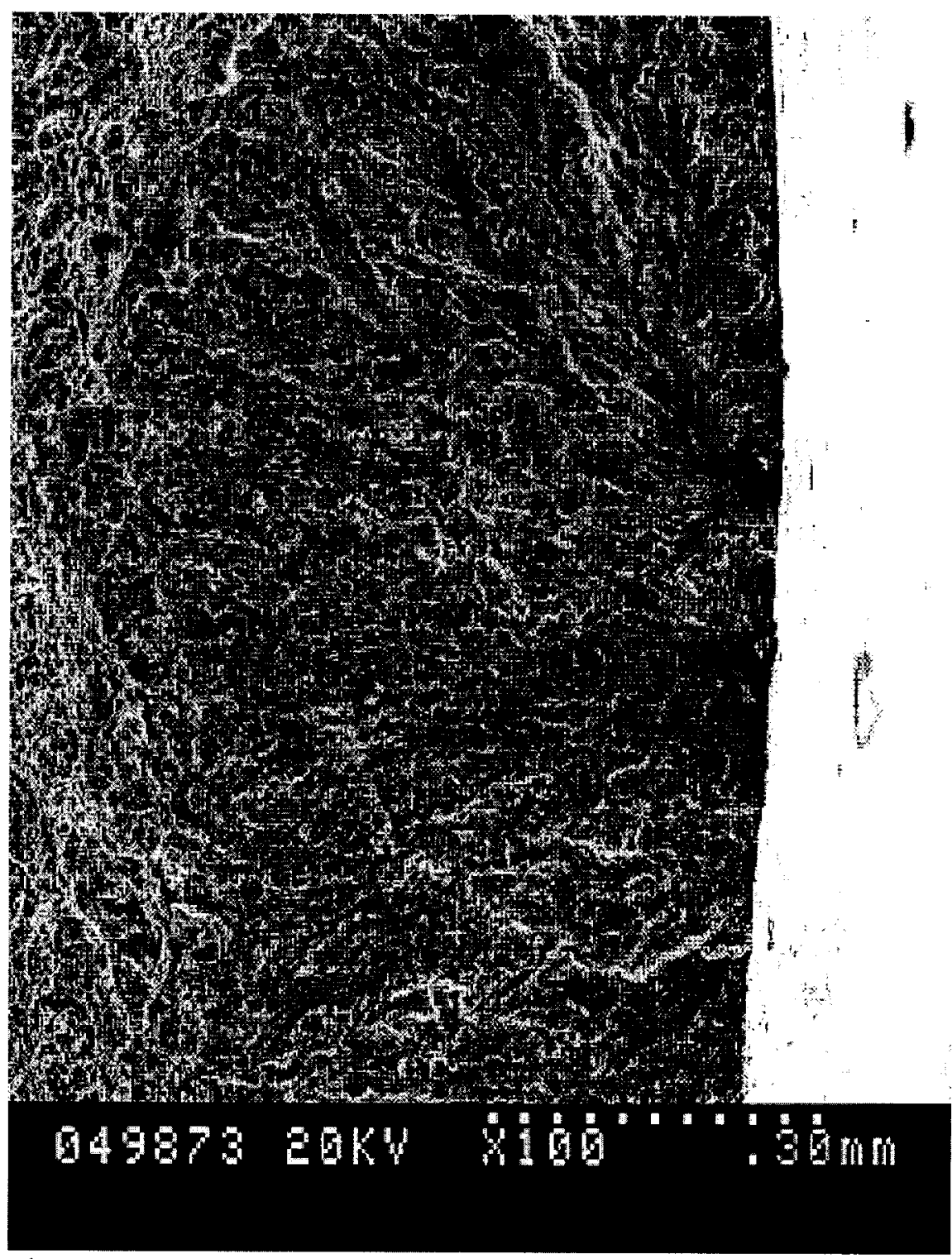

Figure 6.12 Fracture Surface, Ti-6242 Substrate, Spec 6, Secondary Crack Growth Region 


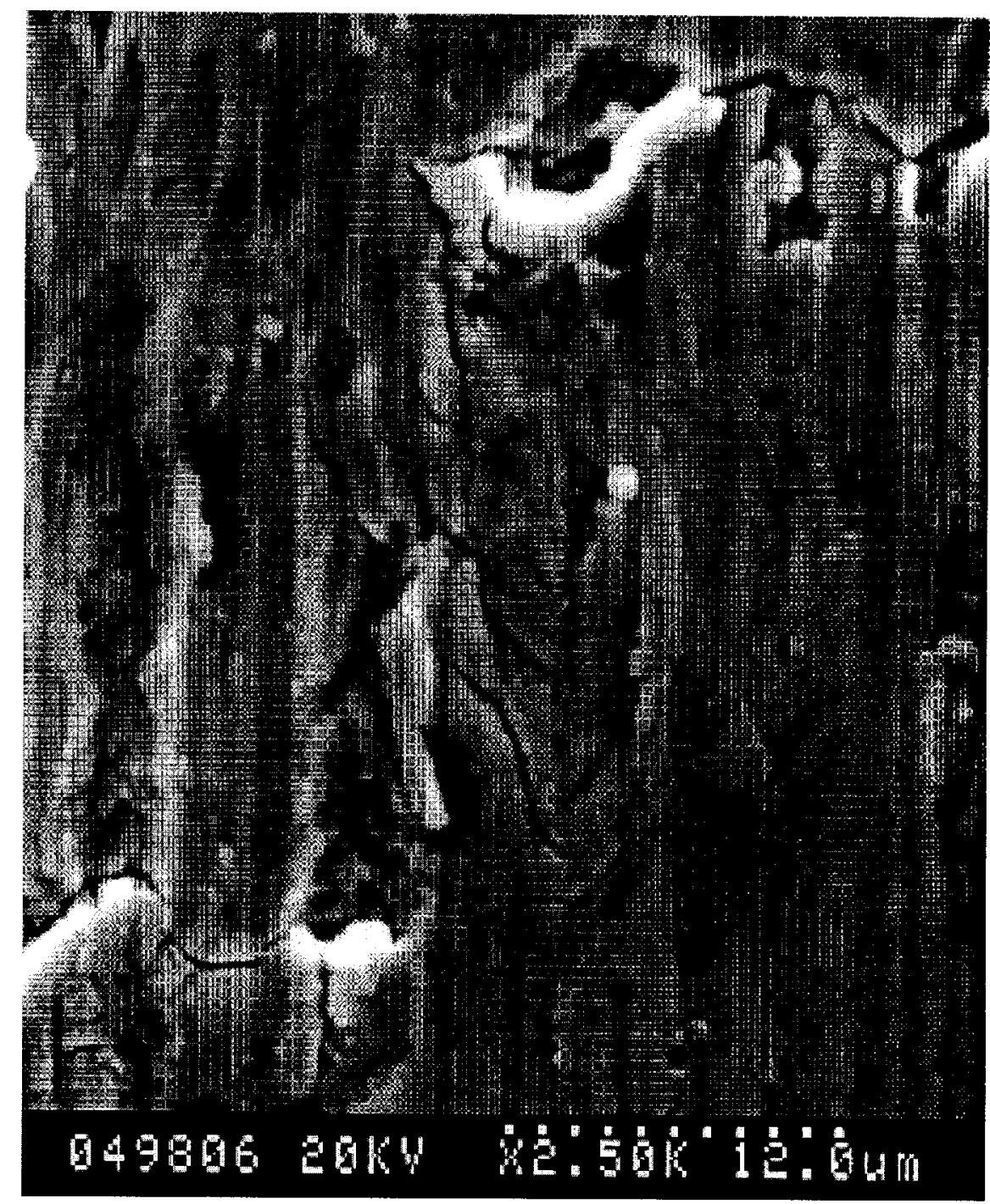

Figure 6.13 Fretted Surface Showing Galled Areas Leading to Surface Cracking, Ti6242 Substrate, Spec. 6 


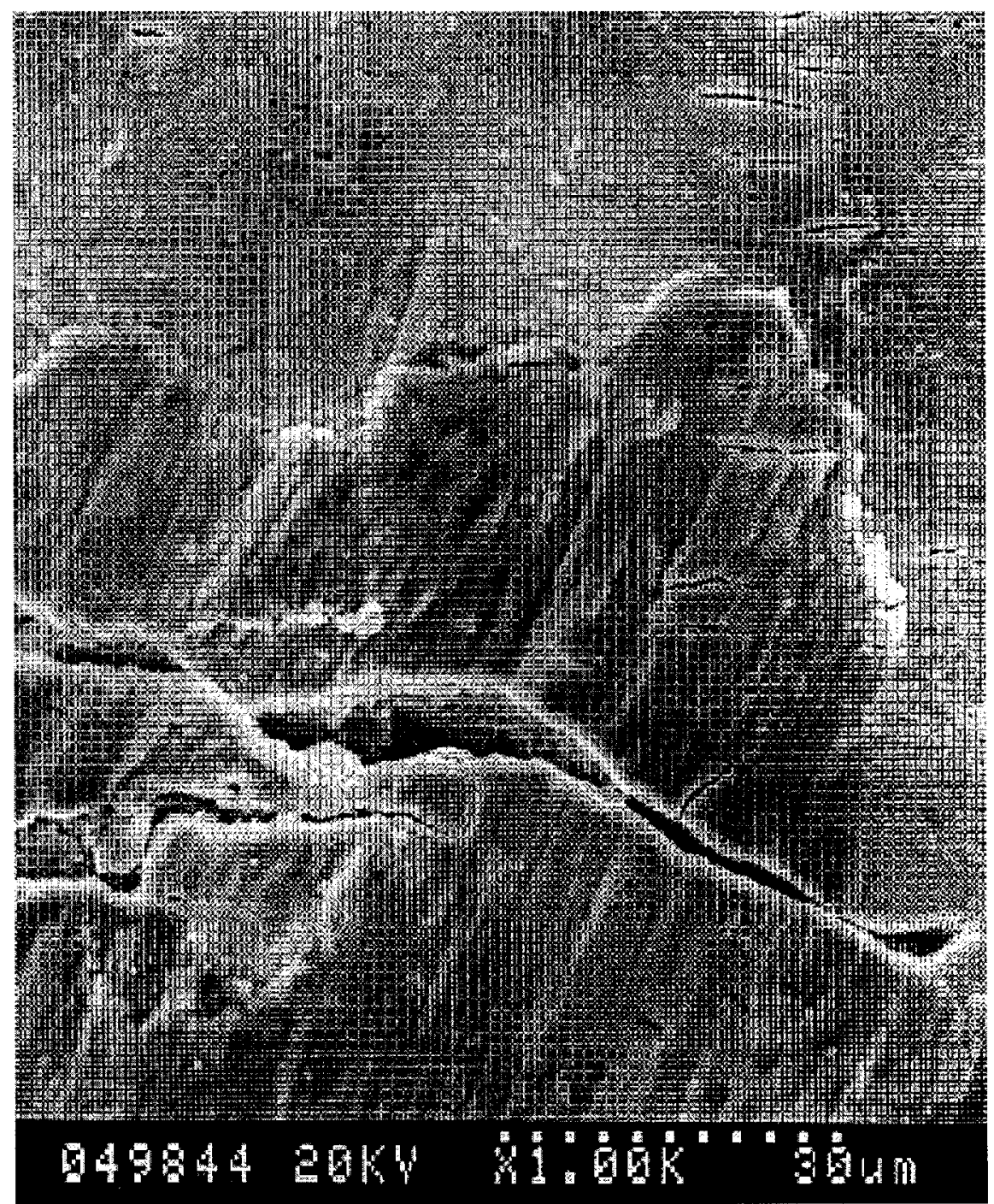

Figure 6.14 Shot Peened Specimen 3, Surface Smearing and Cracking 


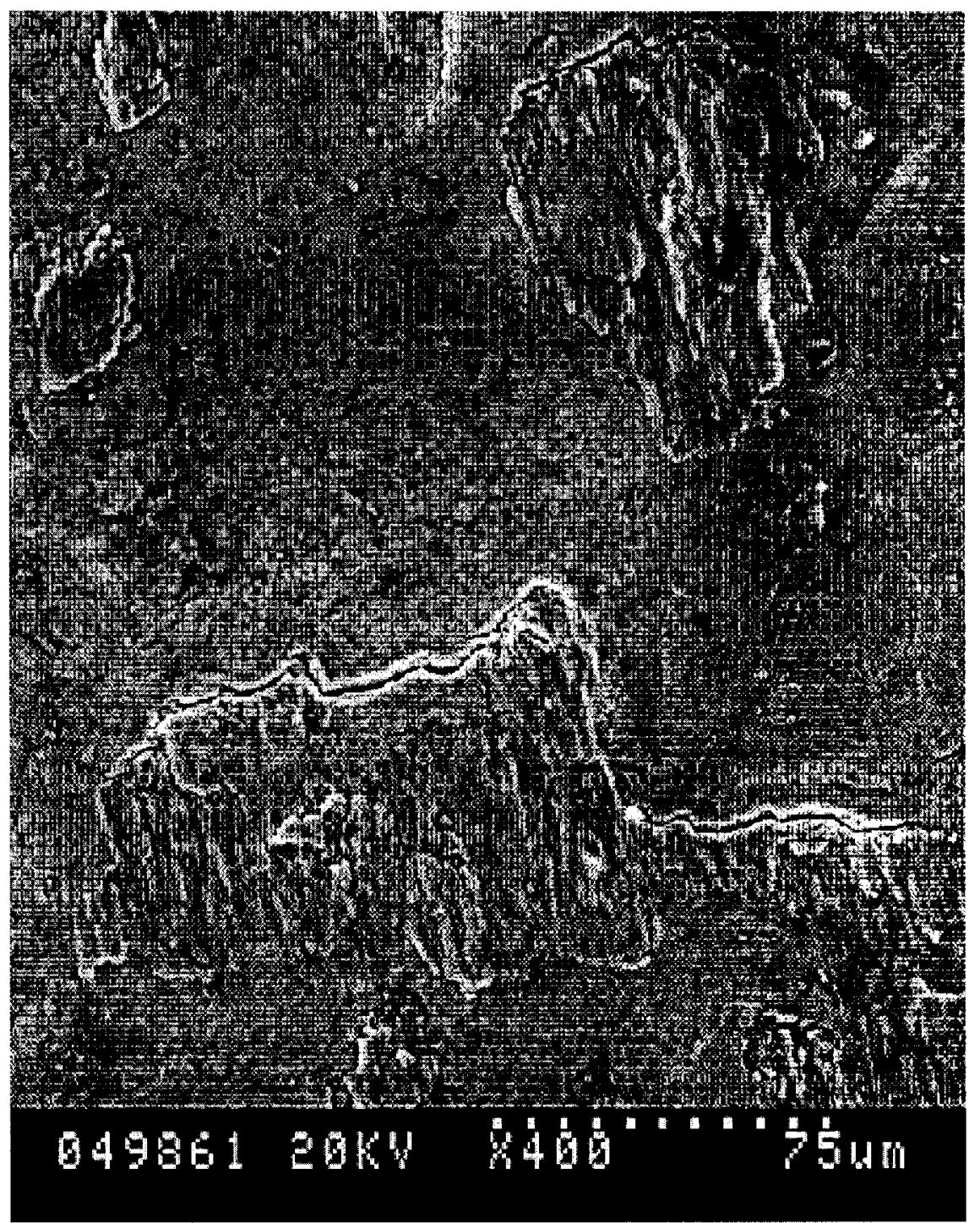

Figure 6.15 Shot Peened Specimen 5, Gouging and Surface Cracks 


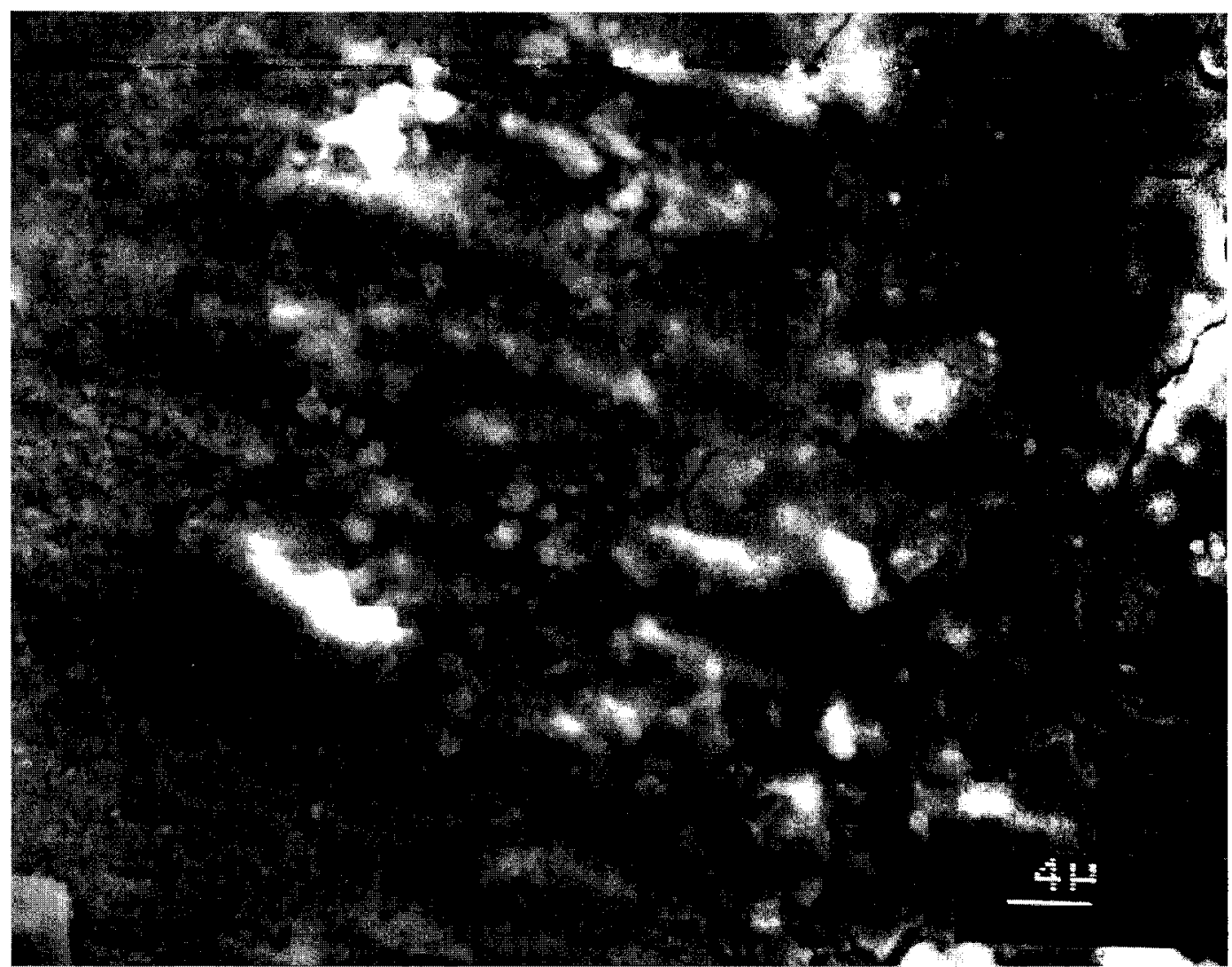

Figure 6.16 SP+OCT+OCC1 Specimen 4, Fretting Ridges, Material Transfer and Cracking 


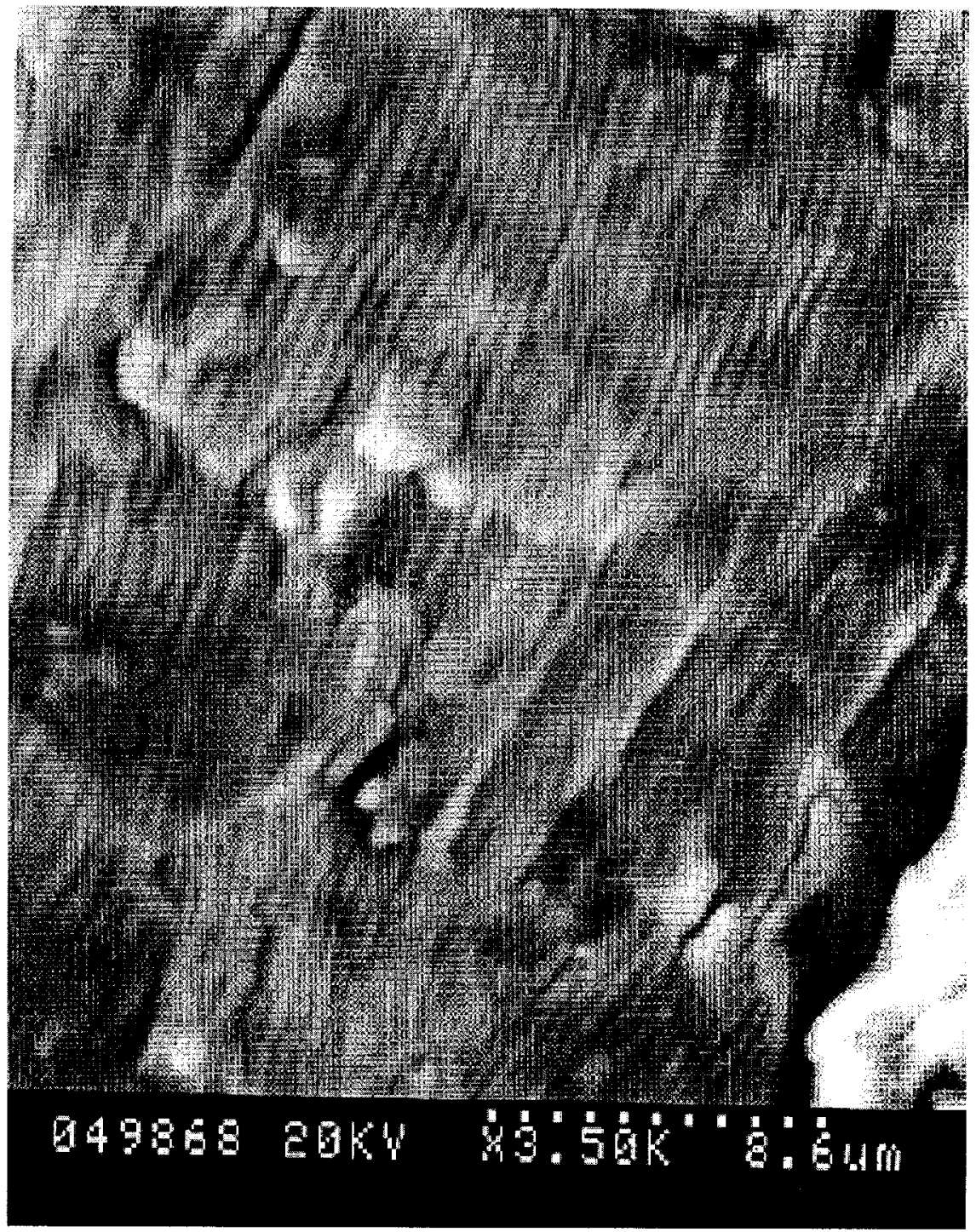

Figure 6.17 Baseline, Ti-6242 Parent Material Specimen 4, Fatigue Striations on Crack Growth Surface 


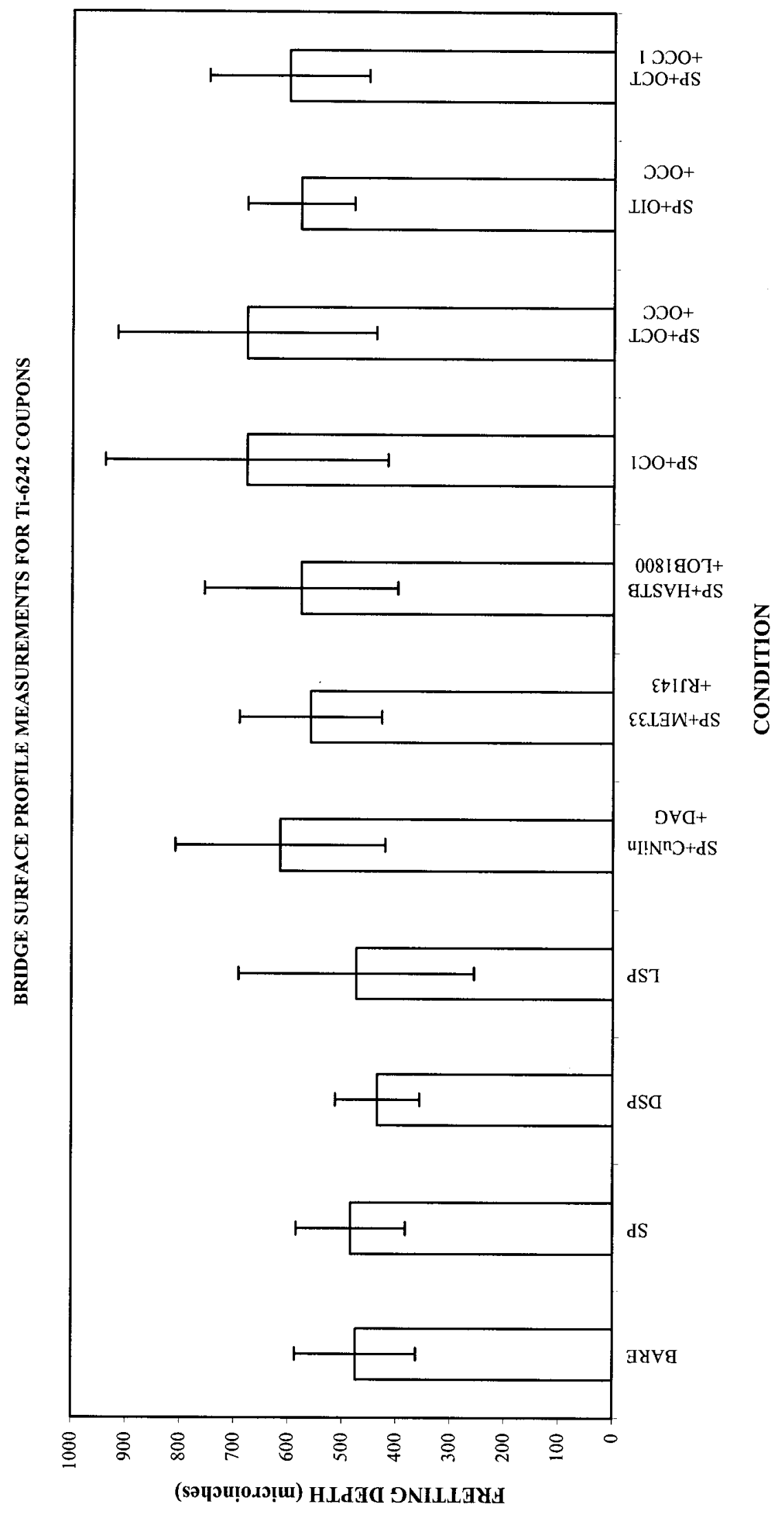

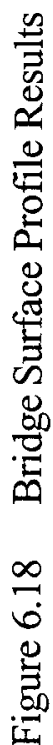




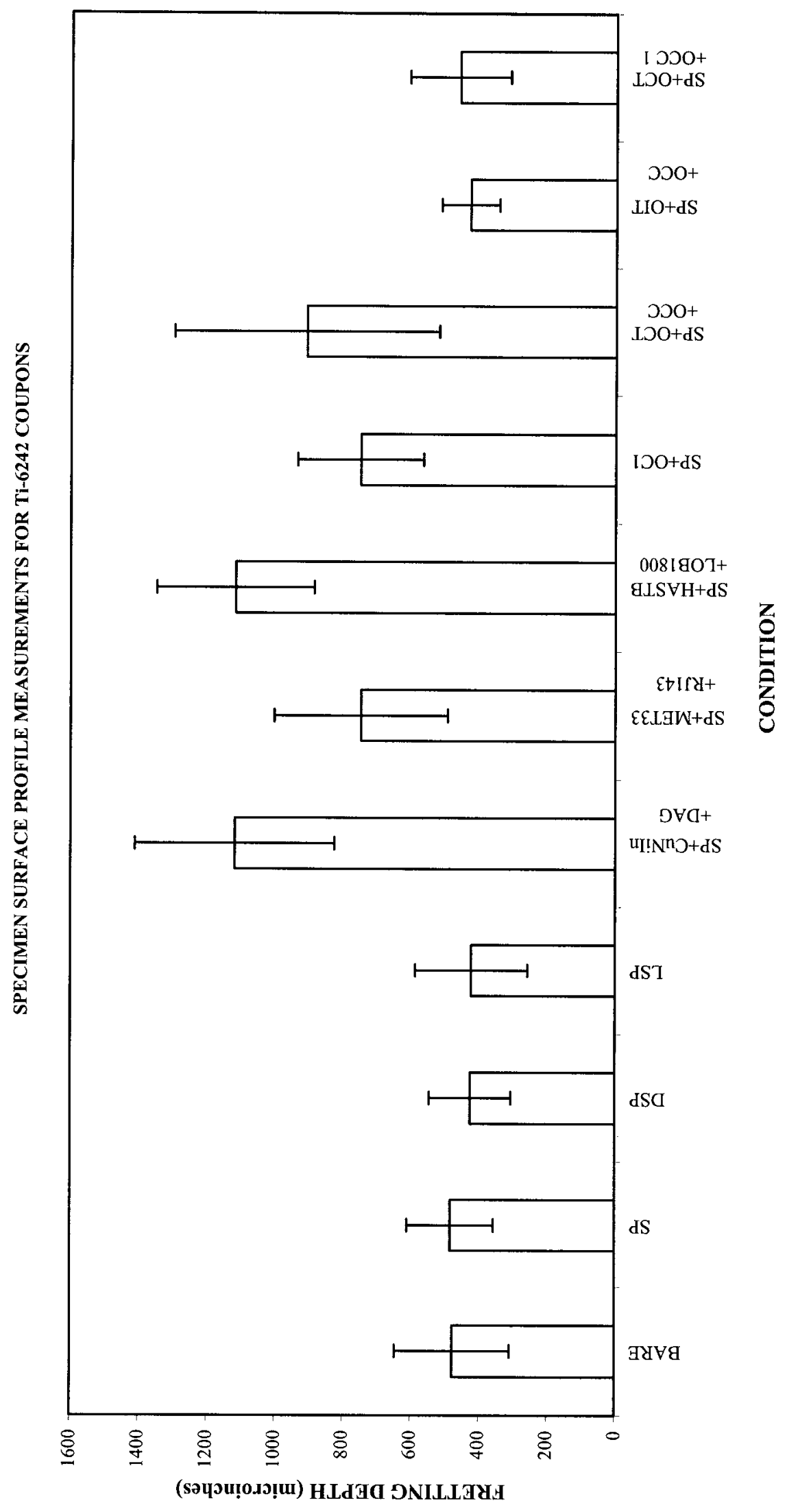

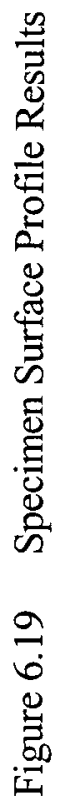

